\title{
Vulnerability to psychopathology in children : developmental and environmental pathways
}

Citation for published version (APA):

Günther, N. C. H. F. (2007). Vulnerability to psychopathology in children : developmental and environmental pathways. [Doctoral Thesis, Maastricht University]. Datawyse / Universitaire Pers Maastricht. https://doi.org/10.26481/dis.20071019ng

Document status and date:

Published: 01/01/2007

DOI:

10.26481/dis.20071019ng

Document Version:

Publisher's PDF, also known as Version of record

\section{Please check the document version of this publication:}

- A submitted manuscript is the version of the article upon submission and before peer-review. There can be important differences between the submitted version and the official published version of record.

People interested in the research are advised to contact the author for the final version of the publication, or visit the DOI to the publisher's website.

- The final author version and the galley proof are versions of the publication after peer review.

- The final published version features the final layout of the paper including the volume, issue and page numbers.

Link to publication

\footnotetext{
General rights rights.

- You may freely distribute the URL identifying the publication in the public portal. please follow below link for the End User Agreement:

www.umlib.nl/taverne-license

Take down policy

If you believe that this document breaches copyright please contact us at:

repository@maastrichtuniversity.nl

providing details and we will investigate your claim.
}

Copyright and moral rights for the publications made accessible in the public portal are retained by the authors and/or other copyright owners and it is a condition of accessing publications that users recognise and abide by the legal requirements associated with these

- Users may download and print one copy of any publication from the public portal for the purpose of private study or research.

- You may not further distribute the material or use it for any profit-making activity or commercial gain

If the publication is distributed under the terms of Article $25 \mathrm{fa}$ of the Dutch Copyright Act, indicated by the "Taverne" license above, 
Vulnerability to psychopathology in children Developmental and environmental pathways 
(C) Nicole C.H.F. Gunther, Maastricht 2007

Design Wil Immink, Sittard

Print Datawyse bv, Universitaire Pers Maastricht

ISBN 978-90-5278-650-6 


\section{Vulnerability to psychopathology in children}

Developmental and environmental pathways

\section{PROEFSCHRIFT}

ter verkrijging van de graad van doctor aan de Universiteit Maastricht, op gezag van de Rector Magnificus, Prof. mr. G.P.M.F. Mols, volgens het besluit van het College van Decanen, in het openbaar te verdedigen op vrijdag 19 oktober 2007 om 12:00 uur

door

Nicole Catharina Hubertina Fransisca Gunther

Geboren op 17 april 1965 te Maastricht

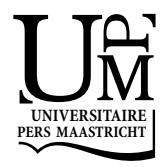




\section{Promotor}

Prof. dr. J. van Os

\section{Copromotor}

Dr. M. Drukker

\section{Beoordelingscommissie}

Prof. dr. M. de Vries (voorzitter)

Prof. dr. C. Hosman

Prof. dr. A. Korebrits

Prof. dr. J. Ormel

Prof. dr. F. Verhulst
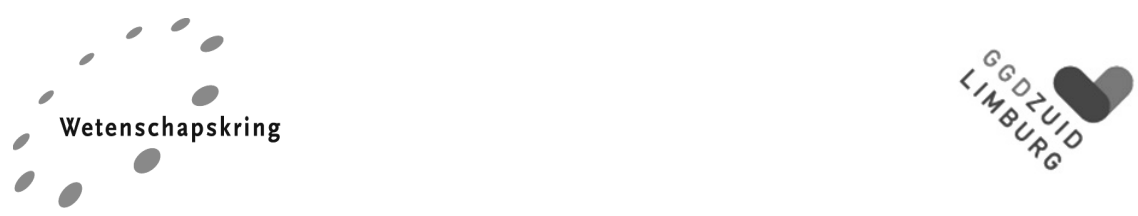

South Limburg Mental Health Research and Teaching Network PhD Series

The research presented in this thesis was conducted at the Maastricht Brain \& Behaviour Institute, the Department of Psychiatry and Neuropsychology of Maastricht University and the Youth Health Care Division, Public Health Service South Limburg, location Maastricht

Publication of this thesis was financially supported by :

Eli Lily bv., Wyeth Pharmaceuticals bv. 



\section{Paranimfen}

Jikke van der Linden

Viviane Thewissen 


\section{CONTENTS}

\section{Chapter 1}

Introduction and outline of the thesis

\section{Chapter 2}

Childhood social and early developmental factors associated with

mental health service use

\section{Chapter 3}

The combination of shared family environment and individual-specific developmental deviance as a cause for treated psychiatric morbidity in children

\section{Chapter 4}

Association of mental health problems in childhood with

prenatal and postnatal physical growth

\section{Chapter 5}

Neighbourhood social environment and childhood experience of being bullied

\section{Chapter 6}

No ecological effect modification of the association between negative life experiences and later psychopathology in adolescence:

a longitudinal community study in adolescents

\section{Chapter 7}

Concluding remarks

\section{Chapter 8}

Summary

Samenvatting

Dankwoord

Curriculum Vitae 



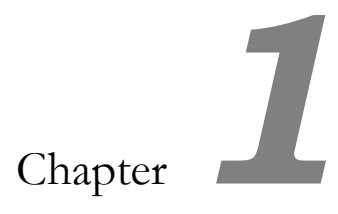

Introduction and outline of the thesis 


\section{INTRODUCTION AND OUTLINE OF THE THESIS}

\section{CHILD PSYCHOPATHOLOGY}

Results from epidemiological studies show that a substantial proportion of children in the community meet criteria for a psychiatric disorder (Shaffer, 1996; Verhulst et al., 1997). The prevalence rates of psychiatric conditions in childhood across studies using DSM-III-R criteria range from 17.6\% in New Zealand (Anderson et al., 1987) to $26 \%$ in the Netherlands (Verhulst et al., 1985). Child psychopathology encompasses problems such as Attention Deficit Hyperactivity Disorder (ADHD), conduct disorder, depression and social phobia and shows a marked propensity for diagnostic overlap (Goodyer, 1995). In addition, childhood emotional and behavioural problems persist to a considerable degree into adolescence and adulthood and contributes to adult psychiatric disorders, such as depression and schizophrenia (Jones et al., 1994; Hofstra et al., 2000). Furthermore, mental health services throughout Europe are confronted with an increasing number of young patients every year (Kooi et al., 2000). A good number of these children will remain in contact with services throughout adolescence and adulthood. However, many children in the general population who can be regarded as deviant do not receive help [e.g. (Verhulst and van der Ende, 1997)].

Child psychopathology in itself creates enduring developmental liabilities over time that contribute to adult illness onset and persistence, including depression and schizophrenia. Considering also the overwhelming demand on child psychiatric services, more systematic studies on the factors influencing psychopathology and subsequent referral are needed, allowing for the development of screening methods. Early identification of children at risk for (different types of) psychopathology and treatment of mental health disturbances is essential to prevent progressions and complications and to improve psychosocial functioning later in life.

\section{THE FILTER MODEL}

From the discrepancy between the high prevalence of psychiatric disorders in children from the general population, and the small proportion of those actually receiving help, it follows that it is important to study factors that are involved in the referral pathway to psychiatric care. Research on factors associated with psychiatric care is needed to enable identifying those adolescents with high levels of problems who need professional help but do not yet receive them. The model for this refer- 
ral pathway to psychiatric care was developed by Goldberg and Huxley (1980) and was adapted by Verhulst and Koot (1995) to be used for children and adolescents. The adapted model (figure 1) consists of five levels, each representing different circumscribed populations of children, including children in the general population (level 1), the population of children referred to primary health care for problem behaviour (e.g. care provided by general practitioner and school physician; level 2), population of children who are identified by the primary health-care physician as disturbed (level 3) and specialist psychiatric services populations (levels 4 and 5). Between these levels there are four filters including illness behaviour, recognition of the health problem by primary health-care workers, and referral behaviour of health professionals to specialist psychiatric services. These filters represent the factors determining which children go on to the next level. Not only type and severity of problems, but also child and family characteristics play a role along the entire referral pathway (Verhulst and Koot, 1995). Consequently, specialist psychiatric services populations (levels 4 and 5) consist of individuals that have passed filters 3 or 4 and these persons have much more serious mental health problems than those identified by questionnaires in the general population (Goldberg and Huxley, 1980; van Os, 2000). In the Netherlands, recognition and referral behaviour of general practitioners and school physicians serve as important filters to psychiatric care. This also applies to Maastricht and surrounding areas, the region of focus in the present thesis. Here, school-age children and adolescents are screened by the school physician of the Youth Health Care Division (YHCD) of the South Limburg Public Health Service. Children with suspected psychiatric disorder are referred to a central intake team and from there referred to the child psychiatric services of the Community Mental Health Services. As such, only children with the highest level of psychiatric morbidity and need of care are referred for treatment in psychiatric services. In the present thesis, the factors that influence the development of psychopathology are studied in samples of populations at two different levels of the filter model. The first sample is an (out-patient) treated sample, hereafter treated psychiatric morbidity (level 4 of the filter model), whereas the second is a general population sample, hereafter psychopathology (level 1 of the filter model). Risk factors of treated psychiatric morbidity probably predispose to severe psychiatric disorders, resulting in referral to psychiatric services, while risk factors of psychopathology in the general population are likely to predispose to the whole spectrum (from mild to severe) of diseases or disorders. 


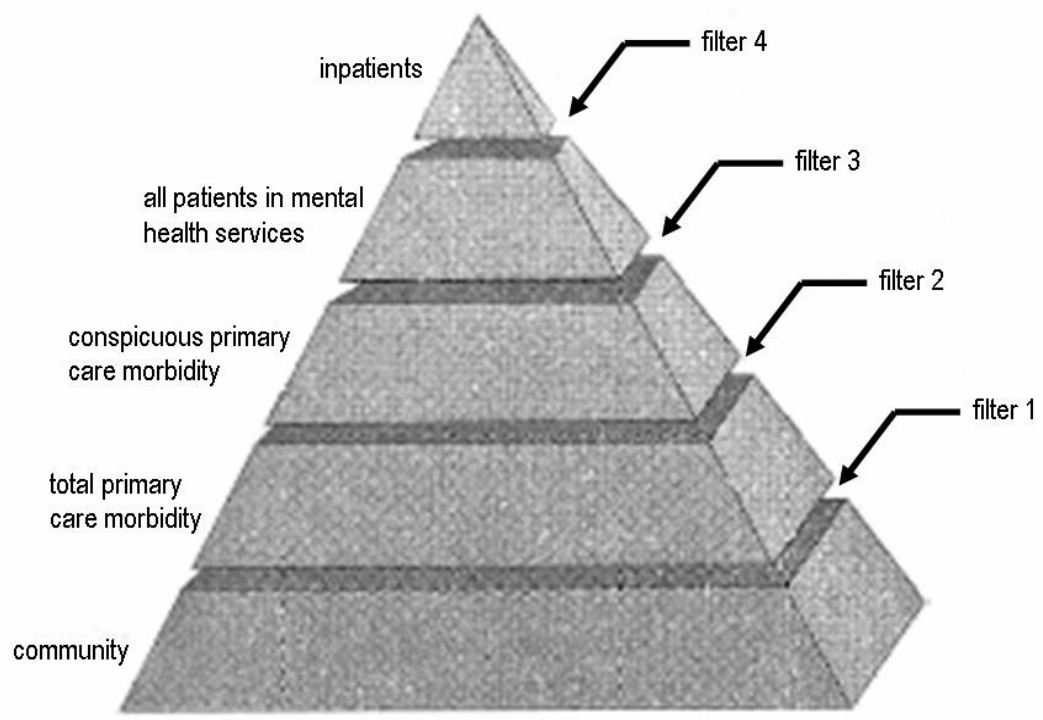

Figure 1. Filter model psychiatric morbidity in children

[Goldberg and Huxley (Goldberg and Huxley, 1980), adapted by Verhulst and Koot (Verhulst and Koot, 1995)]

\section{THE CONTEXT OF RISK}

There is a wide range of potential risk factors for the development of psychopathology and treated psychiatric morbidity, ranging from childhood developmental factors (e.g. early growth, early emotional and behavioural problems) (Tessier et al., 1997; Laitinen-Krispijn et al., 1999; Wahlbeck et al., 2001) and family-related issues (Garralda and Bailey, 1988; Mesman and Koot, 2001) to factors of the wider social environment (such as the neighbourhood) (Drukker et al., 2003; van der Linden et al., 2003). Furthermore, it is generally recognized that these risk factors are not independent, but may operate in conjunction with each other (Mesman and Koot, 2001) and often accumulate or influence each others effect. Given the differing levels of risk factors (child, family, neighbourhood) there is a need for multilevel analysis.

Earlier findings also illustrate a change in the impact of similar risk factors at different ages. For example, learning difficulties at age 8 years were significantly asso- 
ciated with disorder, whereas learning difficulties at 13 were not (Esser et al., 1990).

There has been considerable research on the role of genetic factors and this research has revealed that behaviour problems are subject to substantial genetic influence (Plomin, 1995). However, genetic differences account for about half of the variance in behaviour problems, leaving the other half to be explained by environmental factors (Plomin et al., 2001). Certain family-related issues and factors of the wider social environment may not only be related to the onset and persistence of psychiatric disorders, but also act as a catalyst in the parents' readiness to seek help for the child's problem. For example, single parenthood, low socioeconomic status, parental psychopathology, stressful life events and living in low SES neighbourhoods are related to psychopathology (Cummings and Davies, 1994; Verhulst and Koot, 1995; Pynoos et al., 1999; Mesman and Koot, 2000; Kalff et al., 2001; Drukker et al., 2003) and treated psychiatric morbidity (Garralda and Bailey, 1988; van der Linden et al., 2003).

However, although it has been established that childhood developmental and environmental risk factors differentiate between children coming to the attention of psychiatric services and controls in general population samples, these studies cannot explain why siblings, who are roughly $50 \%$ similar genetically and grow up within the same family (shared environment), differ markedly in personality and psychopathology (Dunn and Plomin, 1991). While such differences in mental health outcomes can be readily quantified in general biometric parameters in genetically sensitive samples (Dunn and Plomin, 1991; Rutter and Silberg, 2002) little is known about comparative developmental pathways of siblings with contrasting child mental health outcomes.

As stated earlier, risk factors often accumulate or influence each others effect. Apart from a direct relation between a risk variable and an outcome measure, the relationship between risk factor and outcome can be moderated by a third factor. It has been demonstrated that relative risks of main effects are insufficient in explaining trajectories towards psychopathology, as moderating effects of the wider social environment additionally shape individual risks (Neeleman, 2003). For example, members of ethnic minority groups living in areas where they represent a larger part of the population have a lower risk of suicide (Neeleman and Wessely, 1999) and psychosis (Boydell et al., 2001). Another example is that the association of low birth weight with ADHD was stronger in the urban than in the suburban populations (Breslau et al., 1996). This is known as ecological effect modification (Neeleman, 2003). Conversely, the association between a risk factor and poor mental health outcomes can be mediated by a third variable. When a variable is a mediator, this variable is on the causal pathway between the risk factor and the effect. 
For example, child shyness may lead to neglected peer status, which in turn may lead to depressed feelings. In conclusion, it is important to identify to what extent childhood developmental and environmental risk factors differentiate between children with treated psychiatric disorders and non-referred children, healthy controls, but also healthy siblings. In addition, it is important to outline possible moderating and mediating effects in explaining trajectories towards psychopathology.

\section{RISK FACTORS}

\section{Developmental factors}

Studies linking indicators of intrauterine or prenatal physical growth, such as birth weight and birth length, with disease in later life have given credence to the notion that part of the vulnerability for severe adult mental disorders such as schizophrenia is shaped early in the foetal period of life (Wahlbeck et al., 2001).

In addition, indicators of prenatal physical growth have also been associated with poor mental health outcomes in childhood. The pattern of behavioural deficits associated with low birth weight ranges from hyperactivity and inattention, to withdrawn, shy, and depressive behaviour (McCormick et al., 1990; Hoy et al., 1992; Szatmari et al., 1993; Weisglas-Kuperus et al., 1993; Breslau et al., 1996; Botting et al., 1997; Tessier et al., 1997). Furthermore, some studies suggested that leanness during childhood, reflecting postnatal physical growth was identified as an independent risk factor for schizophrenia in adults (Wahlbeck et al., 2001). These findings suggest that not only prenatal 'programming', but also postnatal effects act additively to the risk of mental health outcomes.

Studies using checklist measures have consistently identified distinct emotional (internalizing) and behavioural (externalizing) problems. They have provided strong evidence for continuity between early (preschool and kindergarten) behavioural and emotional problems and psychopathology in later childhood [e.g (Mesman and Koot, 2001)] and even adulthood (Caspi et al., 1996). Furthermore, in previous Dutch studies, both internalizing and externalizing problems predicted referral to mental health services in children and adolescents (Koot and Verhulst, 1992; Verhulst and van der Ende, 1997; Laitinen-Krispijn et al., 1999).

A wealth of evidence now supports the notion that abnormal motor and speech development, as indicators of disordered neurodevelopmental processes precede the onset of adult psychiatric disorders such as schizophrenia and depression (Jones et al., 1994; van Os et al., 1997), which is consistent with the assumption that some individuals have a biological vulnerability for these disorders. 


\section{Environmental factors}

\section{Family}

A number of adverse family circumstances have been associated with mental health outcomes in children, including single parenthood, low socioeconomic status and parental psychopathology (see above). Family psychopathology is a potential risk factor for psychopathology in children through genetic or parenting (environmental) mechanisms (Rutter et al., 1999). An example of genetic transmission is that children of, for instance, depressed parents are three times more likely to have a lifetime episode of Major Depressive Disorder (Birmaher et al., 1996) and, therefore, are at higher risk of coming into contact with mental health services. An example of an environmental explanation is that family interactions of depressed adults are characterized by more conflict, more rejection, more problems with communication, less expression of affect, less support and more abuse than are the family interactions of normal controls which may subsequently increase the risk of developing a psychiatric disorder (Kaufman, 1991; McCauley and Myers, 1992). However, family conflict may also reflect a coping strategy in which parents attempt to control the child's disruptive behaviours (Asarnow et al., 1994). Low SES as a risk factor for psychopathology in children is generally hypothesized to be due to the effects of factors thought to be related to low SES such as ineffective parenting and reduced access to a variety of resources (McLoyd, 1998). Since high income and high educational level imply not only better nutrition but often also a more favourable environment associated with better use of medical and social services, children of higher and middle socioeconomic families in any country are on average larger in body size (height) than their peers growing up in lower socioeconomic families (Eveleth and Tanner, 1976; Lasker and Mascie-Taylor, 1989; Lindgren and Cernerud, 1992; Cavelaars et al., 2000). In addition, the rates of infants with a low birth weight is higher when the socioeconomic status (SES) of the family is lower (Verkerk et al., 1994). Therefore, SES is likely to be on the causal pathway to poor growth and any study linking parameters of physical growth to mental health outcomes needs to take into account the effect of SES.

\section{Negative life experiences}

Negative life experiences in the form of being bullied and the experience of adverse life events in childhood and adolescence are strongly associated with both internalizing and externalizing disorders (Velez et al., 1989; Kumpulainen et al., 1998). Furthermore, negative life experiences have also been associated with poor mental health outcomes in adolescence and young adulthood, including depression 
(Kendler, 1995), general anxiety disorders (Murphy et al., 2000) and psychotic experiences (Lataster et al., 2006).

\section{Neighbourbood}

Differences in neighbourhood characteristics may influence the development and health of children and adolescents, who grow up in these environments (Garcia Coll et al., 1996). Neighbourhood characteristics that have been reported to contribute to an increased risk of poor mental health outcomes include measures of socioeconomic deprivation (Kalff et al., 2001) and, more recently, measures of 'social capital' (McKenzie et al., 2002; Drukker et al., 2003). Neighbourhood social capital has been defined as the availability of social resources, social support and social control that neighbourhood residents can count on (Drukker, 2004). It was shown that children had better mental health and behavioural outcomes when they were living in neighbourhoods with higher levels of informal social control, one aspect of social capital (Drukker et al., 2003). Furthermore, a second study showed that children living in more deprived neighbourhoods were at higher risk of coming into contact with mental health services, but this association was mitigated by strong 'social cohesion and trust', another aspect of social capital (van der Linden et al., 2003). Both results may indicate that social capital can decrease the impact of risk factors; for example, if neighbours correct deviant behaviour (this is informal social control) in an early stage of childhood development, this collective intervention may directly prevent the children from behaving badly as well as indirectly provide them with self-confidence and a sense of protection. Since the impact of risk factors on psychopathology may be modified by characteristics of the wider social environment in which a child or adolescent lives, social capital is a plausible candidate to further study in this context.

\section{STUDY DESIGN}

Growing recognition of the possible continuation of childhood problems into adulthood argues for a prospective developmental approach (Achenbach, 1997). Furthermore, there remains much debate in the literature about the direction and causality of effects. Is the psychopathology a result of the interaction of multiple risk factors or do externalizing behaviour problems cause, for example, stress in the family that in turn increases the risk for psychopathology (person-environment correlation)? In this context another important question is whether predictors of problem patterns among referred children differ from predictors for non-referred children? These questions cannot be answered on the basis of cross-sectional data. 
Therefore, in examining childhood developmental and environmental factors in relation to trajectories towards child psychopathology and treated psychiatric morbidity, the current thesis used prospective rather than retrospective designs and adopted a life-course rather than a cross-sectional perspective. The present thesis relied on longitudinal data derived from I) health files of Community paediatric services of Maastricht and surrounding areas (chapters 2, 3, 4 and 6) and ii) the Maastricht Quality of Life Study (MQoL: chapter 5) (Drukker, 2004).

\section{Setting}

The Maastricht population consists of 122000 inhabitants living in 36 residential neighbourhoods, having between 300 and 8500 inhabitants (all ages). The population is of relative ethnic homogeneity, with relatively few residents originating from non-Western countries, in comparison with the ethnically more heterogeneous populations in the cities in the northwest of the country (Drukker et al., 2003). Children living within the city of Maastricht or surrounding villages (total population of 201000 ) were the population of interest in chapters 2, 3 and 4 of this thesis. Chapters 5 and 6 are focussed on children and adolescents living in the city of Maastricht.

\section{Community paediatric services}

In the Netherlands, doctors and nurses of Community paediatric services regularly examine all children at different age points from birth to 16 years of age. A file for each child is initiated at the infant welfare centre, and subsequently transferred to the Youth Health Care Division of the Public Health Service at age 4 years.

Initially, the health files of the community paediatric services consisted of handwritten health information from health professionals (especially the school physician), teachers, parents and, on some occasions, the children themselves. Although most of the health information was assessed systematically and in a standardized way (e.g. motor-function examination, speech-therapy, (birth) weight, (birth) length and family sociodemographic variables), some of the information is only included in open comments about for example parental mental health problems. Analyses presented in chapters 2, 3 and 4 are derived from both standardized information and open comments of these handwritten health files.

Recently, as a result of these analyses of the handwritten files (chapters 2, 3 and 4) a partnership between Maastricht paediatric services and the Maastricht University psychiatric department was initiated (Lataster et al., 2006). In the context of this partnership, health information of children and adolescents was electronically 
available from standard self-report scannable questionnaires, aimed to detect and remediate physical and mental health problems. The analyses described in chapter 6 were performed using these data.

The information of the electronic health files of the community paediatric services presents an important opportunity for the early detection of children and adolescents at risk of (severe) psychiatric disorders and the mobilization of resources for the support of these groups of children.

\section{Maastricht Quality of Life Study}

The Maastricht university psychiatric department and the YHCD of the Public Health Services collaborated in a longitudinal cohort study of children and their families in the city of Maastricht, called the Maastricht Quality of Life Study (MQoL). The study aimed to follow-up a cohort of children, aged 11 years at baseline. The aim of the longitudinal study is to obtain insight in the collective and individual determinants of health-related quality of life. Measures included among others children's quality of life (e.g. general health, mental health, self-esteem and behaviour) and being the victim of neighbourhood bullying (Drukker, 2004). In addition, information on the neighbourhood was obtained firstly from the local authorities and statistics Netherlands (objective neighbourhood socioeconomic measures) and secondly from a questionnaire in the general population (neighbourhood level subjective measures of social capital). Analyses presented in chapter 5 were performed using both MQoL data and information on neighbourhood factors. These neighbourhood factors were also used in chapter 6 .

\section{AIMS AND OUTLINE OF THE THESIS}

The overall aim of the present thesis was to study to what extent childhood developmental and environmental risk factors are important in explaining individual differences in the trajectories towards mental ill health in children.

\section{Part 1}

In this first section, risk factors are examined in relation to treated psychiatric morbidity and data is derived from the handwritten routine examinations of the community paediatric services. In chapters 2 and 4 we compared the effects of several child and family factors on treated psychiatric morbidity between children coming into contact with the child psychiatric service of the Community Mental 
Health services and their matched healthy community controls, with a special focus on a possible mediating effect of indicators of prenatal and postnatal growth in the association between parental SES and treated psychiatric morbidity in chapter 4.

Since brothers and sisters growing up in the same family tend to be rather dissimilar despite their common upbringing, chapter 3 investigated which additional exposures discriminate between patients of the child psychiatric service of the Community Mental Health services and their siblings paying attention to personspecific features, with a special focus on comparative developmental pathways.

\section{Part 2}

This part concerns the association between negative life experiences and the development of psychopathology in the general population, hypothesizing that this association would be moderated by the neighbourhood environment.

As an introduction to chapter 6 , chapter 5 outlined the direct relationship between characteristics of the neighbourhood and exposure to neighbourhood bullying. For this purpose, data was derived from the Maastricht Quality of Life Study. In chapter 6, analyses were based on information from the electronic health files of the community paediatric services. In this chapter possible effects of repeated exposure to bullying and adverse life events at baseline on adolescent psychopathology at two-year follow-up were investigated. Secondly, in the search for factors that moderate the effects of individual risks, the role of neighbourhood social capital was examined. 


\section{REFERENCES}

Achenbach, TM (1997) Manual for the Young Adult Self-Report and Young Adult Behavior Checklist. Burlington: VT: Universtity of Vermont Department of Psychiatry.

Anderson, JC, Williams, S, McGee, R, Silva, PA (1987) DSM-III disorders in preadolescent children. Prevalence in a large sample from the general population. Arch Gen Psychiatry, 44 (1): 69-76.

Asarnow, JR, Tompson, M, Hamilton, EB, Goldstein, MJ , Guthrie, D (1994) Family-expressed emotion, childhood-onset depression, and childhood-onset schizophrenia spectrum disorders: is expressed emotion a nonspecific correlate of child psychopathology or a specific risk factor for depression? J Abnorm Child Psychol, 22 (2): 129-46.

Birmaher, B, Ryan, ND, Williamson, DE, Brent, DA, Kaufman, J, Dahl, RE, Perel, J , Nelson, B (1996) Childhood and adolescent depression: a review of the past 10 years. Part I. J Am Acad Child Adolesc Psychiatry, 35 (11): 1427-39.

Botting, N, Powls, A, Cooke, RW , Marlow, N (1997) Attention deficit hyperactivity disorders and other psychiatric outcomes in very low birthweight children at 12 years. J Child Psychol Psychiatry, 38 (8): 931-41.

Boydell, J, van Os, J, McKenzie, K, Allardyce, J, Goel, R, McCreadie, RG , Murray, RM (2001) Incidence of schizophrenia in ethnic minorities in London: ecological study into interactions with environment. BMJ, 323 (7325): 1336-8.

Breslau, N, Brown, GG, DelDotto, JE, Kumar, S, Ezhuthachan, S, Andreski, P, Hufnagle, KG (1996) Psychiatric sequelae of low birth weight at 6 years of age. J Abnorm Child Psychol, 24 (3): 385-400.

Caspi, A, Moffitt, TE, Newman, DL, Silva, PA (1996) Behavioral observations at age 3 years predict adult psychiatric disorders. Longitudinal evidence from a birth cohort. Arch Gen Psychiatry, 53 (11): 1033-9.

Cavelaars, AE, Kunst, AE, Geurts, JJ, Crialesi, R, Grotvedt, L, Helmert, U, Lahelma, E, Lundberg, O, Mielck, A, Rasmussen, NK, Regidor, E, Spuhler, T , Mackenbach, JP (2000) Persistent variations in average height between countries and between socio-economic groups: an overview of 10 European countries. Ann Hum Biol, 27 (4): 407-21.

Cummings, EM , Davies, PT (1994) Maternal depression and child development. J Child Psychol Psychiatry, 35 (1): 73-112.

Drukker, M (2004). The neighbourhood matters; the neighbourhood social environment and differences in self-reported quality of life and mental health. Psychiatry and Neuropsychology. Maastricht, Maastricht University.

Drukker, M, Kaplan, CD, Feron, FJM , Van Os, J (2003) Children's health-related quality of life, neighbourhood socio-economic deprivation and social capital. A contextual analysis. Soc Sci Med, 57 (5): 825-841.

Dunn, J , Plomin, R (1991) Why are siblings so different? The significance of differences in sibling experiences within the family. Fam Process, 30 (3): 271-83.

Esser, G, Schmidt, MH , Woerner, W (1990) Epidemiology and course of psychiatric disorders in school-age children--results of a longitudinal study. J Child Psychol Psychiatry, 31 (2): 243-63. 
Eveleth, PB , Tanner, JM (1976) World wide variation in human height. Cambridge: Cambridge University Press.

Garcia Coll, C, Lamberty, G, Jenkins, R, McAdoo, HP, Crnic, K, Wasik, BH , Vazquez Garcia, H (1996) An integrative model for the study of developmental competencies in minority children. Child Development, 67 (5): 1891-914.

Garralda, ME , Bailey, D (1988) Child and family factors associated with referral to child psychiatrists. Br J Psychiatry, 153: 81-9.

Goldberg, D , Huxley, P (1980) Mental illness in the community: the pathway to psychiatric care. London: Tavistock.

Goodyer, IM (1995) The epidemiology of depresion in childhood and adolescence. In: Verhulst, FC, Koot, HM (Ed.), The epidemiology of child and adolescent psychopathology (pp. 210-226) Oxford: Oxford University Press.

Hofstra, MB, Van der Ende, J , Verhulst, FC (2000) Continuity and change of psychopathology from childhood into adulthood: a 14-year follow-up study. J Am Acad Child Adolesc Psychiatry, 39 (7): 850-8.

Hoy, EA, Sykes, DH, Bill, JM, Halliday, HL, McClure, BG , Reid, MM (1992) The social competence of very-low-birthweight children: teacher, peer, and self-perceptions. J Abnorm Child Psychol, 20 (2): 123-50.

Jones, P, Rodgers, B, Murray, R , Marmot, M (1994) Child development risk factors for adult schizophrenia in the British 1946 birth cohort. Lancet, 344: 1398-402.

Kalff, AC, Kroes, M, Vles, JSH, Hendriksen, JGM, Feron, FJM, Steyaert, J, van Zeben, TMCB, Jolles, J , van Os, J (2001) Neighbourhood level and individual level SES effects on child problem behaviour: a multilevel analysis. J Epidemiol Community Health, 55 (4): 246-50.

Kaufman, J (1991) Depressive disorders in maltreated children. J Am Acad Child Adolesc Psychiatry, 30 (2): 257-65.

Kendler, KS (1995) Genetic epidemiology in psychiatry. Taking both genes and environment seriously. Arch Gen Psychiatry, 52 (11): 895-9.

Kooi, L, Sytema, S, Wiersma, D, Driessen, G, Wierdsma, AI , Dieperink, CJ (2000) GGZ onder druk? Verkenning met behulp van drie Nederlandse psychiatrische casusregisters. MGV, 55: 223-230.

Koot, HM , Verhulst, FC (1992) Prediction of children's referral to mental health and special education services from earlier adjustment. J Child Psychol Psychiatry, 33 (4): 717-29.

Kumpulainen, K, Rasanen, E, Henttonen, I, Almqvist, F, Kresanov, K, Linna, SL, Moilanen, I, Piha, J, Puura, K, Tamminen, T (1998) Bullying and psychiatric symptoms among elementary schoolage children. Child Abuse Negl, 22 (7): 705-17.

Laitinen-Krispijn, S, Van der Ende, J, Wierdsma, AI , Verhulst, FC (1999) Predicting adolescent mental health service use in a prospective record-linkage study. J Am Acad Child Adolesc Psychiatry, 38 (9): 1073-80.

Lasker, GW , Mascie-Taylor, CG (1989) Effects of social class differences and social mobility on growth in height, weight and body mass index in a British cohort. Ann Hum Biol, 16 (1): 1-8. 
Lataster, T, van Os, J, Drukker, M, Henquet, C, Feron, F, Gunther, N , Myin-Germeys, I (2006) Childhood victimisation and developmental expression of non-clinical delusional ideation and hallucinatory experiences : Victimisation and non-clinical Psychotic experiences. Soc Psychiatry Psychiatr Epidemiol, 41 (6): 423-8.

Lindgren, GW , Cernerud, L (1992) Physical growth and socioeconomic background of Stockholm schoolchildren born in 1933-63. Ann Hum Biol, 19 (1): 1-16.

McCauley, E , Myers, K (1992) Family interactions in mood disordered youth. Child adolesc Psychiatr Clin North Am, 1: 111-127.

McCormick, MC, Gortmaker, SL, Sobol, AM (1990) Very low birth weight children: behavior problems and school difficulty in a national sample. J Pediatr, 117 (5): 687-93.

McKenzie, K, Whitley, R , Weich, S (2002) Social capital and mental health. Br J Psychiatry, 181 (4): 280-283.

McLoyd, VC (1998) Socioeconomic disadvantage and child development. Am Psychol, 53 (2): 185204.

Mesman, J , Koot, HM (2000) Common and specific correlates of preadolescent internalizing and externalizing psychopathology. J Abnorm Psychol, 109 (3): 428-37.

Mesman, J , Koot, HM (2001) Early preschool predictors of preadolescent internalizing and externalizing DSM-IV diagnoses. J Am Acad Child Adolesc Psychiatry, 40 (9): 1029-36.

Murphy, DA, Moscicki, AB, Vermund, SH , Muenz, LR (2000) Psychological distress among HIV(+) adolescents in the REACH study: effects of life stress, social support, and coping. The Adolescent Medicine HIV/AIDS Research Network. J Adolesc Health, 27 (6): 391-8.

Neeleman, J (2003) The relativity of relative risks: disadvantage or opportunity? Br J Psychiatry, 182: $101-2$.

Neeleman, J , Wessely, S (1999) Ethnic minority suicide: a small area geographical study in south London. Psychol Med, 29 (2): 429-36.

Plomin, R (1995) Genetics and children's experiences in the family. J Child Psychol Psychiatry, 36 (1): 33-68.

Plomin, R, Asbury, K, Dunn, J (2001) Why are children in the same family so different? Nonshared environment a decade later. Can J Psychiatry, 46 (3): 225-33.

Pynoos, RS, Steinberg, AM , Piacentini, JC (1999) A developmental psychopathology model of childhood traumatic stress and intersection with anxiety disorders. Biol Psychiatry, 46 (11): 1542-54.

Rutter, M , Silberg, J (2002) Gene-environment interplay in relation to emotional and behavioral disturbance. Annu Rev Psychol, 53: 463-90.

Rutter, M, Silberg, J, O'Connor, T , Simonoff, E (1999) Genetics and child psychiatry: II Empirical research findings. J Child Psychol Psychiatry, 40 (1): 19-55.

Shaffer, D, P. Fisher, M.K. Dulcan et al. (1996) The NIMH Diagnostic Interview Schedule for Children Version 2.3 (DISC-2.3): description, acceptability, prevalence rates, and performance in the MECA study. J Am Acad Child Adolesc Psychiatry, 35: 865-877.

Szatmari, P, Saigal, S, Rosenbaum, P , Campbell, D (1993) Psychopathology and adaptive functioning among extremely low birthweight children at eight years of age. Development and Psychopathology, 5: 345-357. 
Tessier, R, Nadeau, L, Boivin, M , Tremblay, RE (1997) The social behaviour of 11- to 12-year-old children born as low birthweight and/or premature infants. International Journal of Behavioral Development, 21 (4): 795-811.

van der Linden, J, Drukker, M, Gunther, N, Feron, F , van Os, J (2003) Children's mental health service use, neighbourhood socioeconomic deprivation, and social capital. Soc Psychiatry Psychiatr Epidemiol, 38 (9): 507-14.

van Os, J (2000) Indicatoren en cijfers. In: Van den Broucke, S, Van Nuffel, R (Ed.), Naar een geestelijk gezonde samenleving (pp. 17-38): Kluwer Diegem.

van Os, J, Jones, P, Lewis, G, Wadsworth, M , Murray, R (1997) Developmental precursors of affective illness in a general population birth cohort. Arch Gen Psychiatry, 54 (7): 625-31.

Velez, CN, Johnson, J , Cohen, P (1989) A longitudinal analysis of selected risk factors for childhood psychopathology. J Am Acad Child Adolesc Psychiatry, 28 (6): 861-864

Verhulst, FC, Berden, GF , Sanders-Woudstra, JA (1985) Mental health in Dutch children: (II). The prevalence of psychiatric disorder and relationship between measures. Acta Psychiatr Scand Suppl, 324: 1-45.

Verhulst, FC , Koot, HM (1995) The epidemiology of child and adolescent psychopathology. Oxford, UK: Oxford University Press.

Verhulst, FC, van der Ende, J (1997) Factors associated with child mental health service use in the community. J Am Acad Child Adolesc Psychiatry, 36 (7): 901-9.

Verhulst, FC, van der Ende, J, Ferdinand, RF , Kasius, MC (1997) The prevalence of DSM-III-R diagnoses in a national sample of Dutch adolescents. Arch Gen Psychiatry, 54 (4): 329-36.

Verkerk, PH, Zaadstra, BM, Reerink, JD, Herngreen, WP , Verloove-Vanhorick, SP (1994) Social class, ethnicity and other risk factors for small for gestational age and preterm delivery in The Netherlands. Eur J Obstet Gynecol Reprod Biol, 53 (2): 129-34.

Wahlbeck, K, Forsen, T, Osmond, C, Barker, DJ , Eriksson, JG (2001) Association of schizophrenia with low maternal body mass index, small size at birth, and thinness during childhood. Arch Gen Psychiatry, 58 (1): 48-52.

Weisglas-Kuperus, N, Koot, HM, Baerts, W, Fetter, WP, Sauer, PJ (1993) Behaviour problems of very low-birthweight children. Dev Med Child Neurol, 35 (5): 406-16. 



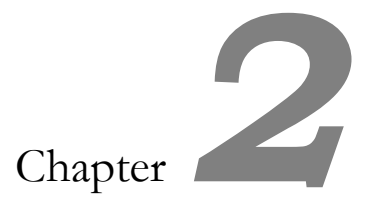

\section{Childhood social and early developmental factors associated with mental health service use}

Nicole Gunther ${ }^{1}$, Barbara Slavenburg${ }^{1}$, Frans Feron ${ }^{2}$ and Jim van Os ${ }^{1,3}$

1 Department of Psychiatry and Neuropsychology, South Limburg Mental Health Research and Teaching Network, EURON, Maastricht University, Maastricht, The Netherlands.

2 Youth Health Care Division, Public Health Service South Limburg, location Maastricht, The Netherlands

3 Division of Psychological Medicine, Institute of Psychiatry, De Crespigny Park, Denmark Hill, London, UK.

Social Psychiatry and Psychiatric Epidemiology, 2003, Vol. 38, No. 3, 101-108 


\section{ABSTRACT}

Background The aim of this study was to determine the influence of family and child variables on the pathway to mental health care in children. Methods A blinded, matched case control study was conducted, involving a retrospective analysis of prospectively collected data from routine examinations at the Youth Health Care Division from the Municipal Health Centre Maastricht (YHCD), where all children in a geographically defined area from foetal life through to age 19 years are periodically screened. The sample included 400 children, 80 referred to the Community Mental Health Centre in Maastricht and 320 matched controls, aged 613 years. Results The most potent risk factors associated with mental health service use were: being small at birth, having a younger mother at delivery, living in a one-parent family, having a divorced mother and/or unemployed father, observations of externalizing behaviour and/or motor developmental problems, speech problems and experiencing several adverse family circumstances. The group of variables pertaining to the family (e.g. one-parent family, parental mental health problems, etc.) influenced mental health service independently of the group of variables pertaining to the child (e.g. birth length, speech problems, etc.) and vice versa. Several combinations of risk factors, under realistic prevalence estimates, had positive predictive values of up to $26 \%$. Conclusion Pathways to child psychiatric care are heavily influenced by the child's family environment as well as by deviance in social, motor and speech development. Independence of child developmental effects suggests these are not merely on the causal pathway between adverse family environment and psychiatric service use outcome. Combinations of risk factors may be useful to develop a screening approach with the possibility of early prevention.

Keywords: Child development - Mental health service use - Pathways to care 


\section{INTRODUCTION}

The prevalence rates of psychiatric conditions in childhood across studies using DSM-III-R criteria range from $17.6 \%$ in New Zealand (Anderson et al., 1987) to $26 \%$ in the Netherlands (Verhulst et al., 1985). A substantial proportion of children with significant levels of psychopathology do not receive specialist treatment (Leaf et al., 1996; Verhulst and van der Ende, 1997) and mental health services throughout Europe are confronted with an increasing number of young patients every year (Kooi et al., 2000). A good number of these children will remain in contact with services throughout adolescence and adulthood.

Research on the factors that determine which children go on to the level of mental health services along the pathways to mental health care (Goldberg and Huxley, 1980) has shown that not only severity and type of mental health disorder but also child and family characteristics play a role in the referral pathway (Verhulst and Koot, 1992).

Several Dutch studies found that early externalizing as well as internalizing problems predicted referral to mental health services in children and adolescents (Koot and Verhulst, 1992; Verhulst and van der Ende, 1997; Laitinen-Krispijn et al., 1999). Furthermore, the association between psychiatric disorders and mental health service use among 4- to16-year-olds was stronger in urban areas than in rural areas (Offord et al., 1987).

Above all, however, mental health service use in childhood has been linked to adverse socioeconomic circumstances such as poverty, minority ethnic groups and low-income families (Garralda and Bailey, 1988; Costello and Janiszewski, 1990; John et al., 1995), poor maternal mental health, psychosocial stress in the family, and inadequate support from the extended family (Garralda and Bailey, 1988). In addition, Jensen and colleagues (Jensen et al., 1990) showed that likelihood of referral was positively associated with life events and parents' history of divorce, and negatively associated with sib ship size.

Given the overwhelming demand on child psychiatric services, more systematic studies on the factors influencing referral are needed, allowing for the development of screening methods. The current study wished to amplify the earlier findings mentioned above, using a prospective rather than a retrospective design and adopting a life-course rather than a cross-sectional perspective. We used prospective information from routine data collected by health professionals at a local Youth Health Care Division from the Municipal Health Centre of Maastricht (YHCD), where data of all children from foetal life through to age 19 years are compiled. This information was used to conduct a follow-back case control study in children who had been referred between the ages of 6 and 13 years to the child psychiatric 
services at the Community Mental Health Centre in Maastricht, the Netherlands. The use of existing routine data for this study (as opposed to study-specific data collection using dedicated researchers and instruments) was deliberate, as screening efforts are only useful if they involve information that can be collected in a sustained and cost-effective manner. Data collected at the YHCD are suitable for such an exercise.

The effects of two groups of variables on mental health service use were assessed. Firstly, we assessed the influence of family variables, such as sociodemographic variables (e.g. one-parent family and unemployed parent), and family circumstances (e.g. parental mental health problems and psychosocial stress in the family). Secondly, we assessed the effects of variables pertaining to the child, such as early developmental variables (e.g. birth weight and birth length, motor development, psychosocial development and bedwetting), and special referrals (e.g. special education and speech therapy). We also tested to what extent any effects of family variables and child variables were independent of each other. Our hypothesis was that they would not be independent of each other, giving credence to the hypothesis that child adverse developmental outcomes are on the causal pathway between adverse family circumstances and use of mental health care in the child.

\section{SUBJECTS AND METHODS}

\section{Setting}

Maastricht is a relatively small city (population 121000 ) located in the extreme south of the Netherlands, and is the capital of the province of Limburg. The population is of relative ethnic homogeneity, there being relatively few non-Dutch inhabitants, in comparison with the ethnically more heterogeneous populations in the cities in the northwest of the country. Children living within the city or surrounding villages (total population of 201 000) were included in the present study. Since both general and mental health services in the Netherlands are accessible to everyone because the costs are covered by a compulsory national insurance scheme (Schnabel, 1997), financial or insurance considerations do not play a role in the help-seeking decision.

In the Netherlands, recognition and referral behaviour of general practitioners and school physicians serve as an important filter to mental health service use. This also applies to Maastricht and surrounding areas, where school-going children are screened by the school physician of the YHCD. Children with suspected psychiatric morbidity are referred to a central intake team and from there referred to the 
Youth Department of the Community Mental Health Services. Previous research in the Netherlands has found that among the total population of children with mental health problems, those that are most severely affected come to the attention of psychiatric services (Koot and Verhulst, 1992). Therefore, children who attend psychiatric services can also be considered as those who are most in need of care. Children with mental retardation are referred to specialized services outside mental health services.

\section{Community paediatric services periodic screening programme}

Community paediatric services in the Netherlands comprise an infant welfare centre for children aged 0-3 years and a Youth Health Care Division from the Municipal Health Centre for children aged 4-19 years. A file for each child is initiated at the infant welfare centre, and subsequently transferred to the YHCD at age 4 years. These health files consist of information from health professionals (especially the school physician), teachers, parents and, on some occasions, the children themselves. Below, the assessments that were included in our study are discussed.

\section{Assessments 0-3 years}

At the infant welfare centre a child's first vaccinations and several health screenings take place. Several of these assessments are made in a standardized way by health professionals. An example of these is the auditory screening at the age of 9 months, called the Ewing-test (recently replaced by the CAPAS-test). The individual nine items of the Ewing-test (e.g. hearing cup and spoon, voice, S.S.S.S., etc.) are rated as positive (normal) or negative. The overall score (sum of the individual items) has an empirically based cut-off, with scores below the cut-off rated as a failed test result (Ewing and Ewing, 1961; NSDSK, 1997). Other variables systematically included in the assessment are date of birth of the child and the parents, gender, birth weight and birth length, family sociodemographic variables such as occupation and marital status of the parents, age at walking, presence of enuresis and any special referrals (e.g. speech therapy). The latter two are also coded at age 4 years and older.

In addition, the file has a range of designated sections in which the health professional is invited to make open comments about aspects of development such as sleeping problems, psychosocial development, psychosocial stress in the family and parental mental health problems at different ages. They are not required to write down comments and can leave the space blank if they feel there is nothing special to comment. In the current study, these items were rated as 'present' when some 
kind of problem had been mentioned by the health professional in the designated section and 'absent' when no comment had been written down.

\section{Assessments 4-19 years}

At the ages of approximately 4, 5, 9, 12 and 13-15 years, the children receive further routine examinations. The item 'motor development' is assessed systematically and in a standardized way at the age of approximately 5 years by a 20 -item motor function examination (Baecke et al., 1984). During the motor function examination, the school physician at the Maastricht YHCD asks the child to make certain movements with eyes, arms, fingers and legs. The movements are rated on an ordinal scale ranging from 0 to 2 or from 0 to 3 , higher scores indicating that the movement was poorly executed.

Between the ages of 4 and 19 years, the physician again was invited to make use of designated sections in which open comments could be made about aspects of development such as coarse motor development problems (e.g. problems with hopping, standing on one leg) and fine motor development problems (e.g. problems with drawing or writing), sleeping problems, psychosocial development, psychosocial stress in the family and parental mental health. In doing so, the physician also makes use of information from other health professionals, parents, teachers and the children themselves. Again these comments were rated as being present or absent.

\section{Subjects and procedure}

The design was a matched, blinded case-control study of a group of children aged 6-13 years who had been referred consecutively to the Community Mental Health Service (hereafter: 'cases'). Power calculations indicated that 80 cases would yield $75 \%$ power to detect an odds ratio of 2 at conventional alpha level for an exposure with 0.25 prevalence and four matched controls for each case. For each case, four controls were selected, matched for gender and year of birth. Controls were chosen by selecting, in the register with the names of all children in temporal order of attendance at the YHCD, the first two children of the same gender and year of birth registered before and after the index child. Thus, our sample comprised 400 children, 80 cases and 320 controls.

The secretary of the Community Mental Health Service asked informed consent of parents of 120 consecutive referrals aged 6-13 years to the child psychiatric department of the Community Mental Health Centre, yielding 80 cases (one-third refused). Parents provided consent to study routine examination data compiled at the YHCD and to obtain the clinical diagnosis made by the Community Mental 
Health Service. A comparison sample of matched controls was selected from the YHCD files by a YHCD staff member, who simultaneously handed over the files of cases and controls to the researchers who, thus, remained blind to case-control status. The parents of the controls were not asked for individual permission as it is within the legal remit of the YHCD to conduct anonymous group comparisons within collected data.

\section{Measures included in the analyses}

\section{Family sociodemographic variables}

The following dichotomous sociodemographic variables were included: marital status of the parents (divorced or not), employment status of the parents (unemployed or not), and living in a single- or two-parent family when the child was approximately 5 years old. Parental occupation when the child was approximately 5 years of age was rated, for the purpose of the analysis, into one of three ordinal occupational groupings: low (manual employees), medium (clerical employees, owners of small businesses, technicians, minor professionals), and high (supervisory employees, major professionals, owners of large businesses, executives, teachers), with the category 'high' as the reference category (CBS, 1993). Mother's age at delivery was analysed as a continuous variable.

\section{Family circumstances}

Three kinds of family circumstances were rated: psychosocial stress in the family (e.g. physical abuse by parents, social and/or emotional neglect by parents, relationship problems between parents, inconsistent discipline by parents), parental mental health problems and other adverse family circumstances (e.g. emigration). These circumstances were included in the analysis as being present or absent. The number of family circumstances, ranging from 0 to 16, was also included in the analysis as a continuous measure.

\section{Child Neonatal period and (early) development}

Auditory development at age 9 months (Ewing-test or CAPAS-test) was rated as passed or failed. Optional remarks on deviant coarse and fine motor development were rated at different ages as being present or absent. Comments noted by health professionals, teachers, parents and/or children themselves about the psychosocial behaviour of the child were categorized into 'positive behaviour', 'externalizing behaviour', 'internalizing behaviour', 'internalizing and externalizing behaviour' or 'else'. Positive behaviour included comments such as: 'doing well', 'having many social contacts', 'spontaneous', 'cooperative', etc. Externalizing behaviour was 
defined as socially undesirable behaviour and behaviour that affected others (e.g. hyperactivity, disturbing behaviour in the classroom, aggression, fighting with other children etc.). Internalizing behaviour was defined as affecting the person in question but not the environment (e.g. being very shy, negative self-image, often nervous, insecure, etc.). In a pilot study, kappas were computed as a measure of interrater reliability across two researchers for several classification items of psychosocial behaviour at different ages, based on 30 cases. These kappas were all satisfactory ( 0.80 or higher). Weighted means (higher scores indicating poorer performance - weighted for number of non-missing items) of the scores on the motor function examination as an indicator of motor development at the age of 5 years were analysed as continuous variables. Length at birth and weight at birth and age at which the child started to walk were analysed as continuous variables. Body Mass Index was defined as birth weight divided by birth length squared.

\section{Child Special referrals}

These included referrals such as special education or speech therapy, and were again coded present or absent.

\section{Other child variables}

These dichotomous variables (present/absent) included bedwetting or wetting during the day.

\section{Statistical analyses}

The analyses of associations between developmental problems and family circumstances on the one hand and mental health service use on the other were restricted to instances where children had experienced these problems or circumstances before they had their first contacts with mental health services. Associations were first calculated separately for each risk factor (univariate analyses) and expressed as odd ratios (ORs). Since the analyses were matched, the ORs and 95\% confidence intervals $(95 \% \mathrm{CI})$ were calculated using the conditional logistic regression procedure (Breslow and Day, 1987) of the STATA computer programme (StataCorp, 1999). Independence of the different significant predictors was assessed by entering these simultaneously in the same regression model (multivariate analyses of independence of predictors). For this purpose, we chose the variables with the largest effect sizes within a group of similar variables such as the sociodemographic variables, motor development variables and family circumstance variables. The variables with the largest effect sizes in each group were entered jointly into the model. 
In order to assess the relative independence of family and child variables (multivariate analyses of independence of family and child variables), a composite variable was made for each group, rated present if any of the statistically significant predictors in each group was rated as present. Continuous variables were dichotomized around the 90th percentile for this purpose. The two composite variables reflecting family and child exposures were subsequently entered jointly in the model. The variables not clearly representing either family or child variables ('other adverse family circumstances' and 'number of circumstances') were left out of this analysis.

As the matching variables were age and sex, all the analyses can be considered adjusted for age and sex.

The positive predictive value (PPV: the probability of developing the outcome, i.e. coming into contact with mental health services, given the presence of the risk factor) of the exposures was assessed using the DIAGTEST procedure in STATA. As the baseline prevalence of the outcome of mental health service use was artificially fixed at $20 \%$ (four controls for each case), which was substantially higher than the reported prevalence of mental health service use between the ages of 6 and 13 years, PPVs were calculated under the assumption of a 5\% prevalence of the outcome of mental health service use. This correction was necessary as the PPV is dependent on the prevalence of the outcome with the risk of inflated estimates of the PPV in case-control studies.

\section{RESULTS}

\section{Univariate analyses}

\section{Family sociodemographic variables}

The majority of the sample was male (66.3\%). Predictors of mental health service use are shown in Table 1.

The probability of coming into contact with mental health services was significantly higher for children living in a one-parent household (OR, 5.37; 95\% CI, 2.49-11.56), if their mothers were divorced (OR, 7.33; 95\% CI, 3.43-15.66) or if their fathers were unemployed (OR, 2.99; 95\% CI, 1.17-7.64). Having a father with a low-status occupation also predicted higher use of mental health services, although this effect was not statistically significant at conventional alpha (OR, 2.29; 95\% CI, 0.96-5.43).

Compared to the mothers of the controls, the mothers of the cases were approximately 1.5 years younger at delivery (OR, 0.92; 95\% CI, 0.87-0.97). 


\section{Family circumstances}

All family circumstances were significantly associated with mental health service use. Children 'at risk' in this context were children who had a parent with a mental health problem (OR, 5.43; 95\% CI, 2.06-14.35), encountered psychosocial stress in the family (OR, 2.51; 95\% CI, 1.45-4.36) or experienced other kinds of family circumstances, such as having a somatically ill parent (OR, 2.44; 95\% CI, 1.38-4.33). The continuous score of any type of family circumstance was a potent continuous risk factor in that children experiencing more events in their lives were at progressively higher risk (summary OR, 1.44, 95\% CI, 1.27-1.62).

\section{Child neonatal period and early development}

Cases were approximately $1 \mathrm{~cm}$ smaller at the time of birth. The risk of mental health service use decreased with 0.92 per $1 \mathrm{~cm}$ length at birth (OR, 0.92; 95\% CI, 0.85-0.99).

The mean birth weight of the cases was $100 \mathrm{~g}$ below that of the controls. The effect of birth weight on the use of mental health services, although not significant, was in the same direction as the effect of birth length (OR per g, 0.99; 95\% CI, 0.99-1.00). Body Mass Index (BMI) was not a significant risk factor (OR, 1.01; 95\% CI, 0.84-1.21).

Children in need of speech therapy (OR, 2.46; 95\% CI, 1.41-4.27) or who had a problem in coarse motor development according to the health professionals (OR, 2.13; $95 \%$ CI, 1.14-4.00) made use of mental health services significantly more often. Children doing worse on the motor function examination also had a higher risk of mental health service use (OR, 4.64; 95\% CI, 1.64-13.11).

Children who exhibited externalizing behaviour had a 4.5 times higher risk of later mental health service use than children receiving only positive comments on their social behaviour (OR, 4.55; 95\% CI, 2.09-9.90).

\section{Multivariate analyses}

\section{Independence of predictors}

Independence of the different significant predictors was assessed by entering these simultaneously in the same model. For this purpose, the variable 'having a divorced mother' was left out of the model, because of collinearity with one-parent family. Included variables were: number of circumstances as the strongest predictor in the group of variables pertaining to family circumstances, motor function examination as the strongest predictor in the group of variables pertaining to motor development, unemployed father, externalizing behaviour, speech therapy, birth length and age of mother at delivery. In this joint model, externalizing behav- 
iour (OR, 4.27; 95\% CI, 1.11-16.48) and the number of family circumstances (OR, $1.51 ; 95 \% \mathrm{CI}, 1.15-1.98)$ were the strongest predictors, whereas other factors exhibited attenuated effects in this model.

\section{Independence of family and child variables}

The two composite variables reflecting the group of family and child exposures (see Table 1) influenced mental health service use significantly when entered separately in the model (OR respectively, 4.27; 95\% CI, 2.43-7.52; OR, 3.27; 95\% CI, 1.74-6.13). Although attenuated, they remained large and significant when entered jointly in the same model (OR respectively, 3.50; 95\% CI, 1.92-6.37; OR, 2.30; 95\% CI, 1.15-4.63).

\section{Positive predictive values}

Table 2 shows that the factors 'one-parent family', 'number of circumstances', 'unemployed father' and 'externalizing behaviour' had a PPV of $10 \%$ or higher, under the assumption of a $5 \%$ prevalence estimate of mental health service use in children between the ages of 6 and 13 years. The PPVs of several combinations of factors were considered. For example, the PPV of the combination 'number of circumstances' and 'externalizing behaviour' was approximately $17 \%$; the combination 'number of circumstances' (dichotomized: $0=$ number of circumstances $<3$ and $1=$ number of circumstances $\geq 3$ ) and 'one-parent family' had a PPV of approximately $26 \%$.

\section{DISCUSSION}

Risk factors for mental health service use in children aged 6-13 years could be traced to several domains of development: social development, motor development and speech development. Also factors related to the child's family environment increased the risk. The most salient risk factors were: being small at birth, having a younger mother at delivery, living in a one-parent family, having a divorced mother and/or unemployed father, showing externalizing behaviour and/or motor developmental problems, having speech problems and experiencing several adverse family circumstances.

The predictive value of, for example, the combination of 'number of circumstances' and 'one-parent family', under the assumption of a $5 \%$ prevalence estimate of mental health service use in children, was approximately $26 \%$. 


\section{Methodological issues}

The aim of this study was to identify the factors that determine mental health service use in children using routine data that can easily be employed for screening efforts. As many, if not most, children with psychiatric disorders remain untreated, the risk factors identified in this study cannot be equated with risk factors for disorder per se. However, it is known that, at least in the Netherlands, the children that do come to the attention of psychiatric services are the most severely affected (Koot and Verhulst, 1992). This also applies to Maastricht and surrounding areas, where all children are screened by a central intake team so that only children with the highest level of psychiatric morbidity and need for care are referred for treatment by mental health services. The risk factors identified in this study can, thus, be conceived as the ones that predispose to severe psychiatric disorder resulting in referral to psychiatric services.

We deliberately focussed on multiple-informant, routine data with a potential application for screening, so that the data used in this study were not collected specifically for the purpose of the study. The results suggest that the variables used may be sensitive enough for possible use in screening.

Due to the fact that we could determine the time order of variables (before/after intake for outpatient mental health services), the analyses were restricted to the risk factors (see above) whose occurrence was described before the first mental health service contact of the child in question took place. Thus, as far as the argument of time order is concerned, we provide evidence of causality or, more relevant, absence of reversed causality (e.g. raters seeing more pathology because the child was in treatment with mental health services) (Hill, 1965). Indeed, most of the ratings were made years before the child was referred to mental health services.

Many studies in this area made use of retrospective data. The present study included prospective information from health files of children of Maastricht and surrounding areas avoiding the pitfalls of recall bias.

The study design has several limitations. Firstly, 30\% of eligible children did not participate, which may hamper the generalizability of the findings. Secondly, working with routine data such as the Maastricht YHCD-files, inevitably introduces a fairly large degree of misclassification, especially in the case of not-systematically assessed variables such as open comments, where the risk of false negatives is highest. Although this cannot be excluded, school physicians work in a standardized way and routinely incorporate comments as a way to longitudinally assess children in important areas. To the extent that misclassification was operating, it is difficult to conceive how that rate would be differentially influenced by future mental health service use. 


\section{Family sociodemographic variables}

Four sociodemographic variables were included: occupational level of the father, living in a one-parent family, divorced status of the mother and unemployed status of the father. In contrast to Koot and Verhulst (Koot and Verhulst, 1992), the 'occupational level of the father' did not have a significant effect by conventional alpha. However, the OR indicated excess risk with an effect size comparable to previous reports (Kalff et al., 2001).

Children coming from a one-parent family were more at risk than children coming from a two-parent family, conform previous work (Kalff et al., 2001). This was also true for children having a divorced mother or an unemployed father. These variables may reflect risk status of the parents or lack of support from the environment. As a result, single parents may, for example, seek help by professionals more quickly when they perceive worrisome behaviour in the child (LaitinenKrispijn et al., 1999).

\section{Child neonatal period and early development}

There is a growing body of evidence that some chronic mental and physical disorders originate possibly during foetal development (Fine et al., 1985; Barker and Osmond, 1986). Three indicators of foetal development were also included in this study, i.e. birth weight, birth length and a combination of these two (BMI). Only one of them seemed to be important: girls and boys who were smaller at birth appeared to be at more risk of coming into contact with mental health services than children who were taller. In a recent study, the risk of schizophrenia not only increased with shortness at birth but also with low birth weight (Wahlbeck et al., 2001). The results of the present study and earlier studies suggest that some factors may exert adverse effects in utero, not only for severe adult disorders such as schizophrenia, but also for a wide range of behavioural problems in children (van Os et al., 2001). The same applies to developmental delays, such as delay in speech and motor development, which in the current study was a powerful predictor and in previous work also predicted adult psychiatric disorders (Jones et al., 1994; van Os et al., 1997).

Externalizing behaviour, more than internalizing behaviour, was one of the strongest predictors of mental health service use. In previous Dutch studies, both internalizing and externalizing problems predicted referral to mental health services in children and adolescents (Koot and Verhulst, 1992; Verhulst and van der Ende, 1997; Laitinen-Krispijn et al., 1999). The explanation for this difference of results 
may lie in the different ways in which these variables were assessed in our study and the studies mentioned above. Externalizing behaviour as defined in our study may be more likely to result in social complications and subsequent referral, and internalizing behaviour in children may be more easily overlooked in routine examination unless sensitive instruments are used to measure it.

\section{Family circumstances}

The finding that unstable family circumstances acted as a good predictor of mental health service utilization is in keeping with earlier research. For example, Verhulst and van der Ende (Verhulst and van der Ende, 1997) found that high levels of family stress (e.g. problems in family functioning and one-parent family) were linked to the referral of children to mental health services, and another study concluded that the frequency of family problems was the most common factor in referral of adolescent patients (Hillard et al., 1987).

The present study also found a high incidence of psychiatric disturbance in parents of children who used mental health services, as did many other studies (Wolff, 1961; Sheperd et al., 1966; Garralda and Bailey, 1988). One reason for this is that parents with psychiatric problems are more likely to seek professional help in relation to a child's problems. Another possible explanation of this finding is genetic transmission: children of, for instance, depressed parents are three times more likely to have a lifetime episode of Major Depressive Disorder (Birmaher et al., 1996) and, therefore, are at more risk of coming into contact with mental health services. A more environmental explanation is that family interactions of depressed adults are characterized by more conflict, more rejection, more problems with communication, less expression of affect, less support and more abuse than are the family interactions of normal controls which may subsequently increase the risk of developing a psychiatric disorder (Kaufman, 1991; McCauley and Myers, 1992). Finally, it is also possible that family conflict may reflect a coping strategy in which parents attempt to control the child's disruptive behaviours (Asarnow et al., 1994).

\section{Independence of child and family variables}

Both exposures reflecting family environment and exposures reflecting child development independently influenced the risk function, suggesting that the effect of child developmental variables is not merely on the causal pathway between adverse family environment and child psychiatric service use, but reflects an independent developmental pathway. Indeed, the strongest independent effect of the child developmental variables was found for externalizing behaviour, and, independent of 
that, for the group of family environment variables the strongest effect was found for the number of family circumstances. The results suggest that there are multiple, additive risk factors that influence the risk for psychiatric service use by exerting their effects in a cascade-like fashion over the course of development.

\section{Implications for early intervention}

A modest but potentially useful level of PPVs was demonstrated using routine data. Early intervention is a pressing issue given the increasing number of referrals to child psychiatric services, and school physicians are ideally placed to pay increased attention to children at risk. Possibilities for early intervention include early parenting and family support strategies. For example, support and aid to parenting may be crucial for mentally ill parents to prevent relapse and promote the child's mental health (Buist, 1998). There are also possibilities to improve the psychosocial prognosis of children at temperamental risk by home-based interventions focussed on parent-child interactions (Teerikangas et al., 1998). In addition, there may be scope for further developing the role of mental health workers in schools in an attempt to reduce behavioural problems at an early stage (Harrington et al., 2000). Given the encouraging results reported in this study, further work is urgently required to use the extensive routine data collections that are taking place in many countries, for screening programmes aimed at identifying not only prevalent but also future deviation from healthy psychosocial development in children.

Acknowledgements This study was funded by the Department of Public Health, Welfare and Sport (Ministerie van VWS). 


\section{REFERENCES}

Anderson, JC, Williams, S, McGee, R, Silva, PA (1987) DSM-III disorders in preadolescent children. Prevalence in a large sample from the general population. Arch Gen Psychiatry, 44 (1): 69-76.

Asarnow, JR, Tompson, M, Hamilton, EB, Goldstein, MJ , Guthrie, D (1994) Family-expressed emotion, childhood-onset depression, and childhood-onset schizophrenia spectrum disorders: is expressed emotion a nonspecific correlate of child psychopathology or a specific risk factor for depression? J Abnorm Child Psychol, 22 (2): 129-46.

Baecke, JAH, Boersma-Slütter, WGM , Van Heeswijk, ALM (1984) Ontwikkeling van een motoriektest voor kleuters: de betrouwbaarheid. T Soc Gezondheidsz, 62: 38-45.

Barker, DJ , Osmond, C (1986) Childhood respiratory infection and adult chronic bronchitis in England and Wales. Br Med J (Clin Res Ed), 293 (6557): 1271-5.

Birmaher, B, Ryan, ND, Williamson, DE, Brent, DA, Kaufman, J, Dahl, RE, Perel, J , Nelson, B (1996) Childhood and adolescent depression: a review of the past 10 years. Part I. J Am Acad Child Adolesc Psychiatry, 35 (11): 1427-39.

Breslow, NE , Day, NE (1987) Statistical methods in cancer research. Lyon: WHO.

Buist, A (1998) Mentally ill families. When are the children unsafe? Aust Fam Physician, 27 (4): 261-5.

CBS (1993) Standaard beroepenclassificatie 1992. Den Haag: SDU.

Costello, EJ , Janiszewski, S (1990) Who gets treated? Factors associated with referral in children with psychiatric disorders. Acta Psychiatr Scand, 81: 523-529.

Ewing, IR , Ewing, WG (1961) New opportunities for deaf children. London: University of London Press Ltd.

Fine, PE, Adelstein, AM, Snowman, J, Clarkson, JA , Evans, SM (1985) Long term effects of exposure to viral infections in utero. Br Med J (Clin Res Ed), 290 (6467): 509-11.

Garralda, ME , Bailey, D (1988) Child and family factors associated with referral to child psychiatrists. Br J Psychiatry, 153: 81-9.

Goldberg, D , Huxley, P (1980) Mental illness in the community: the pathway to psychiatric care. London: Tavistock.

Harrington, R, Peters, S, Green, J, Byford, S, Woods, J , McGowan, R (2000) Randomised comparison of the effectiveness and costs of community and hospital based mental health services for children with behavioural disorders. BMJ, 321 (7268): 1047-50.

Hill, AB (1965) The Environment and Disease: Association or Causation? Proc R Soc Med, 58: 295300.

Hillard, JR, Slomowitz, M , Levi, LS (1987) A retrospective study of adolescents' visits to a general hospital psychiatric emergency service. Am J Psychiatry, 144 (4): 432-6.

Jensen, PS, Bloedau, L , Davis, H (1990) Children at risk: II. Risk factors and clinic utilization. J Am Acad Child Adolesc Psychiatry, 29 (5): 804-12.

John, LH, Offord, DR, Boyle, MH , Racine, YA (1995) Factors predicting use of mental health and social services by children 6-16 years old: findings from the Ontario Child Health Study. Am J Orthopsychiatry, 65 (1): 76-86.

Jones, P, Rodgers, B, Murray, R , Marmot, M (1994) Child development risk factors for adult schizophrenia in the British 1946 birth cohort. Lancet, 344: 1398-402. 
Kalff, AC, Kroes, M, Vles, JSH, Hendriksen, JGM, Feron, FJM, Steyaert, J, van Zeben, TMCB, Jolles, J , van Os, J (2001) Neighbourhood level and individual level SES effects on child problem behaviour: a multilevel analysis. J Epidemiol Community Health, 55 (4): 246-50.

Kaufman, J (1991) Depressive disorders in maltreated children. J Am Acad Child Adolesc Psychiatry, 30 (2): 257-65.

Kooi, L, Sytema, S, Wiersma, D, Driessen, G, Wierdsma, AI , Dieperink, CJ (2000) GGZ onder druk? Verkenning met behulp van drie Nederlandse psychiatrische casusregisters. MGV, 55: 223-230.

Koot, HM , Verhulst, FC (1992) Prediction of children's referral to mental health and special education services from earlier adjustment. J Child Psychol Psychiatry, 33 (4): 717-29.

Laitinen-Krispijn, S, Van der Ende, J, Wierdsma, AI , Verhulst, FC (1999) Predicting adolescent mental health service use in a prospective record-linkage study. J Am Acad Child Adolesc Psychiatry, 38 (9): 1073-80.

Leaf, PJ, Alegria, M, Cohen, P, Goodman, SH, Horwitz, SM, Hoven, CW, Narrow, WE, VadenKiernan, M , Regier, DA (1996) Mental health service use in the community and schools: results from the four-community MECA Study. Methods for the Epidemiology of Child and Adolescent Mental Disorders Study. J Am Acad Child Adolesc Psychiatry, 35 (7): 889-97.

McCauley, E , Myers, K (1992) Family interactions in mood disordered youth. Child adolesc Psychiatr Clin North Am, 1: 111-127.

NSDSK (1997) Vroegtijdige opsporing van gehoorstoornissen. Toelichting jaarcijfers 1995. Amsterdam

Offord, DR, Boyle, MH, Szatmari, P, Rae-Grant, NI, Links, PS, Cadman, DT, Byles, JA, Crawford, JW, Blum, HM, Byrne, C , et al. (1987) Ontario Child Health Study. II. Six-month prevalence of disorder and rates of service utilization. Arch Gen Psychiatry, 44 (9): 832-6.

Schnabel, P (1997) The mental health services: more than psychiatry alone. In: Schrijvers, AJP editor. Health and health care in the Netherlands: a critical self-assessment by Dutch experts in the medical and health sciences (pp. 119-131) Utrecht, the Netherlands: De Tijdstroom.

Sheperd, M, Oppenheim, AN , Mitchell, S (1966) Childhood behavior disorders and the childguidance clinic: an epidemiological study. J Child Psychol Psychiatry, 7: 39-52.

StataCorp (1999). Stata Statistical Software. Texas, College Station, TX: Stata Corporation.

Teerikangas, OM, Aronen, ET, Martin, RP , Huttunen, MO (1998) Effects of infant temperament and early intervention on the psychiatric symptoms of adolescents. J Am Acad Child Adolesc Psychiatry, 37 (10): 1070-6.

van Os, J, Jones, P, Lewis, G, Wadsworth, M , Murray, R (1997) Developmental precursors of affective illness in a general population birth cohort. Arch Gen Psychiatry, 54 (7): 625-31.

van Os, J, Wichers, M, Danckaerts, M, Van Gestel, S, Derom, C, Vlietinck, R (2001) A prospective twin study of birth weight discordance and child problem behavior. Biol Psychiatry, 50 (8): 5939.

Verhulst, FC, Berden, GF , Sanders-Woudstra, JA (1985) Mental health in Dutch children: (II). The prevalence of psychiatric disorder and relationship between measures. Acta Psychiatr Scand Suppl, 324: 1-45. 
Verhulst, FC , Koot, HM (1992) Child Psychiatric Epidemiology: concepts, methods, and findings. Newbury Park, California: Sage.

Verhulst, FC, van der Ende, J (1997) Factors associated with child mental health service use in the community. J Am Acad Child Adolesc Psychiatry, 36 (7): 901-9.

Wahlbeck, K, Forsen, T, Osmond, C, Barker, DJ , Eriksson, JG (2001) Association of schizophrenia with low maternal body mass index, small size at birth, and thinness during childhood. Arch Gen Psychiatry, 58 (1): 48-52.

Wolff, S (1961) Social and family background of pre-school children with behaviour disorders attending a child guidance clinic. J Child Psychol Psychiatry, 2: 260-8. 
Table 1. Univariate associations between mental health service use and family and child risk factors, adjusted for age and sex

\begin{tabular}{|c|c|c|c|c|c|c|}
\hline & \multicolumn{2}{|l|}{ Cases } & \multicolumn{2}{|c|}{ Controls } & \multirow[t]{3}{*}{ OR } & \multirow[t]{3}{*}{$95 \% \mathrm{CI}$} \\
\hline & $\mathrm{N}$ & $\%$ & $\mathrm{~N}$ & $\%$ & & \\
\hline \multicolumn{5}{|l|}{$\underline{\text { Dichotomous variables }}$} & & \\
\hline \multicolumn{7}{|l|}{ Family variables } \\
\hline Low occupation of the father & 16 & 29.1 & 38 & 14.8 & 2.29 & $0.96-5.43$ \\
\hline One-parent family & 17 & 21.3 & 15 & 4.7 & $5.37^{* * *}$ & $2.49-11.56$ \\
\hline Divorced mother & 22 & 27.5 & 17 & 5.3 & $7.33^{* * *}$ & $3.43-15.66$ \\
\hline Unemployment father & 4 & 5.0 & 8 & 2.5 & $2.99 *$ & $1.17-7.64$ \\
\hline Psychosocial stress in the family & 27 & 33.8 & 54 & 16.9 & $2.51 * *$ & $1.45-4.36$ \\
\hline Parental mental health problems & 10 & 12.7 & 7 & 2.2 & $5.43^{* *}$ & $2.06-14.35$ \\
\hline \multicolumn{7}{|l|}{ Child variables } \\
\hline Special education & 5 & 6.3 & 18 & 5.6 & 1.12 & $0.40-3.08$ \\
\hline Externalizing behaviour & 35 & 43.8 & 67 & 20.9 & $4.55^{* * *}$ & $2.09-9.90$ \\
\hline Internalizing behaviour & 6 & 7.5 & 29 & 9.1 & 1.86 & $0.63-5.54$ \\
\hline Insufficient Ewing-test ( 9 months) & 20 & 25.0 & 74 & 23.1 & 1.01 & $0.54-1.88$ \\
\hline Sleeping problems & 22 & 27.9 & 72 & 22.5 & 1.31 & $0.75-2.29$ \\
\hline $\begin{array}{l}\text { Problems with toilet training } \\
\text { (e.g. bedwetting) }\end{array}$ & 19 & 24.1 & 54 & 16.9 & 1.54 & $0.85-2.79$ \\
\hline $\begin{array}{l}\text { Coarse motor development } \\
\text { (e.g. problems with hopping) }\end{array}$ & 19 & 23.8 & 42 & 13.1 & $2.13^{*}$ & $1.14-4.00$ \\
\hline $\begin{array}{l}\text { Fine motor development } \\
\text { (e.g. problems with writing) }\end{array}$ & 30 & 38.0 & 87 & 27.2 & 1.72 & $0.99-2.97$ \\
\hline Speech therapy & 28 & 35.1 & 59 & 18.4 & $2.46^{* *}$ & $1.41-4.27$ \\
\hline \multicolumn{7}{|l|}{ Family/child variables } \\
\hline Other adverse family circumstances & 32 & 40.0 & 75 & 23.4 & $2.44 * *$ & $1.38-4.33$ \\
\hline Continuous variables & Mean & $(\mathrm{SD})$ & Mean & $(\mathrm{SD})$ & OR & $95 \% \mathrm{CI}$ \\
\hline \multicolumn{7}{|l|}{ Family variables } \\
\hline Age mother at delivery & 27.3 & $(4.91)$ & 28.8 & $(4.32)$ & $0.92 * *$ & $0.87-0.97$ \\
\hline \multicolumn{7}{|l|}{ Child variables } \\
\hline Birth weight, g & 3238 & $(599.33$ & 3)3327 & $(577.03)$ & 0.99 & $0.99-1.00$ \\
\hline Birth length, cm & 49.45 & $(2.89)$ & 50.29 & $(3.04)$ & $0.92 *$ & $0.85-0.99$ \\
\hline BMI at birth, $\mathrm{kg} / \mathrm{m} 2$ & 13.07 & $(1.53)$ & 13.04 & $(1.33)$ & 1.01 & $0.84-1.21$ \\
\hline Age child at walking & 13.6 & $(2.93)$ & 13.7 & $(2.46)$ & 0.97 & $0.86-1.09$ \\
\hline $\begin{array}{l}\text { Motor function examination } \\
(0 \leq x \leq 1.5 \text {; at } 5 \text { years })\end{array}$ & 0.38 & $(0.34)$ & 0.29 & $(0.24)$ & $4.64 * *$ & $1.64-13.11$ \\
\hline Family/child variables & & & & & & \\
\hline $\begin{array}{l}\text { Number of circumstances } \\
(0 \leq \mathrm{x} \leq 15)\end{array}$ & 3.00 & $(2.86)$ & 0.98 & $(1.85)$ & $1.44^{* * *}$ & $1.27-1.62$ \\
\hline
\end{tabular}


Table 2. Positive Predictive Values (PPVs), sensitivity and specificity of the strongest significant risk factors

\begin{tabular}{lllll}
\hline \hline & $\mathrm{N}$ & $\begin{array}{c}\text { PPV* } \\
(\%)\end{array}$ & $\begin{array}{l}\text { Sensitivity } \\
(\%)\end{array}$ & $\begin{array}{l}\text { Specificity } \\
(\%)\end{array}$ \\
\hline One-parent family & 32 & 20.18 & 23.94 & 95.02 \\
Unemployment father & 22 & 13.27 & 13.85 & 95.24 \\
Externalizing behaviour & 102 & 9.91 & 43.75 & 79.06 \\
Speech therapy & 87 & 9.08 & 35.00 & 81.56 \\
Birth length $\leq 46 \mathrm{~cm}$ & 24 & 5.18 & 6.76 & 93.49 \\
Age mother at delivery $\leq 21$ years & 24 & 9.47 & 10.13 & 94.90 \\
Motor function examination $\geq 0.44$ & 42 & 9.43 & 20.00 & 89.89 \\
Number of circumstances $\geq 3$ & 82 & 16.03 & 48.75 & 86.56 \\
\hline \hline
\end{tabular}

* Under the assumption of a $5 \%$ prevalence estimate of mental health service use in children. 
Chapter

\title{
The combination of shared family environment and individual-specific developmental deviance as a cause for treated psychiatric morbidity in children
}

\author{
Nicole Gunther ${ }^{1}$, Marjan Drukker ${ }^{1}$, Frans Feron ${ }^{2}$, \\ Andries Korebrits ${ }^{1}$ and Jim van Os ${ }^{1,3}$ \\ 1 Department of Psychiatry and Neuropsychology, South Limburg Mental Health Research and \\ Teaching Network, EURON, Maastricht University, Maastricht, The Netherlands. \\ 2 Youth Health Care Division, Public Health Service South Limburg, location Maastricht, The \\ Netherlands \\ 3 Division of Psychological Medicine, Institute of Psychiatry, De Crespigny Park, Denmark Hill, \\ London, UK.
}

Acta Psychiatrica Scandinavica, 2005, Vol. 112, No. 5, 376-384 


\section{ABSTRACT}

Objective There is an incomplete understanding of why some children growing up in the same family are in need of treatment for psychiatric morbidity whilst their siblings are not. The present paper examined the possible role of individualspecific developmental risk factors. Method Three case-control analyses were conducted: i) 80 children referred to the Community Mental Health Centre (cases) and 320 population controls, ii) 68 healthy siblings of cases and 272 population controls, and iii) 80 children and 68 healthy siblings. Measures of development and psychosocial circumstances were obtained from routine, longitudinal, standardized child medical records. Results Given shared family environments, additional presence of delays in speech and motor development contributed most to differential sibling mental health outcomes. In addition, cases displayed both earlier expression and more severe levels of developmental behavioural deviance than their healthy siblings, who in turn had higher levels of behavioural deviance than population controls. Conclusion In siblings sharing a familial risk environment, development of psychiatric morbidity may be canalized through additional individual-specific developmental exposures.

Keywords: Child development - Community mental health services - Siblings 


\section{INTRODUCTION}

Both family and child characteristics play a role in determining psychiatric morbidity in children (Verhulst and Koot, 1992). Mental health service use is a valuable indicator of psychiatric morbidity in children, because only the most severely affected come to the attention of mental health services in the Netherlands (Koot and Verhulst, 1992; Zwaanswijk et al., 2003). In contrast with many of the earlier studies relating child and family variables to treated psychiatric morbidity (Garralda and Bailey, 1988; Verhulst and van der Ende, 1997), a previous Dutch case-control study adopted a life-course rather than a cross-sectional perspective, using prospectively collected data (Gunther et al., 2003). It was concluded that pathways to child psychiatric care were independently determined by the level of adverse family circumstances as well as by the level of early externalizing behaviour of the child (Gunther et al., 2003). In addition, it was reported that family characteristics such as living in a one-parent household and having an unemployed father were associated with treated psychiatric morbidity in children, although after controlling for confounding variables these associations were reduced (Gunther et al., 2003). 'While the work that has established that psychosocial risk factors differentiate between children coming to the attention of psychiatric services and controls in general population samples has been instructive, it cannot explain why mental health outcomes of siblings growing up in a shared psychosocial environment may be markedly different (Dunn and Plomin, 1991; Rutter and Silberg, 2002). While such differences can be readily quantified in general biometric parameters in genetically sensitive samples (Dunn and Plomin, 1991; Rutter and Silberg, 2002), little is known about comparative developmental pathways of siblings with contrasting child mental health outcomes. The present study hypothesized, using a controlled sibling design, that additional exposure to developmental risk factors (Jones et al., 1994; van Os et al., 1997) would discriminate between siblings growing up in the same family. Thus, more than one child per family was included in controlled comparisons, facilitating the identification of factors specific to each child that predisposes to severe psychiatric disorder resulting in treated psychiatric morbidity, the mental health outcome measure in our study. Developmental pathways as assessed by routine population developmental examinations were compared in controlled samples of siblings living in the same family, one of whom had been referred to the Community Mental Health Centre. This report is an extension of a previous study that compared developmental pathways between a sample of 80 children referred to the Community Mental Health Centre (children with treated psychiatric morbidity) and 320 matched community controls; the current analyses 
additionally included 68 siblings of children with treated psychiatric morbidity and their 272 matched community controls.

\section{Aims of the study}

The present report was to investigate which additional exposures discriminate between siblings discordant for treated psychiatric morbidity growing up in the same family.

\section{MATERIALS AND METHODS}

\section{Setting}

Maastricht is a relatively small city located in the South of the Netherlands. The population is of relative ethnic homogeneity, with relatively few residents originating from non-Western countries, in comparison with the ethnically more heterogeneous populations in the cities in the northwest of the country. Children living within the city or surrounding villages (total population of 201 000) were included in the present study.

In the Netherlands, all children from foetal life to the age of 19 years are regularly examined at community health centres for children and adolescents. These services comprise an infant welfare centre for children aged 0-4 years and a Youth Health Care Division (YHCD) from the Municipal Health Centre for children aged 4-19 years. A file for each child is initiated at the infant welfare centre, and subsequently transferred to the YHCD at the age of 4 years. In order to detect growth deficiencies, children's height and weight are measured at every medical examination. In addition, these health files include information from health professionals (especially the school physician), teachers and parents and, on some occasions, the children themselves.

School physicians of the YHCD as well as general practitioners play an important role in recognizing mental health problems and these professionals can refer children with suspected psychiatric morbidity to a central intake team. From there, the children can be referred to the Youth Department of the Community Mental Health Services. As both general and mental health services in the Netherlands are accessible to everyone because the costs are covered by a compulsory national insurance scheme (Schnabel, 1997), financial or insurance considerations do not play a role in the help-seeking decision. Previous research in the Netherlands reported that among the total population of children with mental health problems, 
those who are most severely affected come to the attention of psychiatric services (Koot and Verhulst, 1992). Therefore, children who attend psychiatric services can also be considered as those who are most in need of care. These children have psychiatric problems such as attention deficit hyperactivity disorder, oppositional defiant disorder, posttraumatic stress disorder, obsessive compulsive disorder and social phobia. Children with mental retardation are referred to specialized services outside mental health services and, therefore, were not included in the present study.

\section{Assessments 044 years}

At the infant welfare centre a child's first vaccinations and several health screenings are carried out. Several of these assessments are made in a standardized way by health professionals. An example of these is the auditory screening at the age of 9 months, called the Ewing-test [recently replaced by the compact Amsterdam paedo-audiometric screener (CAPAS)-test]. The individual nine items of the Ewing-test (e.g. hearing cup and spoon, voice, etc.) are rated as positive (normal) or negative. The overall score (sum of the individual items) has an empirically based cut-off, with scores below the cut-off rated as a failed test result (Ewing and Ewing, 1961). Other variables systematically included in the assessment are date of birth of the child and the parents, gender, birth weight and birth length, family sociodemographic variables such as occupation and marital status of the parents, age at walking, presence of enuresis and any special referrals (e.g. speech therapy). The latter two are also coded at age 4 years and older.

In addition, the file has a range of designated sections in which the health professional is invited to make open comments about aspects of development such as: sleeping problems, psychosocial development, psychosocial stress in the family and parental mental health problems at different ages. It is not compulsory for health professionals to write down comments and spaces can be left blank if the examiner feels there is nothing special to report. In the current study, these items were rated as 'present' when some kind of problem had been mentioned by the health professional in the designated section and 'absent' when no comment had been written down.

\section{Assessments at ages $4-19$ years}

At the ages of approximately 4, 5, 9, 11, 13-15 years, the children receive further routine examinations. The item 'motor development' is assessed systematically and in a standardized way at the age of approximately 5 years by a 20 -item motor function examination (Baecke et al., 1984). During the motor function examination, the school physician at the Maastricht YHCD instructs the child to make certain 
movements with eyes, arms, fingers and legs. The movements are rated on an ordinal scale ranging from 0 to 2 or from 0 to 3 , higher scores indicating that the movement was more poorly executed.

Between the ages of 4 and 19 years, the physician again was invited to make use of designated sections in which open comments could be made about aspects of development such as: gross motor development problems (e.g. problems with hopping, standing on one leg) and fine motor development problems (e.g. problems with drawing or writing), sleeping problems, psychosocial development, psychosocial stress in the family and parental mental health. In doing so, the physician also makes use of information from other health professionals, parents, teachers and the children themselves. Again, these comments were rated as being present or absent.

\section{Subjects and procedure}

The design of the present study was a matched, blinded case-control study, organized by the University Psychiatric Department and the YHCD of the Municipal Health Centre. Three case-control analyses were conducted i) a group of 80 children aged 6-13 years who had been referred consecutively to the Community Mental Health Centre (hereafter: 'children with treated psychiatric morbidity' or 'cases') were compared with a group of 320 population controls; ii) a group of 68 healthy siblings were compared with a group of 272 population controls and iii) the group of 80 cases were compared with the group of 68 siblings. Thus, for each case and for each sibling, four controls were selected, matched for gender and year of birth. The secretary of the Community Mental Health Centre asked informed consent from parents of 120 consecutive referrals aged 6-13 years to the child psychiatric department of the Community Mental Health Centre. The parents of 98 of these children (18\% refused) provided consent for the investigators to study routine data from developmental examinations of these cases and their siblings, compiled at the YHCD. Of the 98 subjects, the records of 80 were included in the study as indicated by power calculations (Gunther et al., 2003). Two comparison samples of matched controls, one for the cases $(n=320)$ and another for the siblings $(n=272)$, were selected from the YHCD files by a YHCD staff member, who simultaneously handed over the files of a case or a sibling and controls to the researchers, thus ensuring that the researchers remained blind to case-control (or sibling-control) status. The parents of the controls were not asked for individual permission as it is within the legal remit of the YHCD to conduct anonymous group comparisons within collected data. For each case and for each sibling, four controls were selected, matched for gender and year of birth. More detailed information on this 
procedure and the assessments at community health services for child and adolescents has been described previously (Gunther et al., 2003).

In order to provide descriptive statistics, in terms of episodes of care, of the 80 cases, information pertaining to the Psychiatric Case Register of Southern Limburg (PCR-SL) was used. In the PCR-SL, data on utilization of psychiatric care (all contacts with psychiatric care facilities) has been collected cumulatively since 1981 for the population in the city of Maastricht and surrounding areas (201 000 inhabitants) (Driessen et al., 2001). Using this data, a description was made of episodes of care of the 80 cases. An episode of care was defined as a period of contacts with psychiatric care facilities over an episode of time ending when there is a gap of 90 days or more without any further contacts (Tansella et al., 1995).

\section{Measures included in the analyses}

Measures of parental socioeconomic status (SES), family circumstances, maternal age of delivery, child neonatal period and early development (length at birth, weight at birth, Body Mass Index at birth, age at which the child started to walk, auditory development at 9 months: Ewing-test or CAPAS-test), motor development, psychosocial behaviour of the child, child special referrals (special education and speech therapy) and bedwetting or wetting during the day were included in the present analyses. Below these variables are briefly described. For a full description and rationale of all variables we refer to a previous publication (Gunther et al., 2003).

The analyses of the associations between developmental problems and family circumstances on the one hand and treated psychiatric morbidity on the other were restricted to instances where children had experienced these problems or circumstances before they had their first contacts with psychiatric services.

\section{Parental socioeconomic status}

Parental occupational status, living in a single- or two-parent family, and parental working situation when the child was approximately 5 years old, selected from the above-mentioned medical examination files, were used as indicators of parental SES. Parental occupational status was defined using the occupation of the father. When the occupation of the father was unknown, parental occupation was defined using maternal occupation. This resulted in a categorical variable, with four categories: low (e.g. manual employees), medium (e.g. clerical employees, owners of small businesses, technicians and minor professionals), high (e.g. supervisory employees, major professionals, owners of large businesses, executives and teachers) and academic (e.g. lawyers and doctors). Because the percentage of parents having an aca- 
demic degree was $>10 \%$ we introduced 'academic' as a separate class in our analyses. The category 'medium' was defined as the reference category. Living in a single- or two-parent family and parental working situation were both analysed as binary variables, with respectively two-parent family and being employed as the reference categories. A family was defined as being 'employed' when one or both of the parents were employed. Missing values were excluded from the analyses.

\section{Family circumstances}

Three kinds of family circumstances were rated: psychosocial stress in the family (e.g. physical abuse by parents, social and/or emotional neglect by parents, relationship problems between parents, inconsistent discipline by parents), parental mental health problems and other adverse family circumstances (e.g. moving and emigration). These circumstances were included in the analysis as being present or absent. In addition, the number of family circumstances was included in the analysis as a continuous measure.

\section{Psychosocial behaviour and motor development}

Comments noted by health professionals, teachers, parents and/or children themselves about the psychosocial behaviour of the child were categorized into 'positive behaviour', 'externalizing behaviour', 'internalizing behaviour', 'internalizing and externalizing behaviour' or 'other' with 'positive behaviour' as the reference category in the analyses. Positive behaviour included comments such as: 'doing well', 'having many social contacts', 'spontaneous', 'cooperative', etc. Externalizing behaviour was defined as socially undesirable behaviour and behaviour that affected others (e.g. hyperactivity, disturbing behaviour in the classroom, being aggressive, fighting with other children, etc.). Internalizing behaviour was defined as affecting the person in question but not the environment (e.g. being very shy, negative self image, often nervous, insecure etc.). In a pilot study, kappas were computed as a measure of interrater reliability across two researchers for several classification items of psychosocial behaviour at different ages, based on 30 cases. These kappas were all satisfactory ( 0.80 or higher).

Two variables were defined with regard to the timing of psychosocial behaviour: one for psychosocial behaviour before the age of 6 (early psychosocial behaviour) and one for psychosocial behaviour at 6 years or older (late psychosocial behaviour). For more details on these variables see our previous paper (Gunther et al., 2003).

Weighted means (higher scores indicating poorer performance weighted for number of non-missing items) of the scores on the motor function examination as an 
indicator of motor development at the age of 5 years were analysed as continuous variables.

\section{Statistical analyses}

Three different sets of case-control analyses were performed. First, cases were compared with their matched controls. Second, siblings were compared with their matched controls and finally, cases were compared with siblings.

\section{Cases versus controls and siblings versus controls}

The analyses comparing both cases and siblings with their controls were performed using Stata (StataCorp, 2001). Based on a priori hypotheses about explanatory child and parent factors (Gunther et al., 2003) in the two case-control comparisons, associations were calculated for each risk factor and expressed as odd ratios (ORs). As the analyses were matched (for age and gender), the ORs and 95\% confidence intervals $(95 \% \mathrm{CI})$ were calculated using the conditional logistic regression procedure (Breslow and Day, 1987).

\section{Cases versus their siblings}

The analyses of comparing the different child and family characteristics between the group of cases and the group of siblings were also performed using the Stata computer programme (StataCorp, 2001). However, some cases did not have a sibling, while other cases had more than one sibling. Because children within one family are more similar, data are in fact clustered by family and are, in statistical terms, part of a multilevel structure with level-one units (siblings) structured into level-two units (families). Multilevel logistic regression analysis can take into account family specific variance, while results (ORs) can be interpreted identically to the estimates in conventional unilevel analyses. Therefore, the hierarchically structured data were subjected to multilevel logistic regression analysis, using generalized estimation equations (Snijders and Bosker, 1999).

Because no matching procedure was performed in the comparisons between cases and siblings, these were adjusted for age and gender. 


\section{RESULTS}

\section{Sample}

About $50 \%$ of the 80 cases had three or more episodes of care. An episode of care was characterized by a mean number of nine contacts and a mean duration of 131 days (data not shown). The majority of the cases was male $(66 \%)$, while in the group of siblings the sex ratio was about equal (girls: 53\%). The mean age in the year 2002 was 10.5 years in both groups ( $\mathrm{SD}=2.4,3.7$ respectively). Descriptives of child and family variables are provided in Table 1.

\section{Child neonatal period and (early) development}

Children who were smaller at birth were more at risk of treated psychiatric morbidity (OR, 0.92; 95\% CI, 0.85-0.99) (Table 2). Birth size did not significantly differentiate between siblings and their controls and the cases were also not smaller or bigger than their siblings.

\section{Child developmental variables}

Children in need of speech therapy (OR, 2.46; 95\% CI, 1.41-4.27), who had a problem in gross motor development (OR, 2.13; 95\% CI, 1.14-4.00), or were performing worse on the motor function examination according to the health professionals (OR, 4.64; 95\% CI, 1.64-13.11) had a higher risk of treated psychiatric morbidity. In addition, the cases were more in need of speech therapy (OR, 2.16; 95\% CI, 1.05-4.45) than the siblings. Furthermore, more cases than siblings had a problem in gross motor development, but this difference was statistically imprecise by conventional alpha (OR, 2.30; 95\% CI 0.90-5.85). These developmental factors did not differentiate between siblings and their controls, with the exception of higher rates of fine motor development problems in the group of siblings (OR, 2.23; 95\% CI 1.12-4.42).

Early and late psychosocial behaviour were also important predictors of treated psychiatric morbidity: children who exhibited in early (before 6 years) or in later childhood (6 years or older) externalizing behaviour or showed in early or in later childhood a combination of internalizing and externalizing behaviour had a higher risk of later treated psychiatric morbidity than children receiving only positive comments on their social behaviour. Internalizing behaviour in later childhood was also significantly associated with treated psychiatric morbidity (OR, 6.35; 95\% CI, 2.02-19.98).

Differences in psychosocial behaviour between siblings and their controls first appeared in later childhood with higher rates of externalizing behaviour (OR, 2.79; 
95\% CI, 1.17-6.62) and higher rates of a combination of internalizing and externalizing behaviour (OR, 3.69; 95\% CI, 1.36-10.02) in siblings. Compared with the siblings, the cases were showing more externalizing behaviour (early: OR, 4.00; 95\% CI, 1.61-9.92; late: OR, 2.84; 95\% CI, 1.23-6.56) and were showing more often a combination of internalizing and externalizing behaviour (early: OR, 4.15; 95\% CI, 1.02-16.83; late: OR, 2.68; 95\% CI, 1.02-7.07), both before and after the age of 6 years.

\section{Family sociodemographic variables and family circumstances}

Compared with the mothers of the controls, the mothers of the cases were approximately 1.5 years younger at delivery (OR, $0.93 ; 95 \% \mathrm{CI}, 0.87-0.98)$.

Furthermore, two out of three SES variables, i.e. living in a one-parent household and having an unemployed parent, were associated with treated psychiatric morbidity. Living in a one-parent family also differentiated between the siblings and their controls (OR, 2.83; 95\% CI, 1.30-6.14), and similarly all adverse family circumstances differentiated between siblings and their controls. There were no differences in family socioeconomic variables and family circumstances between cases and their siblings.

\section{DISCUSSION}

In this study, family psychosocial risk factors for treated psychiatric morbidity displayed obligatory sharing between siblings, and the effects of these showed no differences between cases and siblings in direct or indirect comparisons. For example, adverse family factors differentiated between cases and controls, but also between siblings and controls. However, in spite of sharing the same family circumstances, factors with regard to neonatal variables, motor development and speech development were specific for treated psychiatric morbidity or, in other words, were case-specific. Thus, siblings did not differ significantly from controls on any of these non-behavioural developmental factors with the exception of fine motor development. In contrast, the behavioural factors appeared to be partly familial and partly case-specific in that both cases and siblings showed externalizing behaviour or a combination of internalizing and externalizing behaviour, but cases displayed both earlier expression and more severe levels of deviant behaviour when compared with siblings. 


\section{Methodological issues}

Firstly, the focus of this study was to identify the factors that determine treated psychiatric morbidity in children using routine data that can easily be employed for screening efforts. As many, if not most, children with psychiatric disorders remain untreated, the risk factors identified in this study cannot be equated with risk factors for disorder per se. However, it is known that, at least in the Netherlands, the children that do come to the attention of psychiatric services are the most severely affected (Koot and Verhulst, 1992). This also applies to Maastricht and surrounding areas, where all children referred to mental health services are screened by a central intake team so that only children with the highest level of psychiatric morbidity and need for care are selected for treatment by mental health services. The risk factors identified in this study can thus be conceived as the ones that predispose to severe psychiatric disorder resulting in treatment by psychiatric services.

Secondly, we deliberately focussed on multiple-informant, routine data with a potential application for screening; the data used in this study were therefore not collected specifically for the purpose of research. However, the results suggest that the variables used may be sensitive enough for possible use in screening.

Thirdly, as stated before, family risk factors for treated psychiatric morbidity displayed obligatory sharing between siblings growing up in the same family. However, this does not preclude that a shared risk factor has a differential impact on one child when compared with another in the same family. In addition, while the data were suitable to identify individual-specific developmental effects, there was only a limited amount of information on how shared familial environments may nevertheless impact differentially on siblings in the same family. For example, the variables that made up factors such as 'psychosocial stress in the family', 'adverse family circumstances' and 'number of circumstances' provide only limited information on the possibility of differential impact of shared family environment on children with treated psychiatric morbidity and siblings (e.g. presence of parental neglect in the family that is specifically directed towards only one of several siblings). Given the limited amount of data on such possible differential effects, our conclusion that the cases and siblings were sharing adverse family circumstances does not indicate that there is no differential impact of these shared family environments on treated psychiatric morbidity in siblings growing up in the same family. However, identifying the contribution of such intrafamilial differences in the impact of family circumstances on treated psychiatric morbidity was beyond the scope of the present paper, which focussed specifically on individual-specific aspects of development. 
Furthermore, because we could determine the time order of variables (before/after intake for outpatient psychiatric services), the analyses were restricted to the risk factors (see above) whose occurrence was described before the first contact with psychiatric services. Thus, as far as the argument of time order is concerned, we provide evidence of causality or, more relevantly, absence of reverse causality (e.g. raters seeing more pathology because the child was in treatment with psychiatric services) (Hill, 1965). Indeed, most of the ratings were made years before the child was referred to psychiatric services. In addition, the pitfalls of recall bias were avoided in these prospectively collected data. However, because of collinearity, we had to focus on analyses where the potential risk factors were examined separately. Therefore, it was not possible to assess their relative independence.

Finally, the study design has the limitation that working with routine data such as the Maastricht YHCD-files, inevitably introduces misclassification, especially in the case of non-systematically assessed variables such as open comments (e.g. motor development), where the risk of false negatives is highest. Although this misclassification cannot be excluded, school physicians work in a standardized way and routinely incorporate comments as a way to longitudinally assess children in important areas. In any case, to the extent that misclassification was operating, it is difficult to conceive how that rate would be differentially influenced by future treated psychiatric morbidity. Nevertheless, it remains important that future research attempts to replicate the present findings.

\section{Family sociodemographic variables and family circumstances}

As reported previously (Kalff et al., 2001; Sourander et al., 2001) family factors such as living in a one-parent family increased the risk of treated psychiatric morbidity.

The finding that unstable family circumstances act as a robust predictor of treated psychiatric morbidity even after controlling for several confounding variables is in keeping with earlier research (Hillard et al., 1987; Verhulst and van der Ende, 1997). As expected, these same family variables also significantly differentiated between siblings and their controls. From the present results, we may conclude that, apart from these familial factors, additional individual (case) specific developmental and behavioural risk factors need to be present as component causes for the mental health outcome.

\section{Child developmental variables}

Although there appeared to be a familial liability to externalizing behaviour and a combination of internalizing and externalizing behaviour, these behavioural prob- 
lems differed quantitatively between cases and siblings in that cases displayed both earlier expression and more severe behavioural problems than the siblings. Given the fact that behavioural problems were partly shared between cases and siblings, such problems may reflect the effect of shared genes or the influence of factors in the shared environment, or their interaction (Burcusa et al., 2003). Another explanation for the familial liability of behavioural problems lies in the fact that behaviour can also be learned or imitated. For example, siblings who do or do not share a genetic propensity for aggressive behaviour may develop similar repertoires for aggression [sibling interaction: (Patterson, 1984)].

A wealth of evidence now supports the notion that indicators of compromised neurodevelopment precede the clinical onset of adult psychiatric disorders such as schizophrenia and depression (Jones et al., 1994; van Os et al., 1997). This is in line with the current results, which showed that developmental delays, such as delay in speech and motor development, were powerful case-specific predictors of treated psychiatric morbidity. Thus, non-shared genetic or environmental factors, or their interaction, may contribute to their manifestation. One such non-shared environmental factor, for example, is prenatal hypoxia, which may interact with genetic risk to influence mental health outcomes (Cannon, 1997).

In conclusion, it has been recognized that multiple causes contribute to the development of health

outcomes. The data presented suggest that adverse family circumstances differentiate between children with treated psychiatric morbidity and controls in the general population, but differences in treated psychiatric morbidity in siblings in the same family are additionally associated with differential developmental trajectories. In addition, siblings of children with mental health problems of sufficient severity to warrant psychiatric treatment have lower indices of behavioural deviance than cases, although higher than general population controls. The data suggest that the factors that contribute most to differential mental health outcomes in siblings are the presence of developmental delays, in particular in the area of speech development and motor control, which may be indicators of a compromised central nervous system.

Acknowledgements We gratefully acknowledge the financial support by the ministry of health, welfare and sports (VWS). The authors are grateful to Peter van Neer, employee of the YHCD, Municipal Health Centre for his assistance in the sample data-collection. 


\section{REFERENCES}

Baecke, JAH, Boersma-Slütter, WGM , Van Heeswijk, ALM (1984) Ontwikkeling van een motoriektest voor kleuters: de betrouwbaarheid. T Soc Gezondheidsz, 62: 38-45.

Breslow, NE , Day, NE (1987) Statistical methods in cancer research. Lyon: WHO.

Burcusa, SL, Iacono, WG , McGue, M (2003) Adolescent twins discordant for major depressive disorder: shared familial liability to externalizing and other internalizing disorders. J Child Psychol Psychiatry, 44 (7): 997-1005.

Cannon, TD (1997) On the nature and mechanism of obstetric influences in schizophrenia: a review and synthesis. International Review of Psychiatry, 9: 387-397.

Driessen, G, Evers, S, Verhey, F , van Os, J (2001) Stroke and mental health care: a record linkage study. Soc Psychiatry Psychiatr Epidemiol,

36 (12): 608-12.

Dunn, J , Plomin, R (1991) Why are siblings so different? The significance of differences in sibling experiences within the family. Fam Process,

30 (3): 271-83.

Ewing, IR , Ewing, WG (1961) New opportunities for deaf children. London: University of London Press Ltd.

Garralda, ME , Bailey, D (1988) Child and family factors associated with referral to child psychiatrists. Br J Psychiatry, 153: 81-9.

Gunther, N, Slavenburg, B, Feron, F , van Os, J (2003) Childhood social and early developmental factors associated with mental health service use. Soc Psychiatry Psychiatr Epidemiol, 38 (3): 101-8.

Hill, AB (1965) The Environment and Disease: Association or Causation?

Proc R Soc Med, 58: 295-300.

Hillard, JR, Slomowitz, M , Levi, LS (1987) A retrospective study of adolescents' visits to a general hospital psychiatric emergency service. Am J Psychiatry, 144 (4): 432-6.

Jones, P, Rodgers, B, Murray, R , Marmot, M (1994) Child development risk factors for adult schizophrenia in the British 1946 birth cohort. Lancet, 344: 1398-402.

Kalff, AC, Kroes, M, Vles, JSH, Hendriksen, JGM, Feron, FJM, Steyaert, J, van Zeben, TMCB, Jolles, J , van Os, J (2001) Neighbourhood level and individual level SES effects on child problem behaviour: a multilevel analysis. J Epid Community Health, 55 (4): 246-50.

Koot, HM , Verhulst, FC (1992) Prediction of children's referral to mental health and special education services from earlier adjustment. J Child Psychol Psychiatry, 33 (4): 717-29.

Patterson, GR (1984) A microsocial process: a view from the boundary. In: Masters, JC, Yarkin, KL (Ed.), Boundary areas in

psychology: social and developmental psychology (pp. 43-67) New York: Academic Press.

Rutter, M , Silberg, J (2002) Gene-environment interplay in relation to emotional and behavioral disturbance. Annu Rev Psychol, 53: 463-90.

Schnabel, P (1997) The mental health services: more than psychiatry alone. In: Schrijvers, AJP (Ed.), Health and health care in the Netherlands: 
a critical self-assessment by Dutch experts in the medical and health sciences (pp. 119-131) Utrecht, the Netherlands: De Tijdstroom.

Snijders, T , Bosker, R (1999) Multilevel analysis, an introduction to basic and advanced modeling. London: SAGE Publications.

Sourander, A, Helstela, L, Ristkari, T, Ikaheimo, K, Helenius, H, Piha, J (2001) Child and adolescent mental health service use in Finland. Soc Psychiatry Psychiatr Epidemiol, 36 (6): 294-8.

StataCorp (2001). Stata Statistical Software. Texas, College Station, TX: Stata Corporation.

Tansella, M, Micciolo, R, Biggeri, A, Bisoffi, G, Balestrieri, M (1995) Episodes of care for first-ever psychiatric patients. A long-term case-register evaluation in a mainly urban area. Br J Psychiatry, 167 (2): 220-7.

van Os, J, Jones, P, Lewis, G, Wadsworth, M , Murray, R (1997) Developmental precursors of affective illness in a general population birth cohort. Arch Gen Psychiatry, 54 (7): 625-31.

Verhulst, FC , Koot, HM (1992) Child Psychiatric Epidemiology: concepts, methods, and findings. Newbury Park, California: Sage.

Verhulst, FC, van der Ende, J (1997) Factors associated with child mental health service use in the community. J Am Acad Child Adolesc Psychiatry, 36 (7): 901-9.

Wichers, MC, van Os, J, Danckaert, M, Van Gestel, S, Derom, C, Vlietinck, R (2001) Associations between nonshared environment and child problem behaviour. Soc Psychiatry Psychiatr Epidemiol, 36: 319-323.

Zwaanswijk, M, Verhaak, PF, Bensing, JM, van der Ende, J, Verhulst, FC (2003) Help seeking for emotional and behavioural problems in children and adolescents: a review of recent literature. Eur Child Adolesc Psychiatry, 12 (4): 153-61. 
Table 1. Descriptives of child and family variables

\begin{tabular}{|c|c|c|c|c|c|c|c|c|}
\hline & \multicolumn{2}{|c|}{ Cases } & \multicolumn{2}{|c|}{ Controls } & \multicolumn{2}{|c|}{ Siblings } & \multicolumn{2}{|c|}{ Controls } \\
\hline & $\mathrm{N}$ & $\%$ & $\mathrm{~N}$ & $\%$ & $\mathrm{~N}$ & $\%$ & $\mathrm{~N}$ & $\%$ \\
\hline \multicolumn{9}{|l|}{ Categorical variables } \\
\hline \multicolumn{9}{|l|}{ Child variables } \\
\hline Special education & 5 & 6.3 & 18 & 5.6 & 6 & 8.8 & 15 & 5.5 \\
\hline \multicolumn{9}{|l|}{ Psychosocial behaviour (early) } \\
\hline $\begin{array}{l}\text { Combination of internalizing } \\
\text { and externalizing behaviour }\end{array}$ & 8 & 10.0 & 6 & 1.9 & 1 & 1.5 & 5 & 1.8 \\
\hline Externalizing behaviour & 24 & 30.0 & 35 & 10.9 & 5 & 7.4 & 15 & 5.5 \\
\hline Internalizing behaviour & 3 & 3.8 & 11 & 3.4 & 3 & 4.4 & 4 & 1.5 \\
\hline \multicolumn{9}{|l|}{ Psychosocial behaviour (late) } \\
\hline $\begin{array}{l}\text { Combination of internalizing } \\
\text { and externalizing behaviour }\end{array}$ & 17 & 21.3 & 20 & 6.3 & 8 & 11.8 & 12 & 4.4 \\
\hline Externalizing behaviour & 35 & 43.8 & 51 & 15.9 & 12 & 17.7 & 26 & 9.6 \\
\hline Internalizing behaviour & 8 & 10.0 & 25 & 7.8 & 3 & 4.4 & 26 & 9.6 \\
\hline $\begin{array}{l}\text { Insufficient Ewing-test/CAPAS- } \\
\text { test ( } 9 \text { months) }\end{array}$ & 20 & 25.0 & 74 & 23.1 & 14 & 20.6 & 60 & 22.1 \\
\hline Sleeping problems & 22 & 27.9 & 72 & 22.5 & 15 & 22.1 & 39 & 14.3 \\
\hline $\begin{array}{l}\text { Problems with toilet training (e.g. } \\
\text { bedwetting) }\end{array}$ & 19 & 24.1 & 54 & 16.9 & 10 & 14.7 & 34 & 12.5 \\
\hline $\begin{array}{l}\text { Gross motor development } \\
\text { (e.g. problems with hopping) }\end{array}$ & 19 & 23.8 & 42 & 13.1 & 5 & 7.4 & 26 & 9.6 \\
\hline $\begin{array}{l}\text { Fine motor development (e.g. } \\
\text { problems with writing) }\end{array}$ & 30 & 38.0 & 87 & 27.2 & 18 & 26.5 & 41 & 15.1 \\
\hline Speech therapy & 28 & 35.0 & 59 & 18.4 & 10 & 14.7 & 51 & 18.8 \\
\hline \multicolumn{9}{|l|}{ Family variables } \\
\hline Low occupation & 20 & 25.0 & 47 & 14.7 & 13 & 19.1 & 51 & 18.8 \\
\hline One-parent family & 17 & 21.3 & 17 & 5.3 & 12 & 17.6 & 19 & 7.0 \\
\hline Unemployment & 13 & 16.3 & 22 & 6.9 & 6 & 8.8 & 14 & 5.1 \\
\hline Psychosocial stress in the family & 27 & 33.8 & 54 & 16.9 & 15 & 22.1 & 27 & 9.9 \\
\hline Parental mental health problems & 10 & 12.7 & 8 & 2.5 & 16 & 23.5 & 7 & 2.6 \\
\hline \multicolumn{9}{|l|}{ Family/child variables } \\
\hline $\begin{array}{l}\text { Other adverse family circum- } \\
\text { stances }\end{array}$ & 32 & 40.0 & 76 & 23.8 & 30 & 44.1 & 45 & 16.5 \\
\hline \multirow[t]{2}{*}{ Continuous variables } & \multicolumn{2}{|c|}{ Cases } & \multicolumn{2}{|c|}{ Controls } & \multicolumn{2}{|c|}{ Siblings } & \multicolumn{2}{|c|}{ Controls } \\
\hline & Mean & SD & Mean & SD & Mean & SD & Mean & $\mathrm{SD}$ \\
\hline \multicolumn{9}{|l|}{ Child variables } \\
\hline Birth weight, $g$ & 3238 & 599.3 & 3326 & 577.0 & 3375 & 519.5 & 3336 & 518.1 \\
\hline Birth length, $\mathrm{cm}$ & 49.5 & 2.9 & 50.3 & 3.0 & 50.7 & 2.4 & 50.0 & 2.5 \\
\hline BMI at birth, $\mathrm{kg} / \mathrm{m}^{2}$ & 13.1 & 1.5 & 13.0 & 1.3 & 13.1 & 1.5 & 13.2 & 1.5 \\
\hline Age child at walking & 13.6 & 2.9 & 13.7 & 2.5 & 13.3 & 2.7 & 13.8 & 2.8 \\
\hline $\begin{array}{l}\text { Motor function examination } \\
(0 \leq x \leq 1.5 \text {; at } 5 \text { years })\end{array}$ & 0.4 & 0.3 & 0.3 & 0.2 & 0.3 & 0.2 & 0.2 & 0.3 \\
\hline \multicolumn{9}{|l|}{ Family variables } \\
\hline Age mother at delivery & 27.3 & 4.9 & 28.8 & 4.3 & 28.9 & 5.4 & 29.2 & 4.7 \\
\hline \multicolumn{9}{|l|}{ Family/child variables } \\
\hline $\begin{array}{l}\text { Number of circumstances } \\
(0 \leq \mathrm{x} \leq 15)\end{array}$ & 3.0 & 2.9 & 1.0 & 1.9 & 2.0 & 2.7 & 0.6 & 1.2 \\
\hline
\end{tabular}

CAPAS, compact Amsterdam paedo-audiometric screener; BMI, Body Mass Index. 
Table 2. Associations between treated psychiatric morbidity and child and family risk factors (included seperately), adjusted for age and sex.

\begin{tabular}{|c|c|c|c|c|c|c|}
\hline & \multicolumn{2}{|c|}{ Cases vs. controls } & \multicolumn{2}{|c|}{ Siblings vs. controls } & \multicolumn{2}{|c|}{ Cases vs. siblings } \\
\hline & OR & $95 \% \mathrm{CI}$ & OR & $95 \%$ CI & OR & $95 \% \mathrm{CI}$ \\
\hline \multicolumn{7}{|l|}{ Child variables: continuous } \\
\hline Birth weight, $g$ & 0.99 & $0.99-1.00$ & 1.00 & $0.99-1.00$ & 0.99 & $0.99-1.00$ \\
\hline Birth length, $\mathrm{cm}$ & $0.92^{*}$ & $0.85-0.99$ & 1.10 & $0.97-1.24$ & 0.92 & $0.84-1.01$ \\
\hline BMI at birth, $\mathrm{kg} / \mathrm{m} 2$ & 1.01 & $0.84-1.21$ & 0.94 & $0.78-1.14$ & 0.99 & $0.84-1.19$ \\
\hline Age child at walking & 0.97 & $0.86-1.09$ & 0.94 & $0.84-1.05$ & 0.99 & $0.88-1.11$ \\
\hline $\begin{array}{l}\text { Motor function examination } \\
(0 \leq \mathrm{x} \leq 1.5 \text {; at } 5 \text { years })\end{array}$ & $4.64^{* *}$ & $1.64-13.11$ & 0.94 & $0.30-2.89$ & 2.25 & $0.60-8.36$ \\
\hline \multicolumn{7}{|l|}{ Child variables: categorical } \\
\hline Special education & 1.12 & $0.40-3.08$ & 1.79 & $0.61-5.25$ & 0.43 & $0.13-1.39$ \\
\hline \multicolumn{7}{|l|}{ Psychosocial behaviour (early): } \\
\hline $\begin{array}{l}\text { Internalizing as well as externaliz } \\
\text { ing behaviour }\end{array}$ & $-17.84^{* * *}$ & $4.74-67.18$ & 1.02 & $0.12-9.01$ & $4.15^{*}$ & $1.02-16.83$ \\
\hline Externalizing behaviour & $7.76^{* * *}$ & $3.58-16.83$ & 1.50 & $0.52-4.34$ & $4.00^{* *}$ & $1.61-9.92$ \\
\hline Internalizing behaviour & 2.38 & $0.58-9.76$ & 3.21 & $0.71-14.56$ & 2.10 & $0.38-11.73$ \\
\hline \multicolumn{7}{|c|}{ Psychosocial behaviour (late): } \\
\hline $\begin{array}{l}\text { Internalizing as well as externaliz } \\
\text { ing behaviour }\end{array}$ & $-19.74^{* * *}$ & $6.83-57.04$ & $3.69^{*}$ & $1.36-10.02$ & $2.68^{*}$ & $1.02-7.07$ \\
\hline Externalizing behaviour & $13.56^{* * *}$ & $5.51-33.34$ & $2.79^{*}$ & $1.17-6.62$ & $2.84^{*}$ & $1.23-6.56$ \\
\hline Internalizing behaviour & $6.35^{* * *}$ & $2.02-19.98$ & 0.63 & $0.17-2.29$ & 2.65 & $0.75-9.30$ \\
\hline $\begin{array}{l}\text { Insufficient Ewing-test/CAPAS- } \\
\text { test ( } 9 \text { months) }\end{array}$ & 1.01 & $0.54-1.88$ & 0.88 & $0.40-1.95$ & 1.66 & $0.71-3.88$ \\
\hline Sleeping problems & 1.31 & $0.75-2.29$ & 1.79 & $0.88-3.64$ & 1.07 & $0.53-2.16$ \\
\hline $\begin{array}{l}\text { Problems with toilet training } \\
\text { (e.g. bedwetting) }\end{array}$ & 1.54 & $0.85-2.79$ & 1.22 & $0.56-2.69$ & 1.62 & $0.75-3.51$ \\
\hline $\begin{array}{l}\text { Gross motor development } \\
\text { (e.g. problems with hopping) }\end{array}$ & $2.13^{*}$ & $1.14-4.00$ & 0.74 & $0.27-2.05$ & 2.30 & $0.90-5.85$ \\
\hline $\begin{array}{l}\text { Fine motor development } \\
\text { (e.g. problems with writing) }\end{array}$ & 1.72 & $0.99-2.97$ & $2.23^{*}$ & $1.12-4.42$ & 1.29 & $0.65-2.57$ \\
\hline Speech therapy & $2.46^{* *}$ & $1.41-4.27$ & 0.76 & $0.38-1.55$ & $2.16^{*}$ & $1.05-4.45$ \\
\hline \multicolumn{7}{|l|}{ Family variables: continuous } \\
\hline Age mother at delivery & $0.93^{* *}$ & $0.87-0.98$ & 0.98 & $0.93-1.04$ & 0.96 & $0.91-1.02$ \\
\hline \multicolumn{7}{|l|}{ Family variables: categorical } \\
\hline Low occupation & 1.47 & $0.77-2.81$ & 1.44 & $0.64-3.21$ & 1.02 & $0.52-1.97$ \\
\hline One-parent family & $4.41^{* * *}$ & $2.12-9.17$ & $2.96^{* *}$ & $1.35-6.50$ & 0.97 & $0.50-1.89$ \\
\hline Unemployment & $2.44^{*}$ & $1.14-5.21$ & 1.77 & $0.64-4.88$ & 1.82 & $0.71-4.68$ \\
\hline Psychosocial stress in the family & $2.51^{* *}$ & $1.45-4.36$ & $3.75^{* *}$ & $1.56-9.03$ & 1.20 & $0.64-2.25$ \\
\hline Parental mental health problems & $5.43^{* *}$ & $2.06-14.35$ & $14.30^{* * *}$ & $4.75-3.07$ & 0.62 & $0.28-1.34$ \\
\hline \multicolumn{7}{|l|}{ Family/child variables: continuous } \\
\hline Number of circumstances $(0 \leq x \leq 15$ & $1.44^{* * *}$ & $1.28-1.63$ & $1.84^{* * *}$ & $1.45-2.35$ & 1.07 & $0.97-1.18$ \\
\hline \multicolumn{7}{|c|}{ Family/child variables: categorical } \\
\hline Other adverse family circumstance & $2.44^{* *}$ & $1.38-4.33$ & $4.03^{* * *}$ & $2.22-7.32$ & 0.82 & $0.46-1.49$ \\
\hline
\end{tabular}

${ }^{*} \mathrm{P}<0.05 ;{ }^{* *} \mathrm{P}<0.01 ;{ }^{* * *} \mathrm{P}<0.001$.

OR, odds ratio; BMI, Body Mass Index; CAPAS, compact Amsterdam paedo-audiometric screener. 


\title{
Chapter

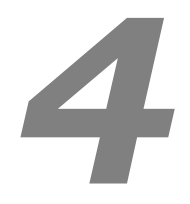

\section{Association of mental health problems in childhood with prenatal and postnatal physical growth}

\author{
Nicole Gunther ${ }^{1}$, Marjan Drukker ${ }^{1}$, Frans Feron ${ }^{2}$, Jim van Os ${ }^{1,3}$
}

1 Department of Psychiatry and Neuropsychology, South Limburg Mental Health Research and Teaching Network, EURON, Maastricht University, Maastricht, The Netherlands.

2 Youth Health Care Division, Municipal Health Centre, Maastricht, The Netherlands

3 Division of Psychological Medicine, Institute of Psychiatry, De Crespigny Park, Denmark Hill, London, UK.

European Psychiatry, 2005, Vol. 20, No 3, 277-286 


\section{ABSTRACT}

Aims The present study was conducted to examine i) prenatal and postnatal patterns of growth in relation to the risk of later mental health problems in children and ii) the possible mediating effect of these patterns of growth in the association between parental socioeconomic status (SES) and children's mental health.

Subjects and methods The present study is part of a blinded, matched case control study, involving a retrospective analysis of prospectively collected data from routine examinations at community health services for children and adolescents. The sample comprised 80 patients, referred between the age of 6-13 years to the Community Mental Health Centre in Maastricht, and 320 matched population controls Results Children coming from unemployed families weighed less at birth, but postnatal growth was not associated with this or other indicators of SES. Although children using mental health care were somewhat smaller at birth, there was no evidence that leanness during childhood was a risk factor for the development of mental health problems.

Conclusions The present results showed some evidence for the impact of intrauterine development on children's mental health problems. In addition, neither prenatal nor postnatal physical growth were on the pathway between parental SES and children's mental health problems.

Keywords: Patterns of growth - Child mental health service use - Socioeconomic status 


\section{INTRODUCTION}

It has been suggested that undernutrition early in life can programme for adult mental illness (Wahlbeck et al., 2001). Several studies have linked indicators of intrauterine or prenatal physical growth, such as birth weight and birth length, with psychiatric disorders in later life. These studies have given credence to the notion that part of the vulnerability for mental disorders is shaped early in the foetal period of life (Fine et al., 1985; Barker and Osmond, 1986; Wahlbeck et al., 2001) as indeed was originally suggested for other multifactorial disorders such as coronary heart disease (Barker, 1995).

In addition, indicators of prenatal physical growth have also been associated with childhood mental health outcomes. Substantial numbers of low birth weight children are diagnosed with moderate to severe emotional and behavioural problems (McCormick et al., 1996; Bennett, 1997; Zubrick et al., 2000; Hille et al., 2001; van Os et al., 2001). The pattern of behavioural deficits associated with low birth weight ranges from hyperactivity and inattention (McCormick et al., 1990; Szatmari et al., 1993; Breslau et al., 1996; Botting et al., 1997), to withdrawn, shy, and depressive behaviour (Hoy et al., 1992; Weisglas-Kuperus et al., 1993; Tessier et al., 1997). These previous studies on birth weight have focussed almost exclusively on special groups of children with low or very low birth weight, or on children with established psychiatric disorders (Szatmari et al., 1990; Sommerfelt et al., 1996). However, a recent study conducted in a general population twin sample (van Os et al., 2001) suggested that lower birth weight is a continuous risk factor for the distribution of problem behaviour in children.

Some studies suggested that not only indicators of prenatal growth, but also indicators of postnatal growth are independent risk factors for later mental health outcomes. For example, not only low birth weight and shortness at birth (reflecting prenatal growth), but also leanness during childhood (reflecting postnatal growth) was identified as an independent risk factor for schizophrenia in adults (Wahlbeck et al., 2001). These findings suggest that both prenatal and postnatal indicators of growth reflect risk for mental health outcomes, indicating that not only prenatal 'programming', but also postnatal effects may act additively to the risk of mental health outcomes.

The present paper addresses both the influence of prenatal and postnatal exposures. If there is only an effect of the prenatal exposure on mental health, there will still be an association between height and weight and mental health in infancy. However, children who are small at birth normally catch-up in growth and the association will disappear when the child grows older. On the other hand, if postnatal exposures were more important, the association between parameters of 
growth and mental health would increase with the age of the child. In both cases, this results in interaction effects of age when analysing growth curve models. In other words, the association of growth parameters with mental health is increasing or decreasing as a function of whether the age of the child comes closer to or grows farther from the age of exposure.

Furthermore, any study linking parameters of physical growth to mental health outcomes needs to take into account the effects of socioeconomic status (SES). As high income and high educational level imply not only better nutrition but often also a more favourable environment associated with better use of medical and social services, children of higher and middle socioeconomic families in any country are on average larger in body size than their peers growing up in lower socioeconomic families (Eveleth and Tanner, 1976; Lasker and Mascie-Taylor, 1989; Lindgren and Cernerud, 1992). In addition, the rate of low birth weight infants is higher when the SES of the family is lower (Verkerk et al., 1994). This may explain why low SES of the parents predicts mental health care use in children, as reported in previous work (Gunther et al., 2003).

In the current study, we wished to investigate, in a retrospective analysis of prospectively collected data, to what degree prenatal and postnatal indicators of growth are independently associated with the risk of later mental health problems in children, and to what degree any effect of lower parental SES on mental health outcomes in the children is mediated through such unfavourable patterns of growth. For this purpose, information on parental SES and physical growth were obtained from routine data collected prospectively by health professionals at a local Youth Health Care Division from the Municipal Health Centre of Maastricht (YHCD), where data of all children from foetal life through to age 19 years are compiled. The objectives of the present study were to examine (1) the association between parental SES on the one hand and indicators of prenatal growth (birth weight and birth length) and postnatal growth (height and weight) on the other, and (2) the association between indicators of prenatal growth and postnatal growth on the one hand and mental health service use (case or control status) as indicator of mental health on the other. If objectives (1) and (2) both yield positive associations, physical growth may be on the causal pathway between parental SES and mental health, warranting further testing to examine a possible mediating effect of indicators of prenatal and postnatal growth in the association between parental SES and mental health. In addition, the interaction of mental health by age as described above was studied. 


\section{SUBJECTS AND METHODS}

\section{Setting}

Maastricht is a relatively small city located in the south of the Netherlands. The population is of relative ethnic homogeneity, with relatively few residents originating from non-Western countries, in comparison with the ethnically more heterogeneous populations in the cities in the northwest of the country. Children living within the city or surrounding villages (total population of 201 000) were included in the present study.

In the Netherlands, all children from foetal life through to age 19 years are regularly examined at community health services for children and adolescents. These services comprise an infant welfare centre for children aged 0-4 years and a Youth Health Care Division from the Municipal Health Centre for children aged 4-19 years. A file for each child is initiated at the infant welfare centre, and subsequently transferred to the YHCD at the age of 4 years. In order to detect growth deficiencies, children's height and weight are measured at every medical examination. In addition, these health files include information from health professionals (especially the school physician), teachers, parents and, on some occasions, the children themselves.

School physicians of the YHCD as well as general practitioners play a role in recognizing mental health problems and these professionals can refer children with suspected psychiatric morbidity to a central intake team. From there the children can be referred to the Youth Department of the Community Mental Health Services. Since both general and mental health services in the Netherlands are accessible to everyone because the costs are covered by a compulsory national insurance scheme (Schnabel, 1997), financial or insurance considerations do not play a role in the help-seeking decision. Previous research in the Netherlands reported that among the total population of children with mental health problems, those that are most severely affected come to the attention of psychiatric services (Koot and Verhulst, 1992). Therefore, children who attend psychiatric services can also be considered as those who are most in need of care. Children with mental retardation are referred to specialized services outside mental health services and, therefore, were not included in the present study.

\section{Research design}

The present study is part of a matched, blinded case-control study in a group of children aged 6-13 years who had been referred consecutively to the Community 
Mental Health Centre (hereafter: 'cases') and population controls, organized by the university psychiatric department and the Youth Health Care Division of the Municipal Health Centre. These children, diagnosed by psychiatrists, have psychiatric problems such as ADHD, oppositional defiant disorder, posttraumatic stress disorder, obsessive compulsive disorder and social phobia.

The secretary of the Community Mental Health Centre obtained informed consent from parents of 120 consecutive referrals aged 6-13 years to the child psychiatric department of the Community Mental Health Centre. The parents of 98 children (18\% refused) provided consent for the investigators to study routine examination data compiled at the YHCD and to obtain the clinical diagnosis made by the Community Mental Health Centre. Power calculations indicated that studying 80 cases and four matched controls for each case would yield $75 \%$ power to detect an odds ratio (OR) of two at conventional alpha level for a dichotomous exposure with 0.25 prevalence.

A comparison sample of controls, matched for gender and year of birth, was selected from the YHCD-files by a YHCD staff member, who simultaneously handed over the files of cases and controls to the researchers who, thus, remained blind to case-control status. The researchers manually searched these files for all relevant information. The parents of the controls were not asked for individual permission as it is within the legal remit of the YHCD to conduct anonymous group comparisons within collected data. For each case, four controls were selected, matched for gender and year of birth. Thus, the sample comprised 400 children, 80 cases and 320 controls, living in Maastricht and surrounding areas. More detailed information on this procedure and the assessments at community health services for child and adolescents has been described previously (Gunther et al., 2003).

In order to provide descriptive statistics of mental health service use, in terms of episodes of care, of the 80 mental health care users (cases), information pertaining to the Psychiatric Case Register of Southern Limburg (PCR-SL) was used. The PCR-SL cumulatively collected data on utilization of mental health care (all contacts with mental health care facilities) for the population in the city of Maastricht and surrounding areas since 1981 (Driessen et al., 2001). Using this data, a description was made of episodes of care of the 80 cases. An episode of care was defined as a period of mental health contacts over an episode of time ending when there is a gap of 90 days or more without any further contact (Tansella et al., 1995). 


\section{Measures included in the analyses}

\section{Height, weight, BMI, and age}

Children's height and weight are systematically registered at every medical examination (medical examinations as described above) at different age points from birth to 19 years of age. All these measures are prospectively documented in case histories, which were searched retrospectively. Length at birth (in $\mathrm{cm}$ ), weight at birth (in g), height (in $\mathrm{cm}$ ) and weight (in $\mathrm{kg}$ ) were analysed as continuous variables. Using height and weight data, the body mass index (BMI: weight / (height/100)2) was calculated for each age.

\section{Parental SES}

Parental occupational status, living in a single- or two-parent family, and parental unemployment when the child was approximately 5 years old are systematically registered by the YHCD. These data were used as indicators of parental SES. Parental occupational status was defined using the occupation of the father. When the occupation of the father was unknown, parental occupation was defined using maternal occupation. This resulted in a categorical variable, with four categories: low (e.g. manual employees), medium (e.g. clerical employees, owners of small businesses, technicians, minor professionals), high (e.g. supervisory employees, major professionals, owners of large businesses, executives, teachers), and scientific (e.g. lawyer, doctor) (CBS, 1993). The categories were recoded into dummy variables in the analysis; the category 'medium' being the reference category. Living in a single- or two-parent family and parental unemployment were both analysed as dichotomous variables, with consecutively two-parent family and being employed as the reference categories. A family was defined as being 'employed' when one or both of the parents were employed. Missing values of these three SES-variables were excluded from the analyses.

\section{Mental health care use}

Mental health care use or 'caseness' was defined as coming into contact with mental health services between the ages of 6 and 13 years. Mental health care use (=case or control status) was a dichotomous variable with controls as the reference category.

\section{Confounding child variables}

Guided by previous work (Gunther et al., 2003) several child variables were considered to be potential confounders. For this purpose, comments noted by health professionals, teachers, parents and/or children themselves about the psychosocial 
behaviour of the child were categorized into 'positive behaviour', 'externalizing behaviour', 'internalizing behaviour', 'internalizing and externalizing behaviour' or 'else', and 'positive behaviour' was defined as the reference category. Externalizing behaviour was defined as socially undesirable behaviour and behaviour that affected others (for example hyperactivity, disturbing behaviour in the classroom, being aggressive, fighting with other children etc.). Internalizing behaviour was defined as affecting the person in question but not the environment (for example being very shy, negative self image, often nervous, insecure etc.). In a pilot study, kappas were computed as a measure of interrater reliability across two researchers for several classification items of psychosocial behaviour at different ages, based on 30 cases. These kappas were all satisfactory ( 0.80 or higher). Two variables were defined: one on psychosocial behaviour before the age of 6 (early psychosocial behaviour) and one on psychosocial behaviour at 6 years or older (late psychosocial behaviour). For more details on these variables see (Gunther et al., 2003).

\section{Confounding family variables}

Two confounding family variables were included in the analyses: mother's age at delivery and parental mental health problems. The assessment of parental mental health problems was based on open comments from the physician. In doing so, the physician also makes use of information from other health professionals, parents, teachers and the children themselves. Examples of these parental mental health problems are alcohol abuse, depression, ADHD, anorexia and partner relational problems. Mother's age at delivery was analysed as a continuous variable. Parental mental health problems were included in the analysis as 'present' or 'absent'.

\section{Statistical Analyses}

\section{Indicators of prenatal growth}

Analyses on birth weight and birth length were carried out using the STATA computer programme. Outcome measures were independent across groups or clusters, each cluster consisting of one case and four controls. Linear regression for clustersampled data was used to study the association between parental SES on the one hand and birth weight and birth length on the other (objective 1), while controlling for parental mental health problems.

Associations between birth weight and birth length on the one hand and mental health service use on the other (objective 2) were expressed as ORs. Since the analyses were matched, the ORs and 95\% confidence intervals (95\% CI) were 
calculated using the conditional logistic regression procedure. Analyses were similarly controlled for parental mental health problems.

In order to assess possible mediating effects of birth weight in any association between parental SES and mental health care use, parental SES and birth weight were entered jointly in the model. The same was done for parental SES and birth length.

\section{Indicators of postnatal growth}

Analyses on growth curves were carried out using MLwiN. Measurements of height and weight (growth) were grouped in children. Because of the matching, groups of one case with four controls can be seen as an extra level in the multilevel analyses. Therefore, in statistical terms, data were part of a three level structure, with level-one units (height and weight measurements) structured into level-two units (individuals) structured into level-three units (groups). These hierarchically structured data were subjected to multilevel regression analysis (Snijders and Bosker, 1999) in order to investigate the effect of parental SES on postnatal growth and the association between mental health care use and postnatal growth. Multilevel or hierarchical linear modelling techniques are a variant of unilevel linear regression analyses and are ideally suited for the analysis of clustered data. The $\beta$ s are the regression outcomes of the predictors in the multilevel model and can be interpreted identically to the estimates in the unilevel analyses.

In all multilevel analyses, the dependent variables were height, weight, and BMI collected at different ages. Unfortunately, coordinate pairs of measurements at birth by time could not be described in the same curve. Therefore, these measurements have been left out of the analyses. The following random effects multilevel linear regression models were found to sufficiently estimate the growth curves:

$$
\begin{aligned}
& \text { Outcome }_{\mathrm{ijk}}=\left(\beta_{0 \mathrm{ijk}}+\nu_{0 \mathrm{k}}+\mu_{0 \mathrm{jk}}+\varepsilon_{0 \mathrm{ijk}}\right)+\left(\beta_{1 \mathrm{j}}+\mu_{1 \mathrm{jk}}\right) \text { age-mean } \mathrm{in}_{\mathrm{jk}}+\beta_{2} \text { age-mean }
\end{aligned}
$$

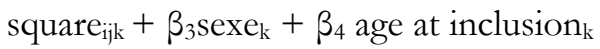

In which the outcome was height, weight, or BMI (measurement-level variables). Age-mean was the age in months minus the mean age in the total sample $(=44.51$ months) and age-mean square was the square term of this age variable (both measurement-level variables). The multiple error terms reflect residual variation at each level: measurement $\left(\varepsilon_{\mathrm{jik} k}\right)$, individual $\left(\mu_{\mathrm{jk}}\right)$, and group $\left(\nu_{\mathrm{k}}\right)$. The slope of the age variable $\left(\beta_{1}\right)$ is allowed to vary (random slope: $\mu_{1 \mathrm{jk} k}$ ), because every child has a different growth curve. Age-mean square was entered as a fixed effect variable in order to avoid collinearity. Because matching took place on gender and age at inclusion these variables were also entered into the model (group level variables). These growth curves as described above were used as base models. 
Height, weight, and BMI were studied using two sets of models. The first identified the association of the three parental SES-variables (parental occupation, single/two-parent family and parental unemployment; individual level variables) and postnatal growth (objective 1). The second examined the association between mental health service use (case/control status; individual level variable) and postnatal growth (objective 2). Crude associations as well as associations after controlling for child confounding variables (psychosocial behaviour) and family confounding variables (parental mental health problems and age mother at delivery) were assessed. In addition, weight at birth, height at birth and BMI at birth were also introduced as confounding variables in the corresponding models. This resulted in the following models.

1) SES (objective 1):

$\begin{aligned} \text { Eq. } 1 & +\beta_{5-7} \text { occupation dummies }(1-3)_{\mathrm{j} k} \\ & +\beta_{8} \text { single-parent }_{\mathrm{jk}} \\ & +\beta_{9} \text { unemployment } \mathrm{jk} \\ & +\beta_{10} \text { age mother at delivery } \mathrm{jk} \\ & +\beta_{11-14} \text { psychosocial behaviour early dummies }(1-4)_{\mathrm{jk}} \\ & +\beta_{15-18} \text { psychosocial behaviour late dummies }(1-4)_{\mathrm{jk}} \\ & +\beta_{19} \text { parental mental health problem } \mathrm{j}_{\mathrm{jk}} \\ & +\beta_{20} \text { growth at birth }_{\mathrm{jk} .}\end{aligned}$

2) Mental health care use (objective 2):

Eq. $\quad \begin{aligned} & +\beta_{5} \text { mental health care use } \mathrm{j}_{\mathrm{jk}} \\ & +\beta_{6} \text { age mother at delivery } y_{\mathrm{jk}} \\ & +\beta_{7-10} \text { psychosocial behaviour early dummies }(1-4)_{\mathrm{jk}} \\ & +\beta_{11-14} \text { psychosocial behaviour late dummies }(1-4)_{\mathrm{jk}} \\ & +\beta_{15} \text { parental mental health problem }{ }_{\mathrm{jk}} \\ & +\beta_{16} \text { growth at birth }_{\mathrm{jk} .}\end{aligned}$

\section{RESULTS}

\section{Sample}

About $50 \%$ of the 80 mental health care users had three or more episodes of care. An episode of care was characterized by a mean number of nine contacts and a mean duration of 131 days (data not shown). The majority of the sample was male $(66 \%)$. The mean age in the year 2002 was 10.5 years $(S D=2.4)$. The mean weight 
and length at birth of the sample were $3400 \mathrm{~g}$ and $50 \mathrm{~cm}$, respectively. About $42 \%$ of the parents required middle-level education for their profession. Seventeen percent required low-level education for their profession and about twenty-seven percent required high-level education or an academic degree for their profession. Thirty-five children (8.8\%) had no working father or mother. About nine percent of the children lived in single parent families (Table 1).

\section{Parental SES and indicators of prenatal growth}

Analyses showed a significant association between parental SES and birth weight, even after controlling for parental mental health problems (Table 2). Thus, children living in unemployed families weighed less at birth. These children were also smaller at birth, albeit statistically imprecise by conventional alpha (after controlling for parental mental health problems). In addition, there was a non-linear association between occupational status and birth weight, in that children living with parents having a low occupational status as well as children living with parents with a scientific occupational status weighed more at birth.

\section{Mental health service use and indicators of prenatal growth}

The crude analyses showed that cases were approximately $1 \mathrm{~cm}$ smaller at the time of birth. The risk of mental health service use decreased with 0.92 per $1 \mathrm{~cm}$ length at birth (Table 3: OR, 0.92; 95\% CI, 0.85-0.99). However, this association between birth length and mental health service use was statistically imprecise by conventional alpha $(P=0.07)$ after controlling for parental mental health problems. The mean birth weight of the cases was $100 \mathrm{~g}$ below that of the controls, but analyses showed that this difference was not statistically significant.

\section{Mediating effects of indicators of prenatal growth}

Single parent family, as an indicator of parental SES, remained large and statistically significant, when entered in the same model with birth weight and birth length, respectively (Table 4). However, the effect of birth weight was attenuated and no longer statistically significant. 


\section{Parental SES and indicators of postnatal growth}

The crude analyses showed a significant association between parental unemployment, one of the three SES-variables, and height and weight (Table 5). Children living with unemployed parents were smaller $(P<0.01)$ and weighed less $(P<0.01)$. However, unemployment did not remain significantly associated with both height and weight after controlling for several confounding variables. There were also no associations between the SES-variables and BMI.

\section{Mental health service use and indicators of postnatal growth}

Both crude analyses and analyses controlling for confounders showed that mental health care use was not significantly associated with postnatal growth parameters (Table 6); children coming into contact with mental health services were not smaller and did not weigh less than their controls. There was also no association between mental health care use and BMI.

There was no interaction between age and mental health service use in the model of postnatal growth: the association between postnatal growth and mental health service use was neither increasing nor decreasing with increasing age of the child (data not shown).

\section{Matching variables and confounding variables}

Girls were smaller and were lower in weight than boys. However, there were no differences in BMI between girls and boys. Children having internalizing behaviour had a lower BMI, but children showing both internalizing and externalizing behaviour had a higher BMI (Table 5 and Table 6).

\section{DISCUSSION}

The results showed that parental SES was related to intrauterine growth, even after controlling for possible confounders. An association between intrauterine growth and mental health care use was also apparent, albeit statistically imprecise by conventional alpha. However, children coming from lower SES families did not stay behind in postnatal growth. In addition, the present study could not provide evidence for any association between postnatal growth and the development of mental health problems. 
Because prenatal growth was not a mediator in the association between parental SES and mental health care use and because there were no associations between postnatal growth and mental health care use, we may conclude that there is no evidence that either prenatal growth or postnatal growth are mediators between parental SES and children's mental health.

\section{Methodological issues}

In the Netherlands, the children that do come to the attention of psychiatric services are the most severely affected (Koot and Verhulst, 1992). This also applies to Maastricht and surrounding areas where all children are screened by a central intake team, so that only children with the highest level of psychiatric morbidity and need for care are referred for treatment by mental health services. The associations studied in the present paper thus refer to severe mental health disorder resulting in referral to psychiatric services.

Until recently, most studies analysing physical growth used unilevel analyses while growth curve analysis or more general multilevel analysis methods are more suitable to study this multilevel matter. Therefore, our study presented results of multilevel analyses. Another advantage of the present study is that prospectively collected information has been used, avoiding the pitfalls of recall bias, while many other studies in this area made use of retrospective data. However, the present study did have some limitations. Firstly, it used information from a case-control study, but postnatal growth instead of the case-control status was the dependent variable in the multilevel analyses. Therefore, the effect of postnatal growth on mental health and possible mediating effects of postnatal growth could not be tested directly. However, since there were no positive associations between indicators of postnatal growth and mental health, there was no need for further testing to examine a possible mediating effect of postnatal growth in the association between parental SES and mental health.

Secondly, working with routine data such as the Maastricht YHCD-files, inevitably introduces a fairly large degree of misclassification, especially in the case of notsystematically assessed variables such as open comments, where the risk of false negatives is highest. Although the possibility of false negatives cannot be ruled out, school physicians work in a standardized way and routinely incorporate comments as a way to longitudinally assess children in important areas.

Thirdly, because the present study did not have accurate information on prematurity, an indicator of duration of gestation, this variable was not introduced as a confounder into our final model. In further analyses, we looked more carefully to the importance of prematurity as a confounding variable. When entering prematurity 
in the models most associations remained and some were even stronger. Therefore, the conclusions of the present study, even without entering prematurity into the models, are still valid.

Fourthly, the study was powered for unilevel comparisons with the implication that this would hold for the multilevel comparisons as well. Power analysis software for multilevel comparisons is not routinely available and therefore future replications with adequately powered samples remain necessary.

Finally, as our hypotheses were based on generic risks for a range of mental health outcomes, no specific mental health diagnostic categories were used. The validity for this approach is suggested by the earlier cited literature showing the relative non-specificity for prenatal effects on psychiatric and somatic outcomes and the increasing focus on generic risk models for morbidity accumulation in the area of both mental and somatic health.

\section{Parental SES and indicators of prenatal and postnatal growth}

Two indicators of foetal development were included in the present study, i.e. birth weight and birth length. In keeping with earlier research (Verkerk et al., 1994), children coming from lower SES families, in particular children coming from unemployed families, weighed less at birth, even after controlling for possible confounding factors. The association between parental SES and length at birth, albeit statistically imprecise by conventional alpha, was in the same direction. Furthermore, children living with parents having a low occupational status as well as children living with parents with scientific occupational status weighed more at birth than children from medium occupational status families. Previously, another SESvariable also showed a non-linear association with outcome variables (quality of life) in Maastricht children (Drukker et al., 2003). In Maastricht, differences in SES are relatively low due to a relatively strong social safety net (De Swaan, 1988; Thompson, 2000). This may explain the non-linear appearance of the association. As far as we know, there are no other studies showing non-linear associations between parental SES and birth weight.

The present multilevel analysis of growth curves did not confirm the earlier unilevel findings showing that children coming from lower SES families were smaller and weighed less in later life (Eveleth and Tanner, 1976; Lasker and Mascie-Taylor, 1989; Lindgren and Cernerud, 1992). A recent multilevel study of Black and Krishnakumar (Black and Krishnakumar, 1999) also did not find any effects of poverty on height and weight. However, the authors commented that all included children were poor, resulting in low variability. Because the present study and the study of Black and Krishnakumar found similar results, we may conclude that chil- 
dren living in lower SES families in samples with relatively low variability are not stunted in growth, compared to the rest of the sample.

Although the SES variance in Maastricht is relatively low, there are still parental SES differences in birth weight, even after adjustment for possible confounders. Factors which were not controlled for in the analysis, such as infections, nutrition, and maternal vascular diseases (Keirse, 1984), may account for these social differences in birth weight. Contrary to the findings on prenatal growth, there was no evidence that social factors exerted a major influence on postnatal growth, at least not in a Western country like The Netherlands. Differences in individual SES are much smaller in European cities, such as Maastricht, than, for example, in American cities. Policies in Europe have resulted in the constitution of a model European 'caring state' which functions to prevent various forms of social exclusion through still relatively strong safety in the Netherlands (De Swaan, 1988; Thompson, 2000; Hortulanus and Machielse, 2001). In the Netherlands, this diminishing disparity in standards of living between different socioeconomic strata may equally have contributed to the increasing equality in growth rate between different socioeconomic classes (Lindgren, 1976).

\section{Mental health care use and indicators of prenatal and postnatal growth}

The results of earlier studies suggest that some factors may exert adverse effects in utero, not only for adult disorders such as schizophrenia, but also for variable mental health problems in children (Zubrick et al., 2000; Wahlbeck et al., 2001). The present study found some evidence for this hypothesis: children coming into contact with mental health services were somewhat smaller at birth than their controls (albeit statistically imprecise by conventional alpha). On the other hand, the present results showed that weighing less during childhood was not a risk factor for children's mental health service use and, therefore, the hypothesis that postnatal growth was an independent risk factor of a child's mental health problems could not be confirmed, although such an effect may exist for particular disorders such as schizophrenia (Wahlbeck et al., 2001). A possible explanation for this difference in association between prenatal and postnatal growth may lie in the fact that the cases who were small at birth displayed catch-up growth during childhood. For this purpose, an interaction between mental health service use and age had been tested but none was evident. Tests for interaction have low power, however, and catch-up growth cannot be excluded, which would explain the lack of an association between child height and weight on the one hand and mental health care use on the other. Therefore, we may conclude that prenatal deficiencies are more 
important than postnatal deficiencies in determining mental health problems in childhood.

\section{Mediating effects of indicators of prenatal and postnatal growth}

The association between parental SES and mental health service use was not mediated by prenatal growth or postnatal growth, suggesting that a child's physical development is not merely on the causal pathway between parental SES and mental health service use. In future studies, other mechanisms by which parental SES is associated with mental health may be examined.

\section{Other variables}

The present results showed that apart from the socioeconomic background, none of the family characteristics, and only one child characteristic was associated with postnatal growth, in that more internalizing problems were associated with lower levels of BMI. Earlier research showed that particularly low birth weight was associated with having more internalizing problems (Laucht et al., 2001). Other studies have suggested an association between low birth weight and more widespread mental health problems, including symptoms of both internalizing and externalizing disorders, such as anxiety/depression and aggression problems respectively (Zubrick et al., 2000). However, the present study showed that later in childhood, the children having both internalizing and externalizing behaviour had a higher BMI. No evident explanation is apparent, although it may reflect in part mental health problems associated with obesity.

\section{CONCLUSIONS}

The present results showed some evidence for the impact of intrauterine development on children's mental health problems. In addition, neither prenatal nor postnatal growth is on the causal pathway between parental SES and children's mental health.

Acknowledgements We gratefully acknowledge the financial support by the ministry of health, welfare, and sports (VWS). The authors are grateful to Peter van Neer, employee of the Youth Health Care Division, Municipal Health Centre for his assistance in the sample data-collection. We thank Dr. Math Candel for his statistical advise on the multilevel regression model of growth curves. 


\section{REFERENCES}

Barker, DJ , Osmond, C (1986) Childhood respiratory infection and adult chronic bronchitis in England and Wales. Br Med J (Clin Res Ed), 293 (6557): 1271-5.

Barker, DJP (1995) Fetal origins of coronary heart disease. BMJ, 311: 171-174.

Bennett, F (1997) The low birth weight, premature infant. In: Gross, R, Spiker, D, Haynes, C (Ed.), Helping low birth weight, premature infants (pp. 3-16) Stanford, California: Stanford University Press.

Black, MM , Krishnakumar, A (1999) Predicting longitudinal growth curves of height and weight using ecological factors for children with and without early growth deficiency. J Nutr, 129 (2S Suppl): 539s-543s.

Botting, N, Powls, A, Cooke, RW , Marlow, N (1997) Attention deficit hyperactivity disorders and other psychiatric outcomes in very low birthweight children at 12 years. J Child Psychol Psychiatry, 38 (8): 931-41.

Breslau, N, Brown, GG, DelDotto, JE, Kumar, S, Ezhuthachan, S, Andreski, P, Hufnagle, KG (1996) Psychiatric sequelae of low birth weight at 6 years of age. J Abnorm Child Psychol, 24 (3): 385-400.

CBS (1993) Standaard beroepenclassificatie 1992. Den Haag: SDU.

De Swaan, A (1988) In Care of State: Health Care, Education and Welfare in Europe and the USA in the Modern Era. Cambridge: Polity Press.

Driessen, G, Evers, S, Verhey, F , van Os, J (2001) Stroke and mental health care: a record linkage study. Soc Psychiatry Psychiatr Epidemiol, 36 (12): 608-12.

Drukker, M, Kaplan, CD, Feron, FJM , Van Os, J (2003) Children's health-related quality of life, neighbourhood socio-economic deprivation and social capital. A contextual analysis. Soc Sci Med, 57 (5): 825-841.

Eveleth, PB , Tanner, JM (1976) World wide variation in human height. Cambridge: Cambridge University Press.

Fine, PE, Adelstein, AM, Snowman, J, Clarkson, JA , Evans, SM (1985) Long term effects of exposure to viral infections in utero. Br Med J (Clin Res Ed), 290 (6467): 509-11.

Gunther, N, Slavenburg, B, Feron, F , van Os, J (2003) Childhood social and early developmental factors associated with mental health service use. Soc Psychiatry Psychiatr Epidemiol, 38 (3): 101-8.

Hille, ET, den Ouden, AL, Saigal, S, Wolke, D, Lambert, M, Whitaker, A, Pinto-Martin, JA, Hoult, L, Meyer, R, Feldman, JF, Verloove-Vanhorick, SP , Paneth, N (2001) Behavioural problems in children who weigh $1000 \mathrm{~g}$ or less at birth in four countries. Lancet, 357 (9269): 1641-3.

Hortulanus, RP , Machielse, JEM (2001) Op het snijvlak van de fysieke en sociale leefomgeving. 'sGravenhage: Elsevier.

Hoy, EA, Sykes, DH, Bill, JM, Halliday, HL, McClure, BG , Reid, MM (1992) The social competence of very-low-birthweight children: teacher, peer, and self-perceptions. J Abnorm Child Psychol, 20 (2): $123-50$.

Keirse, MJ (1984) Epidemiology and aetiology of the growth retarded baby. Clin Obstet Gynaecol, 11 (2): 415-36. 
Koot, HM , Verhulst, FC (1992) Prediction of children's referral to mental health and special education services from earlier adjustment. J Child Psychol Psychiatry, 33 (4): 717-29.

Lasker, GW , Mascie-Taylor, CG (1989) Effects of social class differences and social mobility on growth in height, weight and body mass index in a British cohort. Ann Hum Biol, 16 (1): 1-8.

Laucht, M, Esser, G , Schmidt, MH (2001) Differential development of infants at risk for psychopathology: the moderating role of early maternal responsivity. Developmental Medicine \& Child Neurology, 43 (5): 292-300.

Lindgren, G (1976) Height, weight and menarche in Swedish urban school children in relation to socio-economic and regional factors. Ann Hum Biol, 3 (6): 501-28.

Lindgren, GW , Cernerud, L (1992) Physical growth and socioeconomic background of Stockholm schoolchildren born in 1933-63. Ann Hum Biol, 19 (1): 1-16.

McCormick, MC, Gortmaker, SL, Sobol, AM (1990) Very low birth weight children: behavior problems and school difficulty in a national sample. J Pediatr, 117 (5): 687-93.

McCormick, MC, Workman-Daniels, K, Brooks-Gunn, J (1996) The behavioral and emotional wellbeing of school-age children with different birth weights. Pediatrics, 97 (1): 18-25.

Schnabel, P (1997) The mental health services: more than psychiatry alone. In: Schrijvers, AJP editor. Health and health care in the Netherlands: a critical self-assessment by Dutch experts in the medical and health sciences (pp. 119-131) Utrecht, the Netherlands: De Tijdstroom.

Snijders, T , Bosker, R (1999) Multilevel analysis, an introduction to basic and advanced modeling. London: SAGE Publications.

Sommerfelt, K, Troland, K, Ellertsen, B , Markestad, T (1996) Behavioral problems in lowbirthweight preschoolers. Dev Med Child Neurol, 38 (10): 927-40.

Szatmari, P, Saigal, S, Rosenbaum, P, Campbell, D , King, S (1990) Psychiatric disorders at five years among children with birthweights less than 1000g: a regional perspective. Dev Med Child Neurol, 32 (11): 954-62.

Szatmari, P, Saigal, S, Rosenbaum, P , Campbell, D (1993) Psychopathology and adaptive functioning among extremely low birthweight children at eight years of age. Dev Psychopathol, 5: 345-357.

Tansella, M, Micciolo, R, Biggeri, A, Bisoffi, G, Balestrieri, M (1995) Episodes of care for first-ever psychiatric patients. A long-term case-register evaluation in a mainly urban area. Br J Psychiatry, 167 (2): 220-7.

Tessier, R, Nadeau, L, Boivin, M , Tremblay, RE (1997) The social behaviour of 11- to 12-year-old children born as low birthweight and/or premature infants. International Journal of Behavioral Development, 21 (4): 795-811.

Thompson, H. (2000). "OECD study highlights widespread and persistent poverty in Europe and America." Retrieved 4 februari 2000 from internet:

(http://www.wsws.org/sections/category/about/archive.shtml) http://www.wsws.org/articles/2000/feb2000/pov-f04.shtml

van Os, J, Wichers, M, Danckaerts, M, Van Gestel, S, Derom, C, Vlietinck, R (2001) A prospective twin study of birth weight discordance and child problem behavior. Biol Psychiatry, 50 (8): 5939. 
Verkerk, PH, Zaadstra, BM, Reerink, JD, Herngreen, WP , Verloove-Vanhorick, SP (1994) Social class, ethnicity and other risk factors for small for gestational age and preterm delivery in The Netherlands. Eur J Obstet Gynecol Reprod Biol, 53 (2): 129-34.

Wahlbeck, K, Forsen, T, Osmond, C, Barker, DJ , Eriksson, JG (2001) Association of schizophrenia with low maternal body mass index, small size at birth, and thinness during childhood. Arch Gen Psychiatry, 58 (1): 48-52.

Weisglas-Kuperus, N, Koot, HM, Baerts, W, Fetter, WP, Sauer, PJ (1993) Behaviour problems of very low-birthweight children. Dev Med Child Neurol, 35 (5): 406-16.

Zubrick, SR, Kurinczuk, JJ, McDermott, BM, McKelvey, RS, Silburn, SR , Davies, LC (2000) Fetal growth and subsequent mental health problems in children aged 4 to 13 years. Dev Med Child Neurol, 42 (1): 14-20. 
Table 1. Description of social economic status variables

\begin{tabular}{lcccc}
\hline \hline & \multicolumn{2}{c}{ Cases } & \multicolumn{2}{c}{ Controls } \\
& abs. & $\%$ & abs. & $\%$ \\
\hline Occupational status & & & & \\
Low & 20 & 25.0 & 47 & 14.7 \\
Medium & 35 & 43.8 & 134 & 41.9 \\
High & 10 & 12.5 & 55 & 17.2 \\
Science & 4 & 5.0 & 37 & 11.6 \\
Missing & 11 & 13.8 & 47 & 14.7 \\
Unemployment & & & & \\
Employed & 62 & 77.5 & 269 & 84.1 \\
Unemployed & 13 & 16.3 & 22 & 6.9 \\
Missing & 5 & 6.3 & 29 & 9.1 \\
Single/two-parent family: & & & & \\
Single parent & 17 & 21.3 & 17 & 5.3 \\
Two-parent & 57 & 71.3 & 288 & 90.0 \\
Missing & 6 & 7.5 & 320 & 4.7 \\
& 80 & 100 & & 100 \\
\hline \hline
\end{tabular}


Table 2. Associations between parental SES and birth weight and birth length; coefficients and $95 \%$ CI

\begin{tabular}{|c|c|c|c|c|}
\hline \multirow[t]{2}{*}{ Parental SES } & \multicolumn{2}{|c|}{ Birth weight (g) } & \multicolumn{2}{|c|}{ Birth length $(\mathrm{cm})$} \\
\hline & Beta & $(95 \% \mathrm{CI})$ & Beta & $(95 \% \mathrm{CI})$ \\
\hline \multicolumn{5}{|l|}{ Occupational status crude ${ }^{a}$} \\
\hline Medium occupational status (reference) & 0 & & 0 & \\
\hline Low occupational status & 134.7 & $(-18.1 ; 287.6)$ & 0.4 & $(-0.6 ; 1.4)$ \\
\hline High occupational status & 75.5 & $(-84.7 ; 235.8)$ & 0.2 & $(-0.5 ; 1.0)$ \\
\hline Scientific occupational status & 213.1 & $(26.9 ; 399.2)^{*}$ & 1.0 & $(-0.0 ; 2.0)$ \\
\hline $\begin{array}{l}\text { Single parent crude } \\
\text { (reference }=\text { two-parent family) }{ }^{\mathrm{a}}\end{array}$ & -24.2 & $(-213.6 ; 165.1)$ & -0.3 & $(-1.3 ; 0.8)$ \\
\hline $\begin{array}{l}\text { Parental unemployment crude } \\
\text { (reference }={\text { employed })^{a}}^{a}\end{array}$ & -383.4 & $(-667.4 ;-99.4)^{* *}$ & -1.9 & $(-3.1 ;-0.6)^{* *}$ \\
\hline \multicolumn{5}{|l|}{ Total model $^{\mathrm{b}}$} \\
\hline Medium occupational status (reference) & 0 & & 0 & \\
\hline Low occupational status & 174.9 & $(16.7 ; 333.0)^{*}$ & 0.5 & $(-0.5 ; 1.5)$ \\
\hline High occupational status & 55.9 & $(-112.9 ; 224.6)$ & 0.2 & $(-0.6 ; 0.9)$ \\
\hline Scientific occupational status & 185.9 & $(-9.7 ; 381.4)^{c}$ & 0.8 & $(-0.2 ; 1.9)$ \\
\hline Single-parent (ref=two-parent family) & 90.6 & $(-139.7 ; 320.9)$ & 0.4 & $(-0.8 ; 1.6)$ \\
\hline Parental unemployment (ref=employed) & -638.0 & $(-1107.3 ;-168.6)^{* *}$ & -2.9 & $(-5.9 ; 0.1)^{\mathrm{c}}$ \\
\hline
\end{tabular}

*P<0.05; **P<0.01.

a The missing values were entered in the model as an extra category, but results are not presented.

b SES-variables put simultaneously in model and corrections were made for parental mental health problems.

c Statistically imprecise by conventional alpha. 
Table 3. Associations between birth weight and birth length and mental health service use; ORs and $95 \% \mathrm{CI}$

\begin{tabular}{lll}
\hline \hline & \multicolumn{2}{l}{ Mental health service use } \\
& OR & $(95 \% \mathrm{CI})$ \\
\hline Birth weight, $(\mathrm{g})$ crude $_{\text {Birth weight }^{\mathrm{a}}}$ & 1.00 & $(0.999-1.000)$ \\
Birth length, $(\mathrm{cm})$ crude $_{\text {Birth length }^{\mathrm{a}}}^{1.00}$ & $(0.999-1.000)$ \\
\hline \hline
\end{tabular}

$* \mathrm{P}<0.05$.

${ }^{a}$ Corrected for parental mental health problems.

b Statistically imprecise by conventional alpha. 
Table 4. Mediating effects of birth weight and birth length, respectively, in the association between parental SES and mental health service use

\begin{tabular}{lcc}
\hline \hline & \multicolumn{2}{c}{ Mental health service use } \\
& OR & $(95 \% \mathrm{CI})$ \\
\hline Mediating effect of birth weight & 1.00 & $(1.00-1.00)$ \\
Birth weight (g) & & \\
Occupational status: & 1.85 & $(0.88-3.90)$ \\
$\quad$ Low occupational status & 1 & \\
$\quad$ Medium occupational status (reference) & 0.55 & $(0.21-1.49)$ \\
$\quad$ High occupational status & 0.55 & $(0.16-1.88)$ \\
$\quad$ Scientific occupational status & 5.51 & $(1.96-15.50)^{*}$ \\
Single parent family (two-parent=reference) & 4.11 & $(0.74-23.00)$ \\
Parental unemployment (employed=reference) & & \\
Mediating effect of birth length & 0.90 & $(0.81-1.00)$ \\
Birth length (cm) & & \\
Occupational status: & 2.11 & $(0.96-4.65)$ \\
$\quad$ Low occupational status & 1 & \\
$\quad$ Medium occupational status (reference) & 0.46 & $(0.16-1.31)$ \\
$\quad$ High occupational status & 0.67 & $(0.19-2.36)$ \\
$\quad$ Scientific occupational status & 5.86 & $(1.97-17.44)^{*}$ \\
Single parent family (two-parent=reference) & 3.62 & $(0.66-19.68)$ \\
\hline Parental unemployment (employed=reference) & &
\end{tabular}

* $P<0.01$. 
Table 5. Association between parental SES and postnatal growth (crude and total model); coefficients and $95 \% \mathrm{CI}$

\begin{tabular}{|c|c|c|c|c|c|c|}
\hline & \multicolumn{2}{|r|}{ Height (cm) } & \multicolumn{2}{|r|}{ Weight(kg) } & \multicolumn{2}{|c|}{$\begin{array}{c}\text { BMI } \\
\text { Weight } /(\text { height } / 100)^{2}\end{array}$} \\
\hline & Beta & $(95 \% \mathrm{CI})$ & Beta & $(95 \% \mathrm{CI})$ & Beta & $(95 \% \mathrm{CI})$ \\
\hline \multicolumn{7}{|l|}{ Crude model } \\
\hline Gender (1=boy; $2=\operatorname{girl})$ & -1.46 & $(-2.29 ;-0.62)^{* * *}$ & -0.57 & $(-0.95 ;-0.19)^{* *}$ & -0.21 & $(-0.46 ; 0.05)$ \\
\hline Age at inclusion & -0.13 & $(-0.31 ; 0.06)$ & 0.05 & $(-0.04 ; 0.14)$ & 0.06 & $(0.01 ; 0.12)^{*}$ \\
\hline \multicolumn{7}{|l|}{ Occupational status } \\
\hline Low occupational status & -0.44 & $(-1.46 ; 0.59)$ & -0.01 & $(-0.48 ; 0.47)$ & 0.26 & $(-0.07 ; 0.58)$ \\
\hline $\begin{array}{l}\text { Medium occupational status (refer- } \\
\text { ence) }\end{array}$ & 0 & & 0 & & 0 & \\
\hline High occupational status & -0.59 & $(-1.64 ; 0.47)$ & -0.10 & $(-0.58 ; 0.39)$ & 0.14 & $(-0.20 ; 0.47)$ \\
\hline Scientific occupational status & 0.51 & $(-0.77 ; 1.78)$ & 0.02 & $(-0.58 ; 0.61)$ & -0.24 & $(-0.64 ; 0.16)$ \\
\hline $\begin{array}{l}\text { Single parent family } \\
\text { (two-parent family=reference) }\end{array}$ & 0.32 & $(-1.38 ; 2.02)$ & 0.04 & $(-0.75 ; 0.83)$ & -0.10 & $(-0.64 ; 0.44)$ \\
\hline $\begin{array}{l}\text { Parental unemployment (em- } \\
\text { ployed=reference) }\end{array}$ & -3.38 & $(-5.71 ;-1.04)^{* *}$ & -1.72 & $(-2.81 ;-0.63)^{* *}$ & -0.61 & $(-1.35 ; 0.12)$ \\
\hline \multicolumn{7}{|l|}{ Total model ${ }^{a}$} \\
\hline Gender & -0.66 & $(-1.39 ; 0.08)$ & -0.36 & $(-0.71 ;-0.01)^{*}$ & -0.11 & $(-0.37 ; 0.16)$ \\
\hline Age at inclusion & -0.22 & $(-0.39 ;-0.04)^{*}$ & 0.05 & $(-0.03 ; 0.13)$ & 0.06 & $(0.00 ; 0.12)$ \\
\hline \multicolumn{7}{|l|}{ Occupational status } \\
\hline Low occupational status & -0.61 & $(-1.52 ; 0.29)$ & -0.06 & $(-0.50 ; 0.37)$ & 0.19 & $(-0.13 ; 0.52)$ \\
\hline $\begin{array}{l}\text { Medium occupational status (re fer- } \\
\text { ence) }\end{array}$ & 0 & & 0 & & 0 & \\
\hline High occupational status & -0.52 & $(-1.46 ; 0.42)$ & -0.09 & $(-0.63 ; 0.26)$ & 0.04 & $(-0.29 ; 0.38)$ \\
\hline Scientific occupational status & 0.35 & $(-0.88 ; 1.57)$ & -0.20 & $(-0.80 ; 0.33)$ & -0.40 & $(-0.82 ; 0.02)$ \\
\hline Single parent family & 0.31 & $(-1.19 ; 1.80)$ & -0.25 & $(-0.94 ; 0.45)$ & -0.23 & $(-0.75 ; 0.29)$ \\
\hline $\begin{array}{l}\text { Parental unemployment } \\
\text { (employed=reference) }\end{array}$ & -1.86 & $(-4.04 ; 0.33)$ & -0.77 & $(-1.83 ; 0.28)$ & -0.36 & $(-1.12 ; 0.39)$ \\
\hline Mother's age at delivery & 0.01 & $(-0.08 ; 0.10)$ & 0.02 & $(-0.02 ; 0.06)$ & 0.02 & $(-0.01 ; 0.04)$ \\
\hline Birth length & 0.62 & $(0.50 ; 0.73)^{* * *}$ & & & & \\
\hline Birth weight & & & 1.30 & $(1.01 ; 1.58)^{* * *}$ & & \\
\hline BMI at birth & & & & & 0.24 & $(0.15 ; 0.32)^{* * *}$ \\
\hline \multicolumn{7}{|l|}{ Psychosocial behaviour child (before 6 years) } \\
\hline Positive (reference) & 0 & & 0 & & 0 & \\
\hline Internalizing & -0.13 & $(-2.06 ; 1.80)$ & -0.43 & $(-1.38 ; 0.51)$ & -0.85 & $(-1.52 ;-0.18)^{*}$ \\
\hline Externalizing & 0.34 & $(-0.69 ; 1.37)$ & -0.13 & $(-0.61 ; 0.35)$ & -0.12 & $(-0.49 ; 0.24)$ \\
\hline $\begin{array}{l}\text { Internalizing as well as } \\
\text { externalizing }\end{array}$ & 0.21 & $(-1.66 ; 2.09)$ & 0.44 & $(-0.39 ; 1.28)$ & 0.85 & $(0.18 ; 1.52)^{*}$ \\
\hline Else & -0.89 & $(-1.72 ;-0.06)^{*}$ & -0.28 & $(-0.67 ; 0.11)$ & -0.29 & $(-0.58 ; 0.01)$ \\
\hline \multicolumn{7}{|l|}{$\begin{array}{l}\text { Psychosocial behaviour child (6 years or } \\
\text { older) }\end{array}$} \\
\hline Positive & 0 & & 0 & & 0 & \\
\hline Internalizing & 0.23 & $(-1.09 ; 1.54)$ & -0.04 & $(-0.66 ; 0.58)$ & -0.13 & $(-0.59 ; 0.34)$ \\
\hline Externalizing & -0.25 & $(-1.27 ; 0.78)$ & -0.09 & $(-0.58 ; 0.39)$ & -0.18 & $(-0.54 ; 0.18)$ \\
\hline $\begin{array}{l}\text { Internalizing as well as externali- } \\
\text { zing }\end{array}$ & 1.13 & $(-0.17 ; 2.43)$ & -0.17 & $(-0.78 ; 0.44)$ & -0.14 & $(-0.60 ; 0.31)$ \\
\hline Else & 0.56 & $(-0.34 ; 1.45)$ & 0.35 & $(-0.07 ; 0.78)$ & 0.08 & $(-0.24 ; 0.39)$ \\
\hline $\begin{array}{l}\text { Parental mental health problem } \\
\text { (no problem }=\text { reference) }\end{array}$ & -0.36 & $(-1.87 ; 1.14)$ & -0.29 & $(-1.02 ; 0.43)$ & -0.26 & $(-0.79 ; 0.27)$ \\
\hline
\end{tabular}

$* P<0.05 ; * * P<0.01 ; * * * P<0.001$.

a Controlled for confounders. 
Table 6. Association between case/mental health care use and postnatal growth (crude and total model); coefficients and 95\% CI

\begin{tabular}{|c|c|c|c|c|c|c|}
\hline & \multicolumn{2}{|c|}{ Height $(\mathrm{cm})$} & \multicolumn{2}{|c|}{ Weight (kg) } & \multicolumn{2}{|c|}{$\begin{array}{c}\text { BMI } \\
\text { weight/(height/100)2 }\end{array}$} \\
\hline & Beta & $(95 \% \mathrm{CI})$ & Beta & $(95 \% \mathrm{CI})$ & Beta & $(95 \% \mathrm{CI})$ \\
\hline \multicolumn{7}{|l|}{ Crude model } \\
\hline Gender & -1.29 & $(-2.09 ;-0.49)^{* *}$ & -0.51 & $(-0.89 ;-0.13)^{* *}$ & -0.19 & $(-0.44 ; 0.07)$ \\
\hline Age at inclusion & -0.21 & $(-0.37 ;-0.04)^{*}$ & 0.02 & $(-0.06 ; 0.10)$ & 0.05 & $(0.00 ; 0.10)$ \\
\hline $\begin{array}{l}\text { Case } / \text { mental health care user } \\
\text { (controls }=\text { reference) }\end{array}$ & 0.42 & $(-0.48 ; 1.31)$ & 0.26 & $(-0.15 ; 0.67)$ & 0.14 & $(-0.13 ; 0.41)$ \\
\hline \multicolumn{7}{|l|}{ Total model ${ }^{\mathrm{a}}$} \\
\hline Gender & -0.53 & $(-1.25 ; 0.18)$ & -0.32 & $(-0.68 ; 0.04)$ & -0.09 & $(-0.36 ; 0.18)$ \\
\hline Age at inclusion & -0.24 & $(-0.39 ;-0.08)^{* *}$ & 0.03 & $(-0.05 ; 0.10)$ & 0.05 & $(0.00 ; 0.11)$ \\
\hline $\begin{array}{l}\text { Case } / \text { mental health care use } \\
\text { (controls }=\text { reference) }\end{array}$ & -0.14 & $(-1.03 ; 0.75)$ & 0.04 & $(-0.37 ; 0.46)$ & 0.08 & $(-0.22 ; 0.37)$ \\
\hline Mother's age at delivery & -0.03 & $(-0.11 ; 0.04)$ & -0.00 & $(-0.04 ; 0.03)$ & 0.00 & $(-0.02 ; 0.03)$ \\
\hline Birth length & 0.59 & $(0.48 ; 0.70)^{* * *}$ & & & & \\
\hline Birth weight & & & 1.16 & $(0.90 ; 1.42)^{* * *}$ & & \\
\hline BMI at birth & & & & & 0.23 & $(0.15 ; 0.31)^{* * *}$ \\
\hline \multirow{2}{*}{\multicolumn{7}{|c|}{$\begin{array}{l}\text { Psychosocial behaviour child } \\
\text { (before } 6 \text { years) }\end{array}$}} \\
\hline & & & & & & \\
\hline Positive (reference) & 0 & & 0 & & 0 & \\
\hline Internalizing & -0.54 & $(-2.40 ; 1.33)$ & -0.52 & $(-1.40 ; 0.35)$ & -0.73 & $(-1.35 ;-0.11)^{*}$ \\
\hline Externalizing & 0.48 & $(-0.52 ; 1.48)$ & -0.10 & $(-0.57 ; 0.37)$ & -0.11 & $(-0.46 ; 0.23)$ \\
\hline $\begin{array}{l}\text { Internalizing as well as } \\
\text { externalizing }\end{array}$ & -0.62 & $(-2.42 ; 1.17)$ & 0.01 & $(-0.80 ; 0.82)$ & 0.59 & $(-0.04 ; 1.21)$ \\
\hline Else & -0.99 & $(-1.79 ;-0.18)^{*}$ & -0.36 & $(-0.74 ; 0.01)$ & -0.24 & $(-0.52 ; 0.03)$ \\
\hline \multicolumn{7}{|l|}{ Psychosocial behaviour child } \\
\hline \multicolumn{7}{|l|}{ (6 years or older) } \\
\hline Positive (reference) & 0 & & 0 & & 0 & \\
\hline Internalizing & -0.25 & $(-1.53 ; 1.03)$ & -0.29 & $(-0.89 ; 0.32)$ & -0.22 & $(0.01 ;-0.44)$ \\
\hline Externalizing & -0.50 & $(-1.47 ; 0.47)$ & -0.23 & $(-0.69 ; 0.23)$ & -0.11 & $(-0.44 ; 0.22)$ \\
\hline $\begin{array}{l}\text { Internalizing as well as } \\
\text { externalizing }\end{array}$ & 1.04 & $(-0.22 ; 2.29)$ & -0.12 & $(-0.72 ; 0.48)$ & -0.09 & $(-0.51 ; 0.34)$ \\
\hline Else & 0.47 & $(-0.36 ; 1.31)$ & 0.31 & $(-0.08 ; 0.71)$ & 0.10 & $(-0.20 ; 0.38)$ \\
\hline $\begin{array}{l}\text { Parental mental health problem } \\
\text { (no problem=reference) }\end{array}$ & -0.27 & $(-1.63 ; 1.10)$ & -0.04 & $(-0.69 ; 0.62)$ & 0.04 & $(-0.42 ; 0.51)$ \\
\hline
\end{tabular}





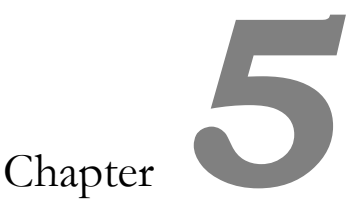

\title{
Neighbourhood social environment and childhood experience of being bullied
}

\author{
Nicole Gunther ${ }^{1}$, Marjan Drukker ${ }^{1,2}$, Frans Feron ${ }^{2}$, Jim van Os ${ }^{1,3}$
}

1 Department of Psychiatry and Neuropsychology, South Limburg Mental Health Research and Teaching Network, EURON, Maastricht University, Maastricht, The Netherlands.

2 Youth Health Care Division, Public Health Service South Limburg, location Maastricht, The Netherlands

3 Division of Psychological Medicine, Institute of Psychiatry, De Crespigny Park, Denmark Hill, London, UK.

Submitted 


\section{ABSTRACT}

Previous work showed that neighbourhood social capital was associated with children's behaviour and an association between neighbourhood social environment and being the victim of bullying could be expected. Therefore, in the present study, this association was studied in the transition from late childhood into early adolescence. Results showed that social capital, as one neighbourhood characteristic, may play a role in the experience of being bullied, but only in boys going to primary school. However, to unravel neighbourhood effects, more longitudinal studies are needed to verify these statistically inconclusive findings.

Keywords: Bullying - Victimization - Neighbourbood environment - Child - Adolescent 


\section{INTRODUCTION}

Children exposed to bullying are more often referred for psychiatric consultation (Kumpulainen et al., 1998). In the longer term, victims of bullying in childhood are more likely to be depressed and have poor self-esteem in adulthood (Olweus, 1993), and a recent Dutch study suggests that the risk for psychosis may be increased (Lataster et al., 2006). Growing evidence indicates that the neighbourhood context, such as neighbourhood socioeconomic disadvantage and social capital, is associated with poor mental health and many aspects of deviant behaviour of children and adolescents (Leventhal and Brooks Gunn, 2000; Drukker et al., 2003; Schneiders et al., 2003). Neighbourhood social capital has been defined as "those features of social organizations - such as networks of secondary associations, high levels of interpersonal trust and norms of mutual aid and reciprocity - which act as resources for individuals and facilitate collective action" (Kawachi et al., 1999). In particular one aspect of social capital, called "informal social control" appears to be associated with behaviour in children. It was shown that children had better behavioural outcomes when they were living in neighbourhoods with higher levels of informal social control (Drukker et al., 2003). For example, if neighbours correct deviant behaviour (this is informal social control) in children this intervention may directly prevent the children from behaving badly as well as indirectly provide them with selfconfidence and a sense of protection. If social capital impacts on behaviour, an association with being bullied can also be expected, but this has never been studied as far as we know. In addition, there is evidence that neighbourhood factors may impact more on boys than on girls (Leventhal and Brooks Gunn, 2000). Thus, an interaction with gender was hypothesized, when studying the association between neighbourhood and being bullied.

In the current study, the association between neighbourhood socioeconomic disadvantage and social capital on the one hand and being bullied in late childhood and early adolescence on the other was examined in the city of Maastricht, The Netherlands, with a particular focus on informal social control and gender differences.

\section{METHODS}

As part of the Maastricht Quality of Life Study (MQoL), a cohort of Maastricht children aged approximately 11 years at baseline $(n=598)$ was followed into adolescence (aged around 13-14 years; $\mathrm{n}=475$ ) (Drukker et al., 2006). The baseline measurements included family-level measures such as parental socioeconomic status and child-level measures such as the neighbourhood of residence. Exposure to 
bullying was measured not only at baseline but also at follow-up and was assessed with the question: "How many times have you been the victim of bullying in your neighbourhood in the past year?" The question was rated on a 5-point scale $(1=$ never, $2=$ one or two times, $3=$ one or two times per month on average, $4=$ ones per week on average, $5=$ several times per week), and was analysed as a continuous variable.

Neighbourhood level socioeconomic disadvantage was based on several objective neighbourhood variables, such as income and unemployment, derived from Statistics Netherlands (CBS) and the local authorities, while neighbourhood social capital was measured in a recent Maastricht community survey. In order to assess social capital, approximately 200 adult inhabitants from each of the 36 Maastricht neighbourhoods, aged 20 to 65 years, were randomly selected, using the municipal database. Forty-eight percent of the 7236 selected adults responded. Social capital was measured using two collective efficacy scales: informal social control (ISC) and social cohesion and trust (SC\&T), developed by Sampson and colleagues (Sampson, 1997) and adapted to the Dutch situation (Drukker et al., 2003). The ISC scale measures the willingness to intervene in hypothetical neighbourhoodthreatening situations, for example in the case of children misbehaving or the opening of a brothel in the street. The SC\&T scale measures bonds and trust among the residents of the neighbourhood. The answers of the respondents were aggregated to the neighbourhood level, resulting in continuous ISC and SC\&T variables. Higher scores on the outcome variable indicated more exposure to bullying and higher scores on the neighbourhood variables indicated more disadvantage and lower levels of social capital. Therefore, we expected the Bs of the neighbourhood variables to be positive.

All analyses were performed using Stata (StataCorp, 2006). Data were grouped according to neighbourhoods and were, in statistical terms, part of a two-level structure with individual and family variables as level-one variables and neighbourhood factors as level-two variables. These hierarchically structured data were subjected to multilevel regression analysis in order to investigate neighbourhood effects at baseline and follow-up, while controlling for individual effects. Guided by previous work (Drukker et al., 2003) several variables were included as confounders in the analyses: parental occupational status (according to the International SocioEconomic Index of occupational status; isei92), parental educational status, family welfare recipient status (yes/no), family single parent status (yes/no), child's grade retention before baseline (yes/no) and child's gender. To study neighbourhood effects on changes in being bullied between late childhood and early adolescence, follow-up analyses were additionally controlled for baseline exposure to bullying. 


\section{RESULTS}

About $6 \%$ of the baseline population was exposed to neighbourhood bullying once per week on average or more. However, at follow-up this was $2 \%$ (data not shown). Baseline results showed that associations between the neighbourhood variables and being the victim of bullying (socioeconomic disadvantage: $\beta=0.15$ $\mathrm{p}=0.001$; informal social control: $\beta=0.06 ; \mathrm{p}=0.007$ ) disappeared after controlling for confounding variables (table 1). However, there was some evidence of an association between social cohesion and trust and being bullied in eleven year old boys, albeit statistically imprecise by conventional alpha (after controlling for confounding variables: $\beta=-0.04 ; p=0.05$ ).

At follow up, none of the associations between the neighbourhood factors and changes in being bullied were statistically significant neither in boys nor in girls and neither before nor after controlling for confounders (data not shown).

\section{DISCUSSION AND CONCLUSIONS}

Social capital in the neighbourhood, in particular social cohesion and trust, may play a role in being bullied. However, this association seemed to be in the opposite direction as expected: low rather than high social cohesion and trust was beneficial. One possible explanation may be that negative interactions between children (for example violence) in high social cohesion neighbourhoods are more often perceived as bullying than in low social cohesion neighbourhoods because of perceived differences in deviation from the norm.

Furthermore, the association between neighbourhood social capital and being bullied seemed to be restricted to boys going to primary school. An explanation for finding suggestive associations at baseline only may be that, at follow up all adolescents went to secondary schools, which are generally located outside their own neighbourhood. Therefore, neighbourhood influences may be of less importance. In addition, it is not surprising that neighbourhood context is more important for boys than girls, because boys are more exposed to neighbourhood social environment as a result of decreased parental supervision and monitoring in late childhood relative to girls (Leventhal and Brooks Gunn, 2000).

However, more longitudinal studies are needed to verify these statistically inconclusive findings. 


\section{REFERENCES}

Drukker, M., Kaplan, C., Schneiders, J., Feron, F. J. , van Os, J., 2006. The wider social environment and changes in self-reported quality of life in the transition from late childhood to early adolescence: a cohort study. BMC Public Health 6, 133.

Drukker, M., Kaplan, C. D., Feron, F. J. M. , Van Os, J., 2003. Children's health-related quality of life, neighbourhood socio-economic deprivation and social capital. A contextual analysis. Soci Sci Med 57 (5), 825-841.

Kawachi, I., Kennedy, B. P. , Glass, R., 1999. Social capital and self-rated health: a contextual analysis. Am J Public Health 89 (8), 1187-1193.

Kumpulainen, K., et al., 1998. Bullying and psychiatric symptoms among elementary school-age children. Child Abuse Negl

22 (7), 705-17.

Lataster, T., et al., 2006. Childhood victimisation and developmental expression of non-clinical delusional ideation and hallucinatory experiences : Victimisation and non-clinical Psychotic experiences. Soc Psychiatry Psychiatr Epidemiol 41 (6), 423-8.

Leventhal, T. , Brooks Gunn, J., 2000. The neighborhoods they live in: The effects of neighborhood residence on child and adolescent outcomes. Psychological Bulletin 126 (2), 309-337.

Olweus, D., 1993. Bullying at school: what we know and what we can do. Blackwell Publishers, Oxford, UK.

Sampson, R. J., 1997. Collective regulation of adolescent misbehavior: Validation results from eighty Chicago neighborhoods. Journal of Adolescent Research 12 (2), 227-244.

Schneiders, J., et al., 2003. Neighbourhood socioeconomic disadvantage and behavioural problems from late childhood into early adolescence. J Epidemiol Community Health 57 (9), 699-703.

StataCorp, 2006. Stata Statistical Software. College Station, TX: Stata Corporation. 
Table 1. Multilevel regression analysis: the association at baseline of socioeconomic disadvantage, residential instability, informal social control and social cohesion and trust on the one hand and being bullied on the other.

\begin{tabular}{|c|c|c|c|c|c|c|}
\hline & \multicolumn{6}{|c|}{ Being bullied } \\
\hline & \multicolumn{2}{|c|}{ Girls and Boys } & \multicolumn{2}{|l|}{ Girl } & \multicolumn{2}{|l|}{ Boy } \\
\hline & $\beta$ & $(\mathrm{CI})$ & $\beta$ & (CI) & B & (CI) \\
\hline \multicolumn{7}{|c|}{ Socioeconomic disad- } \\
\hline \multicolumn{7}{|c|}{ vantage } \\
\hline Crude model & 0.15 & $(0.06 ; 0.23) * *$ & 0.21 & $(0.10 ; 0.33) * * *$ & 0.07 & $(-0.05 ; 0.18)$ \\
\hline Total model ${ }^{a}$ & & & 0.07 & $(-0.06 ; 0.20)$ & -0.09 & $(-0.22 ; 0.04)$ \\
\hline \multicolumn{7}{|c|}{$\begin{array}{l}\text { Residential instabil- } \\
\text { ity }\end{array}$} \\
\hline Crude model & -0.09 & $(-0.25 ; 0.08)$ & -0.14 & $(-0.38 ; 0.09)$ & -0.04 & $(-0.26 ; 0.18)$ \\
\hline Total model ${ }^{a}$ & & & -0.10 & $(-0.34 ; 0.15)$ & -0.10 & $(-0.31 ; 0.11)$ \\
\hline \multicolumn{7}{|l|}{ ISC } \\
\hline Crude model & 0.06 & $(0.02 ; 0.10) * *$ & 0.09 & $(0.03 ; 0.15) * *$ & 0.02 & $(-0.04 ; 0.09)$ \\
\hline Total model ${ }^{a}$ & & & 0.05 & $(-0.02 ; 0.11)$ & -0.02 & $(-0.08 ; 0.05)$ \\
\hline \multicolumn{7}{|l|}{ SC\&T } \\
\hline Crude model & 0.04 & $(0.01 ; 0.06) * *$ & 0.06 & $(0.02 ; 0.09)^{* *}$ & 0.01 & $(-0.02 ; 0.05)$ \\
\hline Total model ${ }^{a}$ & & & 0.02 & $(-0.02 ; 0.06)$ & -0.04 & $(-0.07 ; 0.00)^{1}$ \\
\hline
\end{tabular}

** $P<0.01$; *** $P<0.001$.

a Corrected for occupational status (isei92), educational status, family welfare recipient status (yes/no), single parent (yes/no), child's grate retention and gender.

${ }^{1}$ Statistically imprecise by conventional alpha. 

Chapter

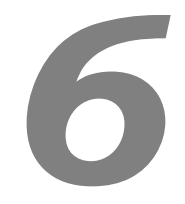

\title{
No ecological effect modification of the association between negative life experiences and later psychopathology in adolescence: a longitudinal community study in adolescents
}

\author{
Nicole Gunther ${ }^{1}$, Marjan Drukker ${ }^{1,2}$, Frans Feron ${ }^{2}$, Jim van Os ${ }^{1,3}$
}

1 Department of Psychiatry and Neuropsychology, South Limburg Mental Health Research and Teaching Network, EURON, Maastricht University, Maastricht, The Netherlands.

2 Youth Health Care Division, Public Health Service South Limburg, location Maastricht, The Netherlands

3 Division of Psychological Medicine, Institute of Psychiatry, De Crespigny Park, Denmark Hill, London, UK.

European Psychiatry, 2007, Vol. 22, No 5, 296-304 


\section{ABSTRACT}

Background The aim of the study was to examine the potential contribution of exposure to bullying and adverse life events to the development of psychopathology in adolescents, and possible effect modification by neighbourhood social capital. Methods Two waves of routine, longitudinal, standard health examinations at local community paediatric health services, pertaining to 749 adolescents living in Maastricht (The Netherlands) who were attending second grade of secondary school (age 13/14 years) and approximately 2 years later going to the fourth grade (age 15/16 years), were analysed. A self-report questionnaire was used, including measures of psychopathology and two measures of negative life experiences, exposure to bullying and adverse life events, that were available for both age groups and subjected to (multilevel) regression analysis. Results Exposure to bullying in the past school-year as well as the experience of adverse life events over a 12 month period, at the age of 13/14 years, predicted an increase in psychopathology at follow-up. Exposure to bullying was associated with the development of hyperactivity and emotional problems, while the experience of adverse life events predicted the development of conduct problems. Family-related adverse events had greatest effect sizes. Effects of bullying and adverse life events were not moderated by neighbourhood social capital. Conclusion Negative life experiences impact on liability to psychopathology in adolescents independent of the wider social environment.

Keywords: Negative life experience - Adolescent - Neighbourbood environment - Psychopathology 


\section{INTRODUCTION}

Negative life experiences in the form of exposure to bullying and the experience of adverse life events in childhood and adolescence may impact on psychopathology (Kroes et al., 2002; Lataster et al., 2006; Spauwen et al., 2006), persisting into adolescence and even adulthood (Olweus, 1993; Caspi et al., 1996; Pine et al., 2002). However, greater levels of informal social control in the neighbourhood environment have been reported to improve mental health and behaviour (Drukker et al., 2003) and it is therefore hypothesized that greater levels of neighbourhood social capital may help children and adolescents to better cope with negative life experiences, and thus reduce the risk of later psychopathology. This report investigates the extent to which psychosocial risk factors in adolescence predict later psychopathology in relation to the possible moderating effect of a protective neighbourhood environment.

Numerous risk factors have been mentioned to be of importance in the development of child psychopathology. Among these, two measures of negative life experiences, repeated exposure to bullying and the experience of adverse life events, are strongly associated with both internalizing and externalizing disorders (Velez et al., 1989; Kumpulainen et al., 1998). Furthermore, negative life experiences (including childhood trauma) have also been associated with mental health outcomes in adolescence and young adulthood, including depression (Kendler, 1995), general anxiety disorders (Murphy et al., 2000) and psychotic experiences (Read et al., 2005; Lataster et al., 2006). There is growing evidence, however, that relative risks of main effects are insufficient in explaining trajectories towards psychopathology, as moderating effects of the wider social environment additionally shape individual risks (Neeleman, 2003). For example, members of ethnic minority groups living in areas where they represent a larger part of the population have a lower risk of suicide (Neeleman and Wessely, 1999) and psychosis (Boydell et al., 2001). Another example is that the association of low birth weight with ADHD was stronger in the urban than in the suburban populations (Breslau et al., 1996). This is known as ecological effect modification (Neeleman, 2003).

Thus, the association between negative life experiences and psychopathology in adolescence may be modified by characteristics of the wider social environment in which the adolescent lives, in particular aspects such as community informal social control, often referred to as "social capital". Neighbourhood social capital has been defined as "those features of social organizations - such as networks of secondary associations, high levels of interpersonal trust and norms of mutual aid and reciprocity - which act as resources for individuals and facilitate collective action" (Kawachi et al., 1999). It was shown that children had better mental health and 
behavioural outcomes when they were living in neighbourhoods with higher levels of informal social control (Drukker et al., 2003). Furthermore, a second study showed that "social cohesion and trust", another aspect of neighbourhood social capital, mitigated the risk-increasing effect of socioeconomic deprivation on children's mental health service use (van der Linden et al., 2003). Both results may indicate that social capital can decrease the impact of risk factors; for example, if neighbours correct deviant behaviour (this is informal social control) in an early stage of childhood development this collective intervention may directly prevent the children from behaving badly as well as indirectly provide them with selfconfidence and a sense of protection. Thus, caring neighbours may help children and adolescents to overcome negative life experiences. Therefore, in considering the moderating role of the neighbourhood context, social capital is a plausible candidate for further study.

The potential contribution of negative life experiences to later psychopathology can be established in a longitudinal design, where controlling for initial symptom level is possible. Therefore, longitudinal data were used to investigate whether possible effects of repeated exposure to bullying and stressful life events at baseline on adolescent psychopathology at 2-year follow-up were moderated by neighbourhood social capital. It was hypothesized that adverse effects of negative life experiences on psychopathology in adolescence would be stronger in neighbourhoods with lower levels of social capital.

\section{METHOD}

\section{Setting}

The Maastricht population consists of 122000 inhabitants living in 36 residential neighbourhoods, having between 300 and 8500 inhabitants (all ages). The population is of relative ethnic homogeneity, with relatively few residents originating from non-Western countries, in comparison with the ethnically more heterogeneous populations in the cities in the northwest of the country (Drukker et al., 2003). Adolescents living in the city of Maastricht were included in the present study.

\section{Subjects}

In the Netherlands, doctors and nurses of Youth Health Care Divisions (YHCD) of (Regional) Public Health Services regularly examine all children aged 4-16 years. In Maastricht, parents of the younger children as well as adolescents aged 13 years 
and older are asked to fill in a questionnaire contemporary with the medical examination (or in substitution for the medical examination). Health information aimed to detect and remediate physical and mental health problems as well as background characteristics (e.g. type of secondary education) were derived from these questionnaires, which were compiled in the context of an academic partnership between YHCD and Maastricht University (Drukker et al., 2003; Gunther et al., 2003). Two waves of these Regional Profiles of Youth health (RPY) data, pertaining to 749 adolescents living in Maastricht who were attending the second grade of secondary school (age 13/14 years) and approximately 2 years later whilst attending the fourth grade (age 15/16 years), were used for the present longitudinal analyses. Since the YHCD archives also contain addresses of the adolescents, the neighbourhood of the adolescents was included in the data set. The self-report questionnaire included, amongst others, questions about psychopathology, exposure to bullying and adverse life events, and type of secondary school.

\section{Assessments}

Self-reported exposure to bullying was assessed at baseline and follow-up with the question: "How many times have you been the victim of bullying in the past schoolyear?" The question was rated on a 5 -point scale $(1=$ never, $2=$ one or two times, $3=$ one or two times per month on average, $4=$ once per week on average, $5=$ several times per week). Guided by previous research, bullying was rated conservatively as present when a subject reported incidents of bullying occurring once a week or more (scores 4 or 5) (Janssen et al., 2004; Lataster et al., 2006).

Two domains of self-reported stressful life events were assessed at baseline and follow-up: family-related (i.e. parents, siblings, other relatives) and school-related. For each domain, students were asked to answer two questions: i) " did you (yes or no) experience particularly unpleasant events of importance during the previous year?" and ii) "how much did these events influence your life?" (at baseline: $1=$ no influence, $2=$ little influence, $3=$ moderate influence, $4=a$ lot of influence; at follow-up: $0=$ no influence, $1-4=$ little to moderate influence, $5-10=$ a lot of influence). Both questions at baseline as well as at follow- up, were combined into one continuous variable per domain, hereafter: "type of life event" $(0=$ no event; $1=$ little to moderate influence and $2=$ much to very much influence). In addition, a sum score of the two domains (family and school) was generated using the two types of life events, resulting in a continuous total adverse life events variable (range 0-4) and thus determining the cumulative effects of adverse life events.

Psychopathology was measured also at each assessment using the Strengths and Difficulties Questionnaire (SDQ) (Goodman, 1997; Treffers, 2000). The SDQ is a brief 
questionnaire, assessing symptoms of psychopathology in children and adolescents. A self-report version that can be completed independently by 11-16-years olds was used for the present analyses. The SDQ consists of 25 items, generating sum scores for five subscales: emotional symptoms, conduct problems, hyperactivity-inattention, peer problems and prosocial behaviour. A few examples of the types of questions used in the SDQ are: "I worry a lot" and "I get very angry and often lose my temper". Each item can be scored on a 3-point scale with $0=$ not true, $1=$ somewhat true, and $2=$ certainly true. Higher scores on the prosocial behaviour subscale reflect strengths, whereas higher scores on the other four subscales reflect difficulties. Although the internal consistencies of the SDQ total score $(\alpha=0.63)$ and subscales ( $\alpha$ ranging from 0.54 to 0.57 ) in the present study were generally acceptable, the internal consistency of the peer problems subscale was below acceptable limits $(\alpha=0.36)$, which was in line with previous research (Muris et al., 2003). Therefore, this scale was not included in the present analyses. For the present study, the sum scores of four subscales (0-10), as well as a total psychopathology symptom score (range 0-40), based on all but the prosocial scale were used. Sum scores for the subscales of the SDQ as well as the total psychopathology symptom score were standardised for the present analyses.

Neighbourhood social capital was measured in a recent Maastricht community survey (Drukker, 2004). In order to assess social capital, approximately 200 adult inhabitants from each of the 36 Maastricht neighbourhoods, aged 20-65 years, were randomly selected, using the municipal database. Forty-eight percent of the 7236 selected adults responded. Social capital was measured using two collective efficacy scales: informal social control (ISC) and social cohesion and trust (SC\&T), developed by Sampson (Sampson, 1997) and adapted to the Dutch situation (Drukker et al., 2003). The ISC scale measures the willingness to intervene in hypothetical neighbourhood-threatening situations, for example in the case of children misbehaving or the opening of a brothel in the street. The SC\&T scale measures bonds and trust among the residents of the neighbourhood. The answers of the respondents were aggregated to the neighbourhood level, resulting in continuous ISC and $S C \& T$ variables, which were standardized $(S D=1)$ for the present study. Higher scores on the outcome variable indicated more exposure to bullying and higher scores on the neighbourhood variables indicated more disadvantage and lower levels of social capital. Therefore, we expected the Bs of the neighbourhood variables to be positive.

Individual level socioeconomic status was based on type of secondary school which the student attended. This resulted in a categorical variable with five categories: one pre-university education; two higher general secondary education; three highest level of technical and vocational training for 12-16 year olds; four medium level of 
technical and vocational training for 12-16 year olds; and five lowest level of technical and vocational training for 12-16 year olds. The categories were recoded into dummy variables in the analysis; the category "pre-university education" was defined as the reference category.

Because duration of follow-up period varied, analyses were also controlled for duration of follow-up.

\section{Statistical analyses}

All analyses were performed using Stata, version 9.2 (StataCorp, 2006). In order to study associations between i) repeated exposure to bullying and ii) the experience of stressful life events on the one hand and longitudinal changes in psychopathology on the other, linear regression analysis was used, with psychopathology at follow-up as the dependent variable. Total adverse life events and exposure to bullying were investigated in separate analyses with as outcome measures four subscale sum scores of psychopathology (emotional symptoms, conduct problems, hyperactivity-inattention, prosocial behaviour) as well as total psychopathology. First, analyses were controlled for psychopathology at baseline, thus assessing change in the dependent variable between baseline and follow-up as a function of the exposures (model 1). Second, analyses were additionally adjusted for age, gender, socioeconomic status and duration of follow-up (model 2).

In order to assess what type of adverse life event (family or school) was most important for the development of psychopathology, these two types were entered jointly in linear regression models for each of the five outcome measures, again adjusting for age, gender, socioeconomic status, duration between baseline and follow-up, and baseline score of the outcome measure.

Independence of the two negative life experiences variables (exposure to bullying and total adverse life events) was assessed by entering them simultaneously in the same regression model and making adjustments for the confounders and the baseline symptom score.

After adding data on neighbourhood social capital to the data set, information of individuals was clustered within neighbourhoods and was, in statistical terms, part of a multilevel structure with level-one units (individuals) clustered into level-two units (neighbourhoods). These hierarchically structured data were subjected to multilevel regression analysis (Snijders and Bosker, 1999) in order to investigate neighbourhood effects while controlling for individual effects. Multilevel regression models analysing the association between bullying and total adverse life events on the one hand and total psychopathology on the other were again adjusted for age, gender, socioeconomic status and duration of follow-up, and the following a 
priory hypothesized interaction terms were added to the models: bullying $\mathrm{x}$ ISC, bullying $\mathrm{x}$ SC\&T, total adverse life event $\mathrm{x}$ ISC and total adverse life event $\mathrm{x}$ SC\&T.

\section{RESULTS}

\section{Sample characteristics}

Baseline and follow-up measurements as well as neighbourhood data were available for 749 adolescents (46\% male), living in Maastricht. The adolescents' mean age was 13.7 years at baseline $(S D=0.9$; range $12-17)$ and 15.1 years at follow-up $(\mathrm{SD}=0.78$, range $14-18)$. Ninety-one subjects $(12.5 \%)$ attended pre-university secondary education (level 5) and 142 subjects (19.5\%) higher general education (level 4). A total of $494(68 \%)$ subjects attended lower professional education: 246 subjects with highest level 3 (33.8\%), 154 subjects with medium level $2(21.2 \%)$ and 94 subjects with lowest level 1 (12.9\%) (data not shown).

At baseline, a total of 33 subjects (4\%) reported being bullied at least once a week and 241 subjects $(33 \%)$ experienced at least one stressful life event during the previous year. Stressful life events in the family were mentioned most frequently $(27 \%)$ (Table 1). The adverse family events that were most mentioned were loss of a family member, family health problems, divorce and conflict in the family. The mean of total negative life events was 0.51 ( $\mathrm{SD}=0.84$ range $0-4)$. Furthermore, five students $(0.69 \%)$ at baseline described negative life events in both family circle and at school with great influence (score 4) (data not shown).

\section{Association between exposure to bullying and change in total psychopathology over time}

Model 1 (analysing psychopathology at follow-up) including exposure to bullying as well as baseline values of the outcome (Table 2, section a) showed that adolescents repeatedly exposed to bullying in the previous year developed significantly more total psychopathology over the follow-up period, irrespective of the initial level of symptom load. In model 2 (Table 2, section b), the association between exposure to bullying and total psychopathology remained statistically significant $(\beta=0.41 ; p=0.02)$, indicating that the average score on total psychopathology score in the group of children exposed to bullying was 0.41 standard deviation higher than in the group of children not exposed to bullying. 


\section{Association between exposure to bullying and change in the five subscales of psychopathology}

Adolescents who were exposed to bullying were significantly more at risk for hyperactivity/inattention problems 2 years later, even after controlling for confounders and baseline symptoms (Table 2). Model 1 (Table 2, section a) showed that these children were also more at risk for having emotional symptoms $(\beta=0.42$; $p=0.02$ ), and after controlling for confounders (model 2; Table 2, section b) this association was only slightly reduced although statistically imprecise by conventional alpha $(\beta=0.37 ; p=0.06$ ). On the other hand, exposure to bullying did not predict an increase in conduct problems.

\section{Association between adverse life events and change in total psychopathology over time}

Adolescent total stressful life events predicted an increased level of total psychopathology, even after controlling for confounders and baseline values of the outcome $(\beta=0.10 ; p=0.03$; Table 3, sections $\mathrm{a}$ and $\mathrm{b}$ ). When the two types of stressful life events (family, school) were included in one model, life events concerning the family of the child had a significant negative impact on total psychopathology ( $\mathrm{Ta}$ ble 3), whereas school life events did not.

\section{Association between adverse life events and changes in the five subscales of psychopathology}

The experience of at least one adverse life event in the year before baseline was specifically associated with the development of conduct problems 2 years later, after controlling for the confounding variables and the baseline symptom score (Table 3 , section $\mathrm{b}: \beta=0.11 ; p=0.03$ ). Thus, on average the psychopathology score was 0.11 standard deviation higher, when the child scores 1 unit higher in the total life event variable (e.g. when the child scored "much" to "very much influence", rather than "little influence" on one of the life event domains). Total adverse life events were not significantly associated with the development of emotional symptoms or decrease in prosocial behaviour.

When family life events and school life events were entered jointly into the same adjusted regression model, associations with the four subscales of psychopathology were again only found for family life events. A specific association with the development of emotional symptoms, hyperactivity and conduct problems (the latter statistically imprecise) 2 years later was apparent (Table 3). 


\section{Independence of the negative life experiences variables}

When the two negative life experiences variables were entered simultaneously into the same adjusted regression model, the effect of exposure to bullying remained significant $(\beta=0.36 ; p=0.03)$, whereas adverse life events exhibited an attenuated effect and was statistically imprecise by conventional alpha $(\beta=0.08 ; p=0.06)$.

\section{Baseline psychopathology and confounders}

Baseline symptoms were a significant predictor of total psychopathology at followup, indicating considerable continuity (in model of exposure to bullying and model of total adverse life events: $\beta=0.45 ; p<0.001$; Tables 2 and 3 ).

Girls reported significantly greater increases in total symptoms over the follow-up period than boys (in model of exposure to bullying: $\beta=0.23$; $p<0.001$; in model of adverse life events: $\beta=0.20 ; p=0.002$ ). There was also an effect of individual socioeconomic status on the total symptom score, in that the lowest level of education was associated with greater increases in self-reported symptoms (in model of exposure to bullying: $\beta=0.34$ and $\beta=0.53$; $p<0.01$; in model of adverse life events: $\beta=0.32 ; p<0.05$ and $\beta=0.49 ; p<0.01)$.

\section{Ecological effect modification}

The interaction terms between the two measures of negative life experiences and neighbourhood social capital were neither large nor statistically significant (bullying x ISC: $\beta=-0.68, p=0.31$; bullying $\mathrm{x}$ SC\&T: $\beta=-0.03, p=0.96$; total adverse life event x ISC: $\beta=-0.05, p=0.74$; total adverse life event $\mathrm{x}$ SC $\& \mathrm{~T}$ : $\beta=-0.06, p=0.65)$, indicating no modification of the relationship between exposure to bullying and the experience of total adverse life events on the one hand and psychopathology in adolescents on the other, by neighbourhood social capital.

\section{DISCUSSION}

Exposure to bullying as well as the experience of total adverse life events were both associated with an increase in psychopathology 2 years later. Exposure to bullying was associated with the development of hyperactivity and emotional problems, while the experience of total adverse life events particularly predicted the development of conduct problems. Stressful family-related events were most important; the effect of total adverse life events was in part reducible to bullying, but 
not the other way round. Associations between negative life experiences and psychopathology in adolescence did not vary as a function of neighbourhood social capital.

\section{Methodological issues}

The strength of the present study is the longitudinal design, including a baseline and a follow-up measurement. Because baseline psychopathology could be controlled for, the results show changes between baseline and follow-up. Although research can never prove causality, these longitudinal analyses provide stronger evidence for causality than cross-sectional research.

Although there may be overlap between exposure to bullying and adverse life events at school, the former concept has more potential to measure the continuous influence on the child over time, while life events are once-only experiences. In addition, next to the multiple choice questions on life events, adolescents also filled in an open-ended question on what life event they experienced and about $80 \%$ of the adolescents reported school events other than exposure to bullying. Therefore, the impacts of these two measures of negative life experiences are unlikely to be identical and were analysed separately.

The present paper has some limitations. First, the duration of the follow-up period varied because nurses scheduled adolescents throughout the school-year. In addition, the duration of the follow-up period of adolescents attending technical and vocational training for 12-16 year olds was shorter, because these children received the questionnaire at the end of the third grade of secondary school rather than in the fourth grade, because of final exams. Therefore, analyses were controlled for the duration between baseline and follow-up.

Second, in the city of Maastricht, there are 1000 children per school grade. However, because of logistical problems intrinsic to starting up the YHCD-registration system, health information was available for only 749 children living in Maastricht. However, we do not expect selection bias to operate, because these logistical problems are independent of the characteristics of the adolescents

Third, although previous research showed that the SDQ questionnaire is a good instrument to detect psychiatric disorders (in particular conduct, hyperactivity, depressive disorders and some anxiety disorders), the parent and teacher version are generally better predictors than the child version used in the present paper (Goodman et al., 2000).

Fourth, because the item "reflective" (I think before I do things) of the hyperactivity subscale loaded extremely low on the hyperactivity scale, we looked more carefully to the relationships between negative life experiences and hyperactivity. When 
the item "reflective" was left out of the analyses, the association between exposure to bullying and hyperactivity remained and the association between stressful life events in the family and the hyperactivity scale, was only slightly reduced $(\beta=0.10$; $p=0.05)$. Therefore, the associations between negative life experiences and hyperactivity are still valid.

Fifth, data were derived from standard health screening procedures including numerous questions over a wide range of physical and mental health problems. Consequently, the assessment of certain items was limited. For example, type of secondary school was used as a proxy of individual level socioeconomic status. However, in the present study, this proxy of individual level socioeconomic status was considered to control sufficiently for individual differences in socioeconomic status. The data presented in the present paper are part of a longitudinal follow-up that will eventually follow individuals throughout childhood. In this longitudinal data-collection, parental socioeconomic status is measured more precisely in younger children. In future cohorts, adolescent data can be linked to childhood data including parental SES. Furthermore, life events were measured by only two questions. However, two important aspects of life events were measured, i.e. the perception of the event (negative) and the impact of the event on the individual, which was in line with previous research (Fennig et al., 2005). Nevertheless, the association between life events and changes in psychopathology of children is a very complex one and future research will need to verify the present results using a more detailed variant of the life events questionnaire.

Finally, at the time the students were filling in the questionnaire, they were aware of the fact that possible problems would be discussed with a nurse during the health screening procedure. Subjects, as a consequence, might have underreported exposure to bullying, adverse life events and psychopathology. For example, the rates of bullying experiences ( $4.4 \%$ at baseline and $0.51 \%$ at follow-up) are much lower than percentages found in other studies (Forero et al., 1999; Rigby, 1999), although decreasing prevalence of bullying in late adolescence is consistent with earlier findings (Kumpulainen et al., 1999; Rigby, 1999). This potential underreporting suggests that the association between negative life experiences and psychopathology might be even stronger than reported in the present study.

\section{Ecological effect modification}

The degree of neighbourhood social capital did not mitigate the effect of individual level exposures in the realm of adversity and negative life experiences on later risk for psychopathology, at least not in secondary school children. Previous work in secondary school children addressed the hypothesis that the effect of social capital 
might be stronger in primary school children, because secondary school children more easily cross the borders of their own neighbourhood (Drukker et al., 2006; Gunther et al., submitted). Results of the present study are in agreement with these studies (Drukker et al., 2006; Gunther et al., submitted). Therefore, future (longitudinal) research may preferentially focus on effects of neighbourhood social capital in younger children.

\section{Differences between boys and girls}

Although previous studies showed that the association between adverse life events and psychopathology is weaker in girls than in boys (Luthar et al., 1993), and others reported opposite findings (being a boy is a protective factor) (Werner and Smith, 1992), in the present study, gender did not modify the association between negative life experiences and psychopathology (bullying x gender: $\beta=0.07, p=0.83$; total adverse life events $\mathrm{x}$ gender: $\beta=0.12, p=0.18$ ).

\section{Exposure to bullying and psychopathology}

The present results are in line with previous longitudinal research in elementary school-aged children (Kumpulainen and Rasanen, 2000), showing that victims of bullying were more prone to psychopathology in later years, even after adjustment for confounders. A notable finding of Schwartz et al. (Schwartz et al., 1998) and Wolke et al. (2000) (Wolke et al., 2000) in an elementary school sample was that exposure to bullying was related to more externalizing problems, such as hyperactivity and not to more internalizing problems, such as emotional problems. In line with these earlier studies using parent and/or teacher-reports, the present selfreport study showed that adolescents who are exposed to bullying are at increased risk of hyperactivity. However, both the present study using self-reports and a previous study (Kumpulainen et al., 1998) found also a (weak) association between exposure to bullying and the development of emotional problems.

Various mechanisms of why exposure to bullying affects psychopathology have been described. First, internalizing and externalizing symptoms may emerge when bullying (probably of long duration) is experienced (Kumpulainen et al., 1998). For example, victimised adolescents may develop aggressive behaviour as a mechanism for defending themselves against their peers (Patterson et al., 1967). Second, victims of bullying are not only more emotionally disturbed but also often have externalizing problems, making them more likely targets of repeated negative life experiences (Wolke et al., 2000). 


\section{Adverse life events and psychopathology}

One third of all adolescents experienced an adverse life event in one domain or more in a 1-year period. Stressful family-related events, such as loss of a family member and family health problems, were most mentioned, which is in accordance with much earlier research in adults (Goldberg and Huxley, 1980). However, comparing variations in frequency of life events between populations is difficult (Goldberg and Comstock, 1980) because prevalence depends on for example the questionnaire that is used. The present questionnaire was specifically designed for the present data-collection and, therefore, no comparison data are readily available.

Adverse life events were introduced into the analyses as a sum score of the two domains (family and school), thus determining the cumulative effects of adverse life events. The rationale for this approach was that experiencing adverse life events in two different domains may have more impact on psychopathology than having only one adverse life event, because when an adolescent has to cope with major life events, both at home and at school he/she cannot seek comfort and stability in the other domain. The present study showed a cumulative effect of adverse life events: higher scores on the adverse life events variable were associated with an increase in psychopathology at follow-up. This is consistent with previous longitudinal research focussing on younger children and adolescents (Berden et al., 1990; DuBois et al., 1992; Hook et al., 1995; Kroes et al., 2002).

When examining the subscales of psychopathology, higher scores on the life events variables were significantly associated with the development of symptoms indicative of conduct problems and to a much lesser extent to the development of symptoms indicative of hyperactivity. This is in line with evidence from cross-sectional studies showing that disruptive disorders are reactive to a broad range of adverse life events, whereas hyperactivity is associated with only some adverse life events (Jensen et al., 1991; Tiet et al., 2001). In addition, in recent research, life events such as being the victim of crime, break-up with boyfriend/girlfriend, mental/emotional problems of a family member, new stepmother or stepfather and parent in trouble with law were associated with conduct disorder (Tiet et al., 2001). Associations with psychopathology outcomes were stronger in the domain of family-related life events than in the domain of school-related life events. This is in agreement with other research. Various epidemiological studies showed that persistence of family discord and disruption were associated with chronic behaviour problems (Campbell, 1995). Second, the family environment has been ascribed salutary or moderating effects on the relationship between life events and depression (Friis et al., 2002). Thus, family-related life events appeared to be crucial for the development of emotional problems among young people. 


\section{Possible mechanism of risk}

The present results showed that negative life experiences at 13/14 years were significantly associated with the development of psychopathology. Student exposed to bullying and adverse life events more often had externalizing problems, such as hyperactivity and conduct problems. The most obvious interpretation is that exposure to negative life experiences worsens the prognosis of psychopathology as a whole and externalizing disorders in particular. Hyperactivity and conduct problems may reflect adolescent's coping styles in interaction with their environment (person-environment interaction) (Craig, 1998). However, it is also possible that adolescents with higher levels of psychopathology, such as hyperactivity, are more prone to bullying and adverse life events through their own mal-adaptation and long-term-difficulties in their environment (person-environment correlation) (Rutter and Silberg, 2002). In order to test this assumption, we examined whether psychopathology at 13/14 years predicted negative life experiences 2 years later. Analysis revealed that there was a large and significant association between baseline psychopathology and adverse life events at follow-up $(\beta=0.29 ; \mathrm{p}<0.001)$, while baseline psychopathology was not associated with exposure to bullying at followup. Although this indicates some evidence for person-environment correlation, the data still indicate that negative life experiences in adolescence is a risk factor for later increase in psychopathology and that it may play an incremental role in the development of symptoms, given the longitudinal character of the present study. The study showed associations between baseline negative life experiences and changes in psychopathology between baseline and follow-up, rather than crosssectional associations. Thus, children with externalizing disorders are at risk for negative life experiences and repeated negative life experiences may heighten (already high) levels of psychopathology.

\section{Clinical implications}

Adolescents who continue to experience negative life experiences may show persistent problems. Therefore, a case can be made for health professionals of the YHCD and mental health services to routinely take a full psychosocial history. The results of the present paper warrant the inclusion of bullying and life events in this history, while previous research also provided a rationale for the inclusion of experience of abuse (Read et al., 2005).

Furthermore, for these adolescents a "wait-and-see" policy may be inappropriate and an active intervention may be required. In particular, there may be a need for interventions given at the school level (teacher training and support, peer support 
systems) whenever bullying arises (Cowie et al., 2002). Interventions addressing the parents may also help prevent children from becoming (more seriously) mentally ill. Examples of such selective interventions are parental health education and parenting support focussed on one-parent families or mentally ill parents (parentfocused programmes) to prevent relapse and promote the child's mental health (Buist, 1998). There are also possibilities to improve the psychosocial prognosis of children at temperamental risk by home-based interventions focussed on parentchild interactions, pointing out the importance of care-giving relationships during development and showing the possibility of modifying the parent-child relationships to the benefit of the child's future mental development (Teerikangas et al., 1998).

Furthermore, in order to manage possible adaptation difficulties, individual interventions may be focused on, for example, coping strategies. In addition, there does not appear to be a need for interventions at the neighbourhood level, at least not in adolescence, because characteristics of the neighbourhood may be less important in adolescence than in childhood.

Acknowledgements The authors are grateful to Peter van Neer, Anke Maas, Rinske Hoogerhuis, Jolanda Huveners and Patricia Senden employees of the Youth Health Care Division, Public Health Service South Limburg, location Maastricht for their assistance in the sample data-collection. 


\section{REFERENCES}

Berden, GF, Althaus, M, Verhulst, FC (1990) Major life events and changes in the behavioural functioning of children. J Child Psychol Psychiatry, 31 (6): 949-59.

Boydell, J, van Os, J, McKenzie, K, Allardyce, J, Goel, R, McCreadie, RG , Murray, RM (2001) Incidence of schizophrenia in ethnic minorities in London: ecological study into interactions with environment. BMJ, 323 (7325): 1336-8.

Breslau, N, Brown, GG, DelDotto, JE, Kumar, S, Ezhuthachan, S, Andreski, P, Hufnagle, KG (1996) Psychiatric sequelae of low birth weight at 6 years of age. J Abnorm Child Psychol, 24 (3): 385-400.

Buist, A (1998) Mentally ill families. When are the children unsafe? Aust Fam Physician, 27 (4): 261-5.

Campbell, SB (1995) Behavior problems in preschool children: a review of recent research. J Child Psychol Psychiatry, 36 (1): 113-49.

Caspi, A, Moffitt, TE, Newman, DL , Silva, PA (1996) Behavioral observations at age 3 years predict adult psychiatric disorders. Longitudinal evidence from a birth cohort. Arch Gen Psychiatry, 53 (11): 1033-9.

Cowie, H, Naylor, P, Talamelli, L, Chauhan, P , Smith, P (2002) Knowledge, use of and attitudes towards peer support: a 2-year follow-up to the Prince's Trust survey. J Adolesc, 25 (5): 453-67.

Craig, WM (1998) The relationship among bullying, victimization, depression, anxiety, and aggression in elementary school children. Personality and Individual Differences., 24 (1): 123-130.

Drukker, M (2004). The neighbourhood matters; the neighbourhood social environment and differences in self-reported quality of life and mental health. Psychiatry and Neuropsychology. Maastricht, Maastricht University: 64.

Drukker, M, Kaplan, C, Schneiders, J, Feron, FJ , van Os, J (2006) The wider social environment and changes in self-reported quality of life in the transition from late childhood to early adolescence: a cohort study. BMC Public Health, 6: 133.

Drukker, M, Kaplan, CD, Feron, FJM , Van Os, J (2003) Children's health-related quality of life, neighbourhood socio-economic deprivation and social capital. A contextual analysis. Soc Sci Med, 57 (5): 825-841.

DuBois, DL, Felner, RD, Brand, S, Adan, AM , Evans, EG (1992) A prospective study of life stress, social support, and adaptation in early adolescence. Child Dev, 63 (3): 542-57.

Fennig, S, Horesh, N, Aloni, D, Apter, A, Weizman, A , Fennig, S (2005) Life events and suicidality in adolescents with schizophrenia. Eur Child Adolesc Psychiatry, 14 (8): 454-60.

Forero, R, McLellan, L, Rissel, C, Bauman, A (1999) Bullying behaviour and psychosocial health among school students in New South Wales, Australia: cross sectional survey. BMJ, 319 (7206): 344-8.

Friis, RH, Wittchen, HU, Pfister, H , Lieb, R (2002) Life events and changes in the course of depression in young adults. Eur Psychiatry, 17 (5): 241-53.

Goldberg, D , Huxley, P (1980) Mental illness in the community: the pathway to psychiatric care. London: Tavistock.

Goldberg, EL , Comstock, GW (1980) Epidemiology of life events: frequency in general populations. Am J Epidemiol, 111 (6): 736-52. 
Goodman, R (1997) The Strengths and Difficulties Questionnaire: a research note. J Child Psychol Psychiatry, 38 (5): 581-6.

Goodman, R, Ford, T, Simmons, H, Gatward, R , Meltzer, H (2000) Using the Strengths and Difficulties Questionnaire (SDQ) to screen for child psychiatric disorders in a community sample. Br J Psychiatry, 177: 534-9.

Gunther, N, Drukker, M, Feron, F , Os van, J (submitted) Neighbourhood social environment and childhood bullying. Health and Place.

Gunther, N, Slavenburg, B, Feron, F , van Os, J (2003) Childhood social and early developmental factors associated with mental health service use. Soc Psychiatry Psychiatr Epidemiol, 38 (3): 101-8.

Hook, B, Hagglof, B , Thernlund, G (1995) Life events and behavioural deviances in childhood: a longitudinal study of a normal population. Eur Child Adolesc Psychiatry, 4 (3): 153-64.

Janssen, I, Krabbendam, L, Bak, M, Hanssen, M, Vollebergh, W, de Graaf, R , van Os, J (2004) Childhood abuse as a risk factor for psychotic experiences. Acta Psychiatr Scand, 109 (1): 38-45.

Jensen, PS, Richters, J, Ussery, T, Bloedau, L , Davis, H (1991) Child psychopathology and environmental influences: discrete life events versus ongoing adversity. J Am Acad Child Adolesc Psychiatry, 30 (2): 303-9.

Kawachi, I, Kennedy, BP , Glass, R (1999) Social capital and self-rated health: a contextual analysis. Am J Public Health, 89 (8): 1187-1193.

Kendler, KS (1995) Genetic epidemiology in psychiatry. Taking both genes and environment seriously. Arch Gen Psychiatry, 52 (11): 895-9.

Kroes, M, Kalff, AC, Steyaert, J, Kessels, AG, Feron, FJ, Hendriksen, JG, van Zeben, TM, Troost, J, Jolles, J , Vles, JS (2002) A longitudinal community study: do psychosocial risk factors and child behavior checklist scores at 5 years of age predict psychiatric diagnoses at a later age? J Am Acad Child Adolesc Psychiatry, 41 (8): 955-63.

Kumpulainen, K , Rasanen, E (2000) Children involved in bullying at elementary school age: their psychiatric symptoms and deviance in adolescence. An epidemiological sample. Child Abuse Negl, 24 (12): 1567-77.

Kumpulainen, K, Rasanen, E , Henttonen, I (1999) Children involved in bullying: psychological disturbance and the persistence of the involvement. Child Abuse Negl, 23 (12): 1253-62.

Kumpulainen, K, Rasanen, E, Henttonen, I, Almqvist, F, Kresanov, K, Linna, SL, Moilanen, I, Piha, J, Puura, K, Tamminen, T (1998) Bullying and psychiatric symptoms among elementary schoolage children. Child Abuse Negl, 22 (7): 705-17.

Lataster, T, van Os, J, Drukker, M, Henquet, C, Feron, F, Gunther, N , Myin-Germeys, I (2006) Childhood victimisation and developmental expression of non-clinical delusional ideation and hallucinatory experiences : Victimisation and non-clinical Psychotic experiences. Soc Psychiatry Psychiatr Epidemiol, 41 (6): 423-8.

Luthar, SS, Doernberger, CH , Zigler, E (1993) Resilience is not a unidimensional construct: insights from a prospective study of inner-city adolescents. Dev Psychopathol, 5: 703-717.

Muris, P, Meesters, C , van den Berg, F (2003) The Strengths and Difficulties Questionnaire (SDQ)-further evidence for its reliability and validity in a community sample of Dutch children and adolescents. Eur Child Adolesc Psychiatry, 12 (1): 1-8. 
Murphy, DA, Moscicki, AB, Vermund, SH , Muenz, LR (2000) Psychological distress among HIV(+) adolescents in the REACH study: effects of life stress, social support, and coping. The Adolescent Medicine HIV/AIDS Research Network. J Adolesc Health, 27 (6): 391-8.

Neeleman, J (2003) The relativity of relative risks: disadvantage or opportunity? Br J Psychiatry, 182: $101-2$.

Neeleman, J , Wessely, S (1999) Ethnic minority suicide: a small area geographical study in south London. Psychol Med, 29 (2): 429-36.

Olweus, D (1993) Bullying at school: what we know and what we can do. Oxford, UK: Blackwell Publishers.

Patterson, GR, Littman, RA , Bricker, W (1967) Assertive behavior in children: a step toward a theory of aggression. Monogr Soc Res Child Dev, 32 (5): 1-43.

Pine, DS, Cohen, P, Johnson, JG , Brook, JS (2002) Adolescent life events as predictors of adult depression. J Affect Disord, 68 (1): 49-57.

Read, J, van Os, J, Morrison, AP , Ross, CA (2005) Childhood trauma, psychosis and schizophrenia: a literature review with theoretical and clinical implications. Acta Psychiatr Scand, 112 (5): 330-50.

Rigby, K (1999) Peer victimisation at school and the health of secondary school students. Br J Educ Psychol, 69 ( Pt 1): 95-104.

Rutter, M , Silberg, J (2002) Gene-environment interplay in relation to emotional and behavioral disturbance. Annu Rev Psychol, 53: 463-90.

Sampson, RJ (1997) Collective regulation of adolescent misbehavior: Validation results from eighty Chicago neighborhoods. Journal of Adolescent Research, 12 (2): 227-244.

Schwartz, D, McFadyen-Ketchum, SA, Dodge, KA, Pettit, GS , Bates, JE (1998) Peer group victimization as a predictor of children's behavior problems at home and in school. Dev Psychopathol, 10 (1): 87-99.

Snijders, T , Bosker, R (1999) Multilevel analysis, an introduction to basic and advanced modeling. London: SAGE Publications.

Spauwen, J, Krabbendam, L, Lieb, R, Wittchen, HU , van Os, J (2006) Impact of psychological trauma on the development of psychotic symptoms: relationship with psychosis proneness. Br J Psychiatry, 188: 527-33.

StataCorp (2006). Stata Statistical Software. Texas, College Station, TX: Stata Corporation.

Teerikangas, OM, Aronen, ET, Martin, RP , Huttunen, MO (1998) Effects of infant temperament and early intervention on the psychiatric symptoms of adolescents. J Am Acad Child Adolesc Psychiatry, 37 (10): 1070-6.

Tiet, QQ, Bird, HR, Hoven, CW, Moore, R, Wu, P, Wicks, J, Jensen, PS, Goodman, S, Cohen, P (2001) Relationship between specific adverse life events and psychiatric disorders. J Abnorm Child Psychol, 29 (2): 153-64.

Treffers, PDA (2000) Dutch translation of the Strengths and Difficulties Questionnaire (SDQ). Internal document. Oegstgeest, The Netherlands: Leiden University Medical Cente, Academic Center for Child and Adolescent Psychiatry, Curium.

van der Linden, J, Drukker, M, Gunther, N, Feron, F , van Os, J (2003) Children's mental health service use, neighbourhood socioeconomic deprivation, and social capital. Soc Psychiatry Psychiatr Epidemiol, 38 (9): 507-14. 
Velez, CN, Johnson, J , Cohen, P (1989) A longitudinal analysis of selected risk factors for childhood psychopathology. J. Am. Acad. Child Adolesc. Psychiatry, 28 (6): 861-864

Werner, EE , Smith, RS (1992) Overcoming the odds: high risk children from birth to adulthood. Ithaca, NY: Cornell University Press.

Wolke, D, Woods, S, Bloomfield, L , Karstadt, L (2000) The association between direct and relational bullying and behaviour problems among primary school children. J Child Psychol Psychiatry, 41 (8): 989-1002. 
Table 1. Prevalence of exposure to bullying, total adverse life events and type of adverse life event in the previous year at baseline.

\begin{tabular}{lll}
\hline \hline & $\mathrm{N}$ & $\%$ \\
\hline Repeated exposure to bullying & 711 & 95.56 \\
$\quad$ Absent & 33 & 4.44 \\
Present & & \\
& & \\
Total Adverse Life events & 488 & 66.94 \\
$\quad$ No life events & 241 & 33.06 \\
$\quad$ At least one life event (1-4) & & \\
& & \\
Type of adverse life event & 512 & 73.35 \\
Family & 186 & 26.65 \\
$\quad$ No life events & & \\
At least one life event (1-2) & 599 & 85.94 \\
School & 98 & 14.06 \\
$\quad$ No life events & \\
At least one life event (1-2) & & \\
\hline \hline
\end{tabular}

Table 2. Effects of exposure to bullying on changes in psychopathology from baseline to follow-up; coefficients and $95 \% \mathrm{CI}$.

\begin{tabular}{|c|c|c|c|c|c|}
\hline $\begin{array}{l}\text { Exposure to bullying } \\
\text { (baseline) }\end{array}$ & $\begin{array}{l}\text { Total psychopath. } \\
\text { symptoms } \\
\beta(95 \% \mathrm{CI})\end{array}$ & $\begin{array}{l}\text { Emotional symp- } \\
\text { toms } \\
\beta(95 \% \mathrm{CI})\end{array}$ & $\begin{array}{l}\text { Conduct prob- } \\
\text { lems } \\
\beta(95 \% \mathrm{CI})\end{array}$ & $\begin{array}{l}\text { Hyperactivity } \\
\beta(95 \% \mathrm{CI})\end{array}$ & $\begin{array}{l}\text { Prosocial } \\
\text { behaviour } \\
\beta(95 \% \mathrm{CI})\end{array}$ \\
\hline \multicolumn{6}{|l|}{ (a) Model 1a } \\
\hline Baseline problem score & $0.45(0.38-0.52)^{* * *}$ & $0.46(0.39-0.54)^{* * *}$ & $0.18(0.11-0.25)^{* * *}$ & $0.49(0.42-0.56)^{* * *}$ & $0.46(0.40-0.53)^{* * *}$ \\
\hline Exposure to bullying & $0.47(0.13-0.81)^{* *}$ & $0.42(0.05-0.79)^{*}$ & $0.14(-0.28-0.57)$ & $0.40(0.12-0.68)^{* *}$ & $-0.02(-0.38-0.35)$ \\
\hline \multicolumn{6}{|l|}{ (b) Model 2b } \\
\hline Exposure to bullying & $0.41(0.08-0.75)^{*}$ & $0.37(-0.02-0.76)^{\mathrm{c}}$ & $0.04(-0.41-0.50)$ & $0.44(0.17-0.71)^{* *}$ & $0.09(-0.29-0.46)$ \\
\hline $\begin{array}{l}* P<0.05 ; * * P< \\
\text { a Controlled for } \\
\text { b Controlled for } \\
\text { score. } \\
\text { c } P=0.06 .\end{array}$ & $\begin{array}{l}0.01 ; * * * P<0.001 . \\
\text { baseline problem s } \\
\text { gender, age, durati }\end{array}$ & $\begin{array}{l}\text { score. } \\
\text { ion between baselin }\end{array}$ & ne and follow-up, $\mathrm{S}$ & SES and baseline pr & oblem \\
\hline
\end{tabular}


Table 3. Effects of the experience of (type of) adverse life events on changes in psychopathology from baseline to follow-up; coefficients and 95\% CI

\begin{tabular}{|c|c|c|c|c|c|}
\hline $\begin{array}{l}\text { Total adverse } \\
\text { life events }\end{array}$ & $\begin{array}{l}\text { Total psychopath. } \\
\text { Sympt. }\end{array}$ & $\begin{array}{l}\text { Emotional } \\
\text { symptoms }\end{array}$ & $\begin{array}{l}\text { Conduct } \\
\text { problems }\end{array}$ & Hyperactivity & $\begin{array}{l}\text { Prosocial } \\
\text { behaviour }\end{array}$ \\
\hline & $\beta \quad(95 \% \mathrm{CI})$ & $\beta \quad(95 \% \mathrm{CI})$ & $\beta \quad(95 \% \mathrm{CI})$ & $(95 \% \mathrm{CI})$ & $\beta \quad(95 \% \mathrm{CI})$ \\
\hline \multicolumn{6}{|l|}{ (a) Model 1a } \\
\hline $\begin{array}{l}\text { Baseline problem } \\
\text { score }\end{array}$ & $0.45(0.38-0.52)^{* * *}$ & $0.46(0.38-0.53)^{* * *}$ & $0.18(0.11-0.25)^{* * *}$ & $0.50(0.43-0.57)^{* * *}$ & $0.47(0.40-0.53)^{* * *}$ \\
\hline $\begin{array}{l}\text { Stressful life events } \\
\text { (baseline) }\end{array}$ & $0.10(0.02-0.19)^{*}$ & $0.08(-0.01-0.16)^{\mathrm{c}}$ & $0.10(0.00-0.20)^{\mathrm{c}}$ & $0.07(-0.00-0.14)^{\mathrm{c}}$ & $-0.08(-0.16-0.01)^{c}$ \\
\hline \multicolumn{6}{|l|}{ (b) Model 2b } \\
\hline $\begin{array}{l}\text { Stressful life events } \\
\text { (baseline) }\end{array}$ & $0.10(0.01-0.18)^{*}$ & $0.05(-0.04-0.14)$ & $0.11(0.01-0.21)^{*}$ & $0.07(-0.01-0.14)^{\mathrm{c}}$ & $-0.07(-0.15-0.02)$ \\
\hline \multirow{2}{*}{\multicolumn{6}{|c|}{$\begin{array}{l}\text { Type of adverse life } \\
\text { events (baseline) }{ }^{\mathrm{b}} \text { : } \\
\text { joint model }\end{array}$}} \\
\hline & & & & & \\
\hline Family & $0.19(0.07-0.30)^{* *}$ & $0.15(0.03-0.27)^{*}$ & $0.14(0.00-0.27)^{\mathrm{c}}$ & $0.12(0.02-0.22)^{*}$ & $-0.08(-0.19-0.03)$ \\
\hline School & $0.01(-0.15-0.16)$ & $-0.05(-0.22-0.11)$ & $0.11(-0.11-0.34)$ & $0.04(-0.11-0.19)$ & $-0.03(-0.17-0.11)$ \\
\hline
\end{tabular}

$* \mathrm{P}<0.05 ; * * \mathrm{P}<0.01 ; * * * \mathrm{P}<0.001$.

a Controlled for baseline problem score.

b Controlled for gender, age, duration between baseline and follow-up, SES and baseline problem score.

c Statistically imprecise by conventional alpha. 
Chapter

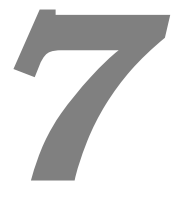

Concluding remarks 


\section{CONCLUDING REMARKS}

Only a minority of children and adolescents in the community with significant problems receive adequate help (Verhulst and van der Ende, 1997). This selection process has been conceptualized by Goldberg and Huxley in the filter model which has been adapted for use in children and adolescents (Verhulst and Koot, 1995). Importantly, psychiatric morbidity in the general population (filter 1) differs from the psychiatric morbidity treated by specialist psychiatric services (filters 3 and 4); psychiatric morbidity in the general population concerns the full range of problem behaviours, including children who do not receive treatment (chapter 1).

It is now clear that a significant number of children and adolescents exhibit psychopathological conditions which are often chronic and affect multiple domains, such as the child's emotional development and the ability to study or work. The (longitudinal) research presented in this thesis points towards markers of developmental risk processes that can both aid early identification of youth at risk for (treated) psychopathology and provide clues for potential intervention. Prevention, detection and (early) treatment of childhood psychopathology may reduce emotional suffering, but also economic loss, both for the individuals concerned and society as a whole.

To increase knowledge concerning the aetiology of treated and non-treated disorders, the studies described in this thesis examined childhood developmental and environmental risk factors for both psychopathology in the general population, and treated psychiatric morbidity. These studies relied almost completely on longitudinal routine health examinations that, by Dutch law, can be used anonymously for epidemiological purposes and as such can easily be employed for screening efforts. In this chapter, risk factors of psychopathology and treated psychiatric morbidity are drawn together and an attempt is made to evaluate the findings in terms of possible mechanisms of risk, clinical implications and future research directions.

\section{PATHWAYS TO TREATED PSYCHIATRIC MORBIDITY}

Pathways to child psychiatric care are strongly and independently influenced by the level of adverse family circumstances as well as by the developmental pathway of the child (in particular external psychosocial behaviour; chapter 2). Multiple, additive developmental and environmental risk factors influence psychiatric service use in children, suggesting that it is the sum of these risk factors (rather than any single factor) which best predicts treated psychiatric morbidity (chapters 2 and 3). Com- 
binations of risk factors may be useful to develop a screening approach with the possibility of early prevention. Furthermore, the effect of child developmental variables was not merely on the causal pathway between adverse family environment and child psychiatric service use, but reflects an independent developmental pathway (chapter 2).

When children are born in adverse family environments they may be launched on a trajectory hurtling towards treated psychiatric morbidity in later life (Dodge and Pettit, 2003); chapter 2). However, different children follow different trajectories. To further understand this process, previous studies have examined siblings who share $50 \%$ of their genetic makeup and grow up in the same family environment, but, are at least 90\% discordant for psychopathology (Dunn and Plomin, 1991). Therefore, another aspect presented in the present thesis was to compare developmental pathways of siblings with contrasting child mental health outcomes, so that factors specific to each child could be identified (chapter 3).

Although siblings share adverse family environments, there are also individualspecific developmental exposures which influence psychiatric morbidity (chapter 3). The presence of delays in speech and motor development contributed most to differential sibling mental health outcomes. This is in line with earlier crosssectional and longitudinal research showing that indicators of compromised neurodevelopment precede the clinical onset of adult psychiatric disorders such as schizophrenia and depression (Jones et al., 1994; van Os et al., 1997). In addition, cases displayed both earlier expression and more severe levels of behavioural deviance than their healthy siblings, who in turn had higher levels of behavioural deviance than population controls. These results support the need for further consideration of externalizing behaviour in very young children.

Studies explaining the mechanisms of risk in the development of psychopathology increasingly consider the role of genetic factors and their interaction or correlation with environmental factors. Twin studies provide a good means to discriminate between effects of genes and environment, where environmental factors again can be separated in shared (e.g. same family or school) and non-shared (e.g. different friends) environmental factors. Several studies give support for gene-environment interactions, suggesting that a person's genetic make-up may affect vulnerability to psychopathology by influencing a person's sensitivity to environmental factors. For example, the effect of stressful life events on depression depends on the genetic make-up (Caspi et al., 2003). In addition, genes may affect the probability of exposure to environmental risk factors (gene-environment correlations). These geneenvironment correlations may come about because the parents who pass on their genes to their children are the same parents who provide their rearing experiences (passive gene-environment correlation) or because people's behaviour serves to 
select their environment and to influence other people's responses to them (active gene-environment correlation).

In this context, the shared familial liability to behavioural problems in chapter 3 can be the result of the effect of shared genes, or environmental influences shared between siblings (e.g. parenting practices), or their interaction (Burcusa et al., 2003). Another explanation for the shared familial liability to behavioural problems lies in the fact that behaviour can also be learned or imitated. This may be the mechanism why healthy siblings develop similar repertoires for aggression (sibling interaction: (Patterson, 1984)). Furthermore, there has to be a non-shared genetic or environmental risk factor in early childhood (e.g. differential treatment of the children by the parents, obstetric complications, such as fetal hypoxia), or their interaction, that may contribute to the manifestation of motor and language deficits and behavioural abnormalities in children with treated psychiatric disorders, which was shown in chapter 3.

In line with earlier research (Zubrick et al., 2000; Wahlbeck et al., 2001), some evidence was found for the hypothesis that some factors may exert adverse effects in utero for variable mental health problems in children, even after controlling for familial risk (chapter 4). Children with a treated psychiatric disorder were at birth somewhat smaller than their healthy controls. Because the hypothesis that postnatal growth is an independent risk factor for children's psychiatric problems could not be confirmed, it was concluded that prenatal deficiencies are more important than postnatal deficiencies on the pathway to treated psychiatric morbidity. However, in line with much of the earlier research, our study focussed on the association between isolated prenatal risk factors and psychiatric morbidity. However, isolated obstetric complications, such as low birth weight, are rare and often accompanied or followed by a number of others (Touwen et al., 1980). Furthermore, obstetric factors can counteract each other so that one optimal condition can compensate for another less favourable one. For instance, a study of Batstra et al (2003) suggested that the early negative consequences of maternal smoking during pregnancy are limited if the child is breast-fed. In addition, this same study showed that externalizing and internalizing behaviour styles have different early risk factors. Externalizing behaviours are independently linked to maternal smoking during pregnancy, while internalizing behaviour is not (Batstra et al., 2003). In order to quantify this complex process surrounding pregnancy and delivery, an aggregated obstetric optimality score was used in analysing for the associations between early risk factors and emotional problems and substance use in young adulthood (Batstra et al., 2004). While other studies found that emotional disorders are generally better predicted by isolated early risk factors than substance use (Allen et al., 1998), the generic obstetric situation is stronger related to substance use than to emo- 
tional disorders (Batstra et al., 2004). Therefore, future studies should not only use isolated early risk factors, but also aggregated obstetrical scores in analysing the associations between early risk factors and childhood behavioural and (different types of) emotional problems.

Although socioeconomic status was mentioned as an important factor in the association between physical growth and a child's mental health in previous studies, the association between parental SES and treated psychiatric morbidity was not mediated by prenatal growth or postnatal growth, suggesting that a child's physical development is not merely on the causal pathway between parental SES and psychiatric care (chapter 4). In future studies, other mechanisms by which parental SES is associated with mental health should be examined.

\section{PATHWAYS TO PSYCHOPATHOLOGY IN THE GENERAL POPULATION}

The biggest advantage of studies in general population samples as compared to clinical samples (chapters 2, 3 and 4) is that the full range of problem behaviours can be studied. This results in better generalizability of the findings as subjects who do not receive treatment are also included and therefore there is no bias caused by factors involved in the clinical referral process (Caron and Rutter, 1991). Another strength of the (general population) studies presented in the current thesis is their prospective longitudinal design, including a baseline and a follow-up measurement, and controlling for baseline symptom scores. Therefore, the potential contributions of risk factors in the development of later psychopathology could be established. Although research can never prove absolute causality, such longitudinal analyses provide stronger evidence for causality than cross-sectional research.

When examining the mechanisms of how the wider social context (i.e. the neighbourhood environment) may be associated with behaviour and mental health, firstly the direct relationship between characteristics of the neighbourhood and exposure to bullying was studied during the developmental period from late childhood to early adolescence (chapter 5). Results suggest that social capital, may be one neighbourhood characteristic, which influences exposure to bullying, but only in boys going to primary school. These results agree with the hypothesis that effects of neighbourhood characteristics on behaviour are more important in young children than in adolescents (12 years and older), because young children spent more time in the neighbourhood, while secondary school children spent more time outside the neighbourhood of residence (Drukker et al., 2006). The present findings illustrate a change in the impact of similar risk factors at different ages. 
Chapter 6 described a study demonstrating that exposure to bullying and adverse life events (especially family-related adverse events) in adolescence are risk factors for psychopathology later in life (Berden et al., 1990; DuBois et al., 1992; Hook et al., 1995; Kroes et al., 2002). It was hypothesized that these negative life experiences may play an incremental role in the development of symptoms (chapter 6). It was found that the effects were not moderated by neighbourhood social capital, suggesting again that the effects of the neighbourhood environment may be less important during adolescence (chapter 6).

Furthermore, when examining the subscales of psychopathology based on the Strengths and Difficulties Questionnaire (SDQ), children exposed to bullying and adverse life events more often had externalizing problems, such as hyperactivity and conduct problems, even after controlling for confounding variables. Because the effect of total adverse life events was in part reducible to bullying, but not the other way around, interventions addressing bullying seem to be urgently needed. In contrast to most previous studies using parent and/or teacher reports (Schwartz et al., 1998; Wolke et al., 2000), the present self-report analyses showed some evidence for the association between exposure to bullying and the development of emotional symptoms, supporting the proposition that self-report of such symptoms is more reliable than objective reports from teachers and family (Wolke et al., 2000).

The association between adverse life events and later psychopathology seems in part to be independent of current symptoms of psychopathology (chapter 6). Thus, hyperactivity and conduct problems may reflect adolescents' coping styles in interaction with their environment (person-environment interaction) (Craig, 1998). However, there was also a predictive relationship between baseline symptoms of psychopathology and adverse life events at follow-up, suggesting that some adolescents may be more prone to adverse life events through their own mal-adaptation and long-term-difficulties in their environment (person-environment correlation) (Rutter and Silberg, 2002). In addition, bi-directionality has also been suggested in mothers of infants who are difficult in temperament, whereby the infant might contribute to or exacerbate the mother's depression (Cutrona and Troutman, 1986). In fact, such a bidirectional relationship between a risk factor and disease is not unusual, at least not for psychiatric disorders (Van Os and Sham, 2003). More research is needed to obtain insight in these mechanisms of risk. 


\section{CLINICAL IMPLICATIONS}

Preventive interventions should address malleable determinants, including diseasespecific as well as more generic risk and protective factors, which may be common to various different mental health problems and disorders (Saxena et al., 2006). The results of chapters 2, 3 and 4 of the present thesis increased our knowledge about generic risks for a range of mental health outcomes and, therefore, no specific mental health diagnostic categories were examined. The validity for the generic approach is suggested by earlier studies showing the relative non-specificity of prenatal effects and deviance in motor and language development on psychiatric outcomes and the increasing focus on generic risk models for morbidity accumulation in the area of both mental and somatic health (Jones et al., 1994; van Os et al., 1997; Zubrick et al., 2000; Wahlbeck et al., 2001). There is also evidence that childhood adversity (e.g. parental psychopathology) non-specifically increases the likelihood of various forms of mental disorders (Sareen et al., 2005). Factors that are associated with the onset of more than one type of psychopathology may be more important to target since they may reduce the risk for the development of a wide range of disorders (Birmaher et al., 1996; De Hert et al., 2000). The efficacy of interventions targeting these generic risks, is based on their capacity to reduce the more generic or non-specific burden of mental health disorders (De Hert et al., 2000).

Treated psychiatric morbidity in children appeared to be part of multiple psychosocial stress in the family environment (chapter 2), and aspects of the shared family environment also influence the co-existence of externalizing psychosocial behaviour (chapter 3), demonstrating the importance of the family environment in the prediction of mental health outcomes. Apart from shared familial risk factors, additional case specific developmental risk factors such as early, extreme externalizing behaviour and deviance in language and motor development need to be present to predict treated psychiatric morbidity (chapter 3). In addition, exposure to bullying and adverse life events were important psychosocial predictors of later psychopathology in a general population sample (chapter 6). This thesis shows the value of assessing and addressing contextual risk factors, such as distressed families, as well as child factors when targeting resources for prevention and early intervention.

All too often (mental) health services are designated restrictively for the child with the disorder, while for example the functioning of siblings or of (depressed) adults as parents are neglected. This thesis showed once again that mental health professionals need to balance their role of providing care to the patients and preventing future need for care among their families (parents as well as siblings) (Saxena et al., 
2006). In addition, children at risk of treated psychiatric morbidity may be identifiable during infancy, suggesting that interventions, beginning when children are very young, are very important. In this context, early identification and intervention of children with behavioural and neurodevelopmental deficits (language and motor delay) are important (chapter 4). School physicians are ideally placed for the above-mentioned early detection of children at risk for psychiatric disorders and the mobilization of resources for the support of youths with serious emotional and behavioural problems and their families.

Because previous research discussed that though there is a genetic component the quality of mother-child interaction partially mediates the maternal depressive symptomatology and child behaviour problems (Harnish et al., 1995). Interventions addressing the parents may also help prevent children from becoming (more seriously) mentally ill. Examples of such selective interventions are parental health education and parenting support focussed on one-parent families or mentally ill parents (parent-focused programmes) to prevent relapse and promote the child's mental health (Buist, 1998). There are also possibilities to improve the psychosocial prognosis of children at temperamental risk by home-based interventions focussed on parent-child interactions, pointing out the importance of care-giving relationships during development and showing the possibility of modifying the parentchild relationships to the benefit of the child's future mental development (Teerikangas et al., 1998).

There may be scope for the development of effective interventions for groups of children on a school-wide basis (school-based programmes) in order to reduce the incidence of psychopathology. Examples of such interventions are effective school-based programs for children of divorced parents. In these programmes specific cognitive-behavioural coping skills are trained, so that social support is provided and stigmatization is reduced. It has been shown that these programmes can decrease depressive symptomatology and behaviour problems (Wolchik et al., 2000). Other possibilities for school-based programmes are school bully programs and further development of the role of mental health workers in schools in an attempt to reduce behavioural problems at an early stage (Harrington et al., 2000).

Finally and most important, there was no additional neighbourhood effect on deviant behaviour over and above the effect of individual level factors, at least not in adolescence. In addition, the results of the present thesis could not confirm the hypothesis that neighbourhood social capital defines different pathways to adolescent's psychopathology (i.e. neighbourhood social capital is not a moderator). For now, there does not appear to be a need for prevention programmes for high risk adolescents directed at the neighbourhood social capital. 


\section{DIRECTIONS FOR FUTURE RESEARCH}

Analyses taking into account direct and indirect (moderating) effects of neighbourhood characteristics on behaviour and mental health showed that the neighbourhood environment, in particular social capital, was of some importance in childhood, but of no importance in adolescence (chapter 5 and 6). Therefore, future (longitudinal) research may focus on effects of neighbourhood social capital in younger children. Thus, this type of research is needed to determine the pathway of risk associated with the neighbourhood environment in younger children. In addition, further development of possible risk factors and validation of, for example, the concept of adverse life events is necessary, as well as the use of multiple informants in defining psychopathology. In future, more systematic studies of more than one child in a family are needed to clarify what the significant protective or vulnerability factors of psychopathology may be. Additionally, more studies may focus on the search of genes that may have a role in neurodevelopment and the interactions of these susceptibility genes with environmental risk factors such as exposure to prenatal infections.

Given the encouraging results of the (handwritten and electronic) health files of the community paediatric services reported in the present thesis, further work is urgently required to use these and other extensive routine data collections that are taking place in The Netherlands and many other countries, for screening programmes aimed at identifying deviation from healthy psychosocial development in children and to further develop models of risk to increase the effectiveness of efforts directed towards prevention and early intervention. In addition, these extensive routine data collections are extremely important in evaluating the effects of changes in services provided to youth and effects of changes in for example roles of school physicians in the detection, referral, and provision of help for child and adolescent psychopathology on (mental) health outcomes of children and adolescents. In South-Limburg, data on utilization of psychiatric care (all contacts with psychiatric care facilities) have been collected cumulatively since 1981 for the population in the city of Maastricht and surrounding areas (201 000 inhabitants) (Driessen et al., 2001) in the Psychiatric Case register of South-Limburg (PCR-SL). Combining data of the electronic health files of Community paediatric services of Maastricht and surrounding areas with these PCR-data will give opportunities for a (more complete) mental health (service use) monitor, the promise of the future. 


\section{REFERENCES}

Allen, NB, Lewinsohn, PM , Seeley, JR (1998) Prenatal and perinatal influences on risk for psychopathology in childhood and adolescence. Dev Psychopathol, 10 (3): 513-29.

Batstra, L, Hadders-Algra, M, Ormel, J , Neeleman, J (2004) Obstetric optimality and emotional problems and substance use in young adulthood. Early Hum Dev, 80 (2): 91-101.

Batstra, L, Neeleman, J , Hadders-Algra, M (2003) Can breast feeding modify the adverse effects of smoking during pregnancy on the child's cognitive development? J Epidemiol Community Health, 57 (6): 403-4.

Berden, GF, Althaus, M , Verhulst, FC (1990) Major life events and changes in the behavioural functioning of children. J Child Psychol Psychiatry, 31 (6): 949-59.

Birmaher, B, Ryan, ND, Williamson, DE, Brent, DA, Kaufman, J, Dahl, RE, Perel, J , Nelson, B (1996) Childhood and adolescent depression: a review of the past 10 years. Part I. J Am Acad Child Adolesc Psychiatry, 35 (11): 1427-39.

Buist, A (1998) Mentally ill families. When are the children unsafe? Aust Fam Physician, 27 (4): 261-5.

Burcusa, SL, Iacono, WG , McGue, M (2003) Adolescent twins discordant for major depressive disorder: shared familial liability to externalizing and other internalizing disorders. J Child Psychol Psychiatry, 44 (7): 997-1005.

Caron, C , Rutter, M (1991) Comorbidity in child psychopathology: concepts, issues and research strategies. J Child Psychol Psychiatry, 32 (7): 1063-80.

Caspi, A, Sugden, K, Moffitt, TE, Taylor, A, Craig, IW, Harrington, H, McClay, J, Mill, J, Martin, J, Braithwaite, A , Poulton, R (2003) Influence of life stress on depression: moderation by a polymorphism in the 5-HTT gene. Science, 301 (5631): 386-9.

Craig, WM (1998) The relationship among bullying, victimization, depression, anxiety, and aggression in elementary school children. Personality and Individual Differences., 24 (1): 123-130.

Cutrona, CE , Troutman, BR (1986) Social support, infant temperament, and parenting self-efficacy: a mediational model of postpartum depression. Child Dev, 57 (6): 1507-18.

De Hert, M, Van den Broucke, S, Van Nuffel, R, Eds. 2000. Naar een geestelijk gezonde samenleving. Diegem, Kluwer.

Dodge, KA , Pettit, GS (2003) A biopsychosocial model of the development of chronic conduct problems in adolescence. Dev Psychol, 39 (2): 349-71.

Driessen, G, Evers, S, Verhey, F , van Os, J (2001) Stroke and mental health care: a record linkage study. Soc Psychiatry Psychiatr Epidemiol, 36 (12): 608-12.

Drukker, M, Kaplan, C, Schneiders, J, Feron, FJ , van Os, J (2006) The wider social environment and changes in self-reported quality of life in the transition from late childhood to early adolescence: a cohort study. BMC Public Health, 6: 133.

DuBois, DL, Felner, RD, Brand, S, Adan, AM , Evans, EG (1992) A prospective study of life stress, social support, and adaptation in early adolescence. Child Dev, 63 (3): 542-57.

Dunn, J , Plomin, R (1991) Why are siblings so different? The significance of differences in sibling experiences within the family. Fam Process, 30 (3): 271-83. 
Harnish, JD, Dodge, KA, Valente, E (1995) Mother-child interaction quality as a partial mediator of the roles of maternal depressive symptomatology and socioeconomic status in the development of child behavior problems.Conduct Problems Prevention Research Group. Child Dev, 66 (3): 739-53.

Harrington, R, Peters, S, Green, J, Byford, S, Woods, J , McGowan, R (2000) Randomised comparison of the effectiveness and costs of community and hospital based mental health services for children with behavioural disorders. BMJ, 321 (7268): 1047-50.

Hook, B, Hagglof, B , Thernlund, G (1995) Life events and behavioural deviances in childhood: a longitudinal study of a normal population. Eur Child Adolesc Psychiatry, 4 (3): 153-64.

Jones, P, Rodgers, B, Murray, R , Marmot, M (1994) Child development risk factors for adult schizophrenia in the British 1946 birth cohort. Lancet, 344: 1398-402.

Kroes, M, Kalff, AC, Steyaert, J, Kessels, AG, Feron, FJ, Hendriksen, JG, van Zeben, TM, Troost, J, Jolles, J , Vles, JS (2002) A longitudinal community study: do psychosocial risk factors and child behavior checklist scores at 5 years of age predict psychiatric diagnoses at a later age? J Am Acad Child Adolesc Psychiatry, 41 (8): 955-63.

Patterson, GR (1984) A microsocial process: a view from the boundary. In: Masters, JC, Yarkin, KL (Ed.), Boundary areas in psychology: social and developmental psychology (pp. 43-67) New York: Academic Press.

Rutter, M , Silberg, J (2002) Gene-environment interplay in relation to emotional and behavioral disturbance. Annu Rev Psychol, 53: 463-90.

Sareen, J, Fleisher, W, Cox, BJ, Hassard, S , Stein, MB (2005) Childhood adversity and perceived need for mental health care: findings from a Canadian community sample. J Nerv Ment Dis, 193 (6): 396-404.

Saxena, S, Jane-Llopis, E , Hosman, C (2006) Prevention of mental and behavioural disorders: implications for policy and practice. World Psychiatry, 5 (1): 5-14.

Schwartz, D, McFadyen-Ketchum, SA, Dodge, KA, Pettit, GS , Bates, JE (1998) Peer group victimization as a predictor of children's behavior problems at home and in school. Dev Psychopathol, 10 (1): 87-99.

Teerikangas, OM, Aronen, ET, Martin, RP , Huttunen, MO (1998) Effects of infant temperament and early intervention on the psychiatric symptoms of adolescents. J Am Acad Child Adolesc Psychiatry, 37 (10): 1070-6.

Touwen, BC, Huisjes, HJ, Jurgens-van der Zee, AD, Bierman-van Eendenburg, ME, Smrkovsky, M , Olinga, AA (1980) Obstetrical condition and neonatal neurological morbidity. An analysis with the help of the optimality concept. Early Hum Dev, 4 (3): 207-28.

van Os, J, Jones, P, Lewis, G, Wadsworth, M , Murray, R (1997) Developmental precursors of affective illness in a general population birth cohort. Arch Gen Psychiatry, 54 (7): 625-31.

Van Os, J , Sham, P (2003) Gene-environment interactions. In: Murray, R, Jones, PB, Susser, E, Van Os, J, Cannon, M (Ed.), The epidemiology of schizophrenia (pp. 235-254) Cambridge: Cambridge University Press.

Verhulst, FC , Koot, HM (1995) The epidemiology of child and adolescent psychopathology. Oxford, UK: Oxford University Press. 
Verhulst, FC , van der Ende, J (1997) Factors associated with child mental health service use in the community. J Am Acad Child Adolesc Psychiatry, 36 (7): 901-9.

Wahlbeck, K, Forsen, T, Osmond, C, Barker, DJ , Eriksson, JG (2001) Association of schizophrenia with low maternal body mass index, small size at birth, and thinness during childhood. Arch Gen Psychiatry, 58 (1): 48-52.

Wolchik, SA, West, SG, Sandler, IN, Tein, JY, Coatsworth, D, Lengua, L, Weiss, L, Anderson, ER, Greene, SM , Griffin, WA (2000) An experimental evaluation of theory-based mother and mother-child programs for children of divorce. J Consult Clin Psychol, 68 (5): 843-56.

Wolke, D, Woods, S, Bloomfield, L, Karstadt, L (2000) The association between direct and relational bullying and behaviour problems among primary school children. J Child Psychol Psychiatry, 41 (8): 989-1002.

Zubrick, SR, Kurinczuk, JJ, McDermott, BM, McKelvey, RS, Silburn, SR , Davies, LC (2000) Fetal growth and subsequent mental health problems in children aged 4 to 13 years. Dev Med Child Neurol, 42 (1): 14-20. 
Chapter

\author{
Summary \\ Samenvatting \\ Dankwoord \\ Curriculum Vitae \\ List of publications
}




\section{SUMMARY}

The longitudinal studies described in the present thesis, "Vulnerability to psychopathology in children; developmental and environmental pathways", examine childhood developmental and environmental risk factors for both treated and non-treated disorders in children. The results of these studies can both aid early identification of youth at risk for (treated) psychiatric morbidity and provide clues for potential intervention.

Chapter 1 of this thesis stresses the importance of the early detection of children at increased risk for psychopathology and subsequent early intervention of mental health disturbances. This can prevent childhood conditions to become chronic affecting multiple domains of the child's development, which may also contribute to the onset and persistence of adult mental illness. This chapter briefly discusses the context of risk, showing that i) developmental as well as environmental factors are important in relation to trajectories towards childhood psychiatric morbidity, and ii) showing that such factors often modify or mediate each others effect. An overview of previous findings on the association between developmental and environmental factors on the one hand and (treated) psychiatric morbidity on the other is given. Because of the growing recognition of the possible continuation of childhood problems into adulthood and the debate about the direction and causality of effects, the importance to study developmental and environmental factors in prospective rather than retrospective designs, adopting a life-course rather than a cross-sectional perspective is recognized. The two longitudinal data sets that are used in the present thesis are described in this first chapter, i.e. information of the Youth Health Care Division from the Public Health Service South Limburg, location Maastricht (YHCD) and the Maastricht Quality of Life Study.

In chapter 2 the influence of family and child-specific variables on the pathway into psychiatric care is examined, in a blinded, matched case control study of 400 children, 80 referred to the Community Mental Health Centre in Maastricht and 320 matched controls, aged 6-13. It is demonstrated that in addition to multiple psychosocial stressors within the family environment, deviance in a child's social, motor and speech development and combinations of these risk factors, strongly and independently influence (treated) psychiatric morbidity.

Chapter 3 examines why some children born into adverse family environments need psychiatric treatment while their siblings do not. For this purpose, the analyses of chapter 2 are extended by additionally including 68 siblings of children with 
treated psychiatric morbidity and their 272 matched community controls. It is concluded that although siblings share adverse family environments, there are also individual specific developmental exposures which influence psychiatric morbidity; additional presence of delays in speech and motor development contributed most to treated psychiatric morbidity. In addition, children referred to child psychiatric care displayed both earlier expression and more severe levels of developmental behavioural deviance than their healthy siblings, who in turn had higher levels of behavioural deviance than population controls.

Chapter 4 studies the independent associations between unfavourable prenatal and postnatal patterns of physical growth and the risk of later treated psychiatric problems in children, and whether any effect of lower parental socioeconomic status on mental health outcomes in the children is mediated through such unfavourable patterns of growth. Although the results provide some evidence for the impact of intrauterine development on the pathway into child psychiatric care, as children using psychiatric care were somewhat smaller at birth, there was no evidence for an association between postnatal growth and the development of psychiatric problems. Neither prenatal nor postnatal physical growth were on the pathway between low parental SES and children's mental health problems.

Chapter 5 studies the direct relationship between neighbourhood characteristics and exposure to bullying during the developmental period from late childhood to early adolescence, using data from the Maastricht Quality of Life Study. Results suggest that there is an association between neighbourhood social capital and exposure to bullying in boys going to primary school. However, this association was not found in girls or in early adolescence. This supports the hypothesis that effects of neighbourhood characteristics on behaviour are more important in children than in adolescents, who attend schools outside the own neighbourhood.

Using information from the electronic health files of the community paediatric services, chapter 6 examines possible effects of exposure to bullying and adverse life events at baseline on adolescent psychopathology at two-year follow-up. Secondly, the moderating role of neighbourhood social capital is examined, as a putative mechanism to understand the association between neighbourhood environment and mental health. Results show the importance of exposure to bullying in the development of hyperactivity and emotional problems, while the experience of adverse life events predicts the development of conduct problems. In this context, family-related adverse events are most important. The hypothesis that neighbourhood social capital impacts on the association between negative life experiences 
and psychopathology is not supported by results of the present study, i.e. effects of bullying and adverse life events are not moderated by neighbourhood social capital.

In chapter 7 the results of the present thesis are discussed and an attempt is made to evaluate the findings in terms of possible mechanisms of risk in the development of psychopathology, paying attention to the role of genetic factors and their interaction or correlation with environmental factors. Clinical implications of the findings in this thesis are provided as well as future research directions. 


\section{SAMENVATTING}

In een aantal longitudinale studies is bestudeerd welke factoren met betrekking tot de ontwikkeling van het kind en kenmerken van diens omgeving van invloed zijn op het ontstaan van behandelde maar ook van niet-behandelde psychopathologie. Dergelijke studies bieden ons mogelijkheden om in een vroeg stadium risicojeugd te traceren en preventieve interventies te ontwikkelen.

Hoofdstuk 1 beschrijft in het kort de omvang van de psychiatrische problematiek bij kinderen. Een aanzienlijk aantal kinderen in de algemene populatie kent psychiatrische problemen. Deze problemen hebben vaak een chronisch beloop en dragen daarmee mogelijk bij an het ontstaan van psychiatrische problematiek bij volwassenen. Vroege signalering en interventie bij kinderen met een verhoogd risico op psychopathologie is dan ook van groot belang. In dit hoofdstuk wordt een literatuuroverzicht gegeven van ontwikkelings- en omgevingskenmerken van het kind in relatie tot het ontstaan van psychopathologie. Verder is angegeven dat allereerst gebruik is gemaakt van informatie over de contactmomenten van de afdeling JeugdGezondheidsZorg (JGZ) van de GGD Zuid-Limburg (locatie Maastricht). Daarnaast is informatie verkregen uit de Maastricht Kwaliteit-van-Leven studie, waarin vragenlijsten werden uitgedeeld en weer ingenomen tijdens het onderzoek van de schoolarts van de GGD Zuid-Limburg.

In hoofdstuk 2 staat een patient-controle onderzoek centraal waarin 80 jonge geestelijke gezondheidszorg (GGZ-) gebruikers (leeftijd 6-13 jaar) worden vergeleken met 320 op leeftijd en geslacht gematchte controles. Hierbij is zowel naar kindspecifieke gegevens, als naar kenmerken van het gezin gekeken. Hieruit blijkt dat naast verschillende psychosociale stressoren in het gezin, achterstand in taal, motoriek en psychosociale ontwikkeling van invloed zijn op het GGZ-gebruik.

In hoofdstuk 3 staat de vraag centraal waarom het ene kind in een gezin wel in behandeling is bij de geestelijke gezondheidszorg en zijn broertje of zusje niet. Met andere woorden: wat zijn de individueel-specifieke risicofactoren van psychopathologie bij kinderen die in dezelfde gezinsomstandigheden leven? Hiertoe zijn naast de patient-controle vergelijking, zoals beschreven in hoofdstuk 2, 68 broertjes en zusjes van jonge GGZ-gebruikers vergeleken met 272 gematchte controles. Geconcludeerd wordt dat, onafhankelijk van de gezinsomstandigheden, achterstand in taal en motoriek het GGZ-gebruik het meest beïnvloedt. Ook komt naar voren dat GGZ-gebruikers vaker externaliserend gedrag vertonen (bijvoorbeeld hyperactief, 
aggressief gedrag) dan hun gezonde controles. Dit gedrag is in vergelijking met hun gezonde broertjes en zusjes niet alleen ernstiger, maar het komt ook op een jongere leeftijd tot uitdrukking. De gezonde broertjes en zusjes vertonen op hun beurt ernstiger externaliserend gedrag dan hun controles, maar minder ernstig dan de GGZ-gebruiker uit het gezin.

Hoofdstuk 4 bestudeert de onafhankelijke relatie tussen ongunstige groeicurven vanaf de geboorte en het risico op psychiatrische problemen in de kindertijd. Hiertoe zijn opnieuw de cases vergeleken met hun gezonde gematchte controles, zoals beschreven in hoofdstuk 2. Tevens is bestudeerd in hoeverre de sociaaleconomische status van de ouders van invloed is op de groeicurven. Er zijn enige aanwijzingen voor een effect van geboortelengte op GGZ-gebruik; jonge GGZgebruikers zijn iets kleiner bij de geboorte dan hun gezonde controles. Echter, de hypothese dat ook ongunstige groei in de kindertijd een effect zou hebben op het later ontwikkelen van psychiatrische problemen, kan niet worden bevestigd. Daarnaast lijken geboortelengte en groei in de kindertijd beiden geen intermediair te zijn in het verband tussen lage sociaal-economische status en psychiatrische problematiek. Met andere woorden: er kon niet worden aangetoond dat een lage sociaaleconomische status kan leiden tot een achterstand in groei en dat psychiatrische problemen in de kindertijd vervolgens weer een gevolg is van deze groei achterstand.

Hoofdstuk 5 vormt een eerste aanzet tot de studie naar de sociale context van het kind in relatie tot diens gedrag en geestelijke gezondheid. In dit hoofdstuk wordt gekeken naar de directe relatie tussen kenmerken van de woonbuurt van het kind en het slachtoffer zijn van pesten in die buurt in twee leeftijdsgroepen: kinderen uit groep 8 van de basisschool en kinderen uit klas 2 van de middelbare school. Hiertoe wordt gebruik gemaakt van informatie uit de Maastricht Kwaliteit-van-Leven Studie. Uit de analyses blijkt dat er een relatie is tussen het sociaal kapitaal van de buurt en het gepest worden onder jongens uit groep 8. Genoemde relatie werd echter niet gevonden bij meisjes en bij de jeugd uit klas 2 van de middelbare school. Deze resultaten bevestigen de hypothese dat effecten van buurtkenmerken vooral van invloed zijn op het gedrag van kinderen op de basisschool. Cohesie in de buurt lijkt minder invloed te hebben op middelbare scholieren, omdat die meestal buiten de eigen buurt naar school gaan.

In hoofdstuk 6 wordt informatie gebruikt van de afdeling JGZ van de GGD om mogelijke effecten te bestuderen van gepest worden en het ervaren van negatieve life events (13/14 jaar) op de ontwikkeling van psychopathologie twee jaar later. 
Daarnaast is gekeken of deze relatie wordt beïnvloed door het sociaal kapitaal in de buurt, ook weer om beter zicht te krijgen op de relatie tussen buurtkenmerken en geestelijke gezondheid.

Wat blijkt is dat adolescenten die het slachtoffer zijn van pesten een groter risico hebben op het ontwikkelen van hyperactiviteit en emotionele problemen, terwijl het ervaren van negatieve life events de ontwikkeling van gedragsproblemen voorspelt. In deze context hebben familie-gerelateerde negatieve life events de grootste invloed. Daarnaast blijkt dat deze relatie tussen negatieve levenservaringen en het ontwikkelen van psychopathologie even sterk is bij kinderen afkomstig uit een buurt met veel of weinig sociaal kapitaal. Effecten van negatieve levenservaringen op het ontwikkelen van psychopathologie worden derhalve niet beïnvloed door het sociaal kapitaal van de woonbuurt.

In hoofdstuk 7 worden de resultaten van de artikelen uit dit proefschrift bediscussieerd. Er is aandacht voor de rol van genetische factoren en hun interactie of correlatie met omgevingsfactoren in de verklaring van het ontwikkelen van psychopathologie. Tevens worden er aanbevelingen gedaan met betrekking tot de (klinische) praktijk alsmede suggesties voor toekomstig wetenschappelijk onderzoek. 



\section{DANKWOORD}

Het schrijven van een proefschrift lukt niet in je eentje. Al die mensen die hebben bijgedragen aan de totstandkoming daarvan wil ik dan ook hartelijk danken. Om te beginnen mijn promotor Prof. dr. Jim van Os. Jim, onvermoeibaar was je in het vragen: "Waar is je artikel?" Je steeds weer motiverende en bemoedigende woorden, je humoristische opmerkingen over een droppot die je vaak asociaal leeg vond, je ideeën over een Maastrichts integratiefeest in het Frans, met uiteindelijk een Spaans tintje en natuurlijk niet in de laatste plaats de gedrevenheid en het enthousiasme waarmee je onderzoek doet, zorgden er voor dat ik alsnog besloot te promoveren. Bedankt voor dit alles.

Dr. Marjan Drukker, mijn copromotor, dank je wel dat je me de afgelopen jaren wegwijs hebt gemaakt in het land van de statistiek: multi-level is voor jou een peulenschil. Ik heb veel geleerd van je deskundigheid, nauwkeurigheid en je niet aflatende positieve kijk op de dingen. Daarnaast was er altijd ruimte voor een persoonlijk gesprek.

Het zou onmogelijk zijn geweest het onderzoek op te zetten en uit te voeren zonder de toestemming van de ouders van de jonge RIAGG cliënten en hun broertjes en zusjes om GGD-dossiers te mogen inzien. Heel hartelijk dank daarvoor.

Dr. Frans Feron, JeugdGezondheidsZorg (JGZ)-arts van de GGD Maastricht, dank dat ik bij mijn onderzoek gebruik mocht maken van GGD-data, dat je bereid was om als co-auteur van diverse internationale publicaties op te treden en als lid van het team Regionale Profielen Jeugdgezondheid (RPJ) je kennis en ervaring met enthousiasme en humor in te zetten voor een digitaal GGD-bestand ten behoeve van individuele zorg en wetenschappelijk onderzoek. Natuurlijk wil ik ook de overige (ex)leden van het RPJ, Maria Jansen, Carel Thijs, Brigitte de Pree, Marjon Lemmens en Marjan Drukker hartelijk danken voor de fijne samenwerking waardoor de bevindingen van mijn onderzoek ook voor de praktijk van de zorg meer betekenis kregen.

Een speciaal woord van dank gaat uit naar Peter van Neer die als medewerker van de afdeling JGZ van de GGD Maastricht onvermoeibaar was in het beantwoorden van mijn vele vragen. Dank ook voor het beschikbaar stellen van de GGDdossiers. Voorts wil ik ook de overige JGZ-medewerkers hartelijk danken voor hun inzet met betrekking tot de dataverzameling.

Prof. dr. Andries Korebrits dank ik voor zijn klinische blik op de onderzoeksresultaten en de bereidheid om als co-auteur op te treden. 
Barbara Slavenburg, Jikke van der Linden en Simonne Delnooz hebben een deel van het dossieronderzoek voor hun rekening genomen. Barbara, bedankt voor je zorgvuldigheid en betrokkenheid. Zonder jouw hulp had mijn onderzoek vele malen langer geduurd. Jikke, ook jij hebt een tijdje voor mij gesampled en je besloot je onderzoeksstage te doen aan de hand van de GGD-gegevens. Het was voor mij een zeer leerzame ervaring om je hierin te mogen begeleiden. Simonne, het was voor mij afkicken na alle kitkatten en twixen die we hebben genuttigd tijdens het doornemen van de dossiers.

Diverse (ex-)collega's van de capaciteitsgroep Psychiatrie en Neuropsychologie hebben mij gevraagd dan wel ongevraagd gesteund en naar de vorderingen geïnformeerd. Veel inspiratie deed ik op tijdens de lunchpauzes en de internationale congressen, waardoor we elkaar ook op een informele manier leerden kennen. Een aantal mensen wil ik in het bijzonder bedanken. Ger, bedankt dat je steeds weer bereid was om PCR-data zo te bewerken dat ook een leek hiermee aan de slag kon. Karola en Nele, ik heb met jullie een doldwaze tijd gehad: de tocht naar Zutphen, lekker jezelf kunnen zijn en niet te vergeten de vele evaluaties. Petra, het was fijn om van alles en nog wat te delen, met name onze liefde voor dieren. Margo en Anny, jullie waren mijn trouwste kamergenoten die mij door dik en dun hebben gesteund. Samen met Monique, Simone en Simonne halen wij regelmatig SPherinneringen boven. Bedankt ook dat jullie met zijn vijven bereid waren om speciaal voor mij een nimfenjurk aan te trekken. Marieke, bedankt voor je nuchtere, positieve kijk op de dingen. Cecile, tijdens de laatste fase van mijn onderzoek kreeg ik van jou allerlei handige tips en heb je me met liefde opgenomen als je nieuwe kamergenote.

Degenen die hebben bijgedragen aan de vormgeving en laatste afwerking van mijn proefschrift ben ik uiteraard ook heel dankbaar. Gabriel Esquivel and Judith Allardyce, I appreciate your fine work in the correction of the English text in my manuscript. Dirk Geurts nam de lay-out van het manuscript voor zijn rekening. Wil Immink gaf grafische adviezen en zorgde ervoor dat de kaft gezien mag worden. Nogmaals bedankt hiervoor.

Jikke van der Linden en Viviane Thewissen zijn mij als paranimfen in de laatste fase voor de promotie tot steun geweest. Jikke, te paard leerden we elkaar pas goed kennen en waarderen. Viviane, in hetzelfde jaar promoveren en samen met Karola het integratiefeest organiseren schept een band.

Dank aan vrienden en familie voor alle ontspanning en hartelijkheid. Pap en mam, Kim en Guido, bedankt voor jullie geduld en begrip. En tenslotte, dank je wel Dirk, Femke en Jannik, dat jullie er in alle omstandigheden voor mij zijn. 


\section{CURRICULUM VITAE}

Nicole Catharina Hubertina Fransisca Gunther werd geboren op 17 april 1965 te Maastricht. Na het doorlopen van de lagere school op de Don Bosco school te Maastricht van 1971 tot 1977, voltooide zij de middelbare school op het St. Maartenscollege te Maastricht met het verkrijgen van het Atheneum alpha diploma in 1983.

In september 1983 begon zij aan de studie Gezondheidswetenschappen aan de Universiteit Maastricht. Het propaedeuse examen werd gehaald in 1984, en het doctoraal examen Verplegingswetenschap in maart 1988.

Op 1 april 1988 werd zij als toegevoegd onderzoeker aangesteld ten behoeve van het Mental Health Case Register (thans Psychiatrisch Casus Register ZuidLimburg) van de afdeling Sociale Psychiatrie van de faculteit Geneeskunde van de Universiteit Maastricht. In 1991 was zij tevens verbonden an een NWO-project over somatisering in de huisartspraktijk. Dit project was een samenwerkingsverband tussen de afdeling Sociale Psychiatrie en Huisartsgeneeskunde van de Universiteit Maastricht. In 2000 startte zij in samenwerking met de jeugdafdeling van de GGD Maastricht en Groene Kruis Domicura een studie naar determinanten van psychopathologie bij kinderen, wat uiteindelijk zou resulteren in haar thesis getiteld: "vulnerability to psychopathology in children. Developmental and environmental pathways". Daarnaast heeft zij als lid van het team Registratie Profielen Jeugdgezondheid (RPJ) een digitalisering van GGD-gegevens van Zuid-Limburg, locatie Maastricht bewerkstelligd.

Nicole Gunther is gehuwd met Dirk Geurts. Samen hebben zij twee kinderen: Femke (1995) en Jannik (1999). 


\section{LIST OF PUBLICATIONS}

\section{International journals}

Bak, M, van der Spil, F, Gunther, N, Radstake, S, Delespaul, P , van Os, J (2001) Maastricht Assessment of Coping Strategies (MACS-I): a brief instrument to assess coping with psychotic symptoms. Acta Psychiatr Scand, 103 (6): 453-9.

Bak, M, van der Spil, F, Gunther, N, Radstake, S, Delespaul, P , van Os, J

(2001) MACS-II: does coping enhance subjective control over psychotic symptoms? Acta Psychiatr Scand, 103 (6): 460-4.

De Loore, E, Drukker, M, Gunther, N, Feron, F, Deboutte, D, Sabbe, B, Mengelers, R, van Os, J, Myin-Germeys, I (2007) Childhood negative experiences and subclinical psychosis in adolescence: a longitudinal general population study. Early Intervention in Psychiatry, 1 (2): 201-7.

Drukker, M, Gunther, N, Feron, F, van Os, J (2003) Social capital and mental health v. objective measures of health in The Netherlands. Br J Psychiatry, 183: 174.

Drukker, M, Gunther, N , van Os, J (2007) Disentangling associations between poverty at various levels of aggregation and mental health. Epidemiol Psychiatr Soc, 16 (1): 3-9.

Gunther, N, Slavenburg, B, Feron, F, van Os, J (2003) Childhood social and early developmental factors associated with mental health service use. Soc Psychiatry Psychiatr Epidemiol, 38 (3): 101-8.

Gunther, N, Drukker, M, Feron, F, Korebrits, A, van Os, J (2005) The combination of shared family environment and individual-specific developmental deviance as a cause for treated psychiatric morbidity in children. Acta Psychiatr Scand, 112 (5): 376-384.

Gunther, N, Drukker, M, Feron, F, van Os, J (2005) Association of mental health problems in childhood with prenatal and postnatal physical growth. Eur Psychiatry, 20 (3): 277-86.

Gunther, N, Drukker, M, Feron, F, van Os, J (2007) No ecological effect modification of the association between negative life experiences and later psychopathology in adolescence: a longitudinal community study in adolescents. Eur Psychiatry, 22 (5): 296-304.

Gunther, N, Drukker, M, Feron, F, van Os, J (submitted) Neighbourhood social environment and childhood bullying. Health and Place. 
Lataster, T, van Os, J, Drukker, M, Henquet, C, Feron, F, Gunther, N , MyinGermeys, I (2006) Childhood victimisation and developmental expression of non-clinical delusional ideation and hallucinatory experiences : victimisation and non-clinical psychotic experiences. Soc Psychiatry Psychiatr Epidemiol, 41 (6): 423-8.

Portegijs, PJ, van der Horst, FG, Proot, IM, Kraan, HF, Gunther, NC, Knottnerus, JA (1996) Somatization in frequent attenders of general practice. Soc Psychiatry Psychiatr Epidemiol, 31 (1): 29-37.

van der Linden, J, Drukker, M, Gunther, N, Feron, F, van Os, J (2003) Children's mental health service use, neighbourhood socioeconomic deprivation, and social capital. Soc Psychiatry Psychiatr Epidemiol, 38 (9): 507-14.

van Os, J, Driessen, G, Gunther, N, Delespaul, P (2000) Neighbourhood variation in incidence of schizophrenia. Evidence for person-environment interaction. $\mathrm{Br}$ J Psychiatry, 176: 243-8.

\section{National journals}

Drukker, M, Gunther, N, Jansen, M, van Os, J (2006) Kinderen screenen. Maandblad Geestelijke volksgezondheid, 61 (2): 108-110.

Gunther, NCHF, Noorthoorn, EO, Hamers, HJFR, de Jong, JTVM, Kaplan, CD, de Vries, MW (1993) De buurt als sleutel: sociale indicatoren en het gebruik van geestelijke gezondheidszorg. Tijdschrift voor Psychiatrie, 35 (10): 675-690.

Gunther, NCHF, van der Horst, FG, Portegijs, PJM, Kaplan, Ch (1995) werkloosheid, psychische morbiditeit en hulpzoekgedrag binnen de geestelijke gezondheidszorg. TSG, 73 (8): 512-519.

Portegijs, PJM, van der Horst, FG, Proot, IM, Kraan, HF, Gunther, NCHF (1996) Somatisatie bij patiënten met een hoge consultfrequentie. Huisarts en wetenschap, 39: 604-612.

\section{Abstracts}

Gunther, N, Slavenburg, B, Feron, F, van Os, J (2002) Childhood social and early developmental factors associated with mental health service use. Acta Psychiatr Scand, 105: 100.

Gunther, N, Drukker, M, van Os, J (2004) Shared social adversity and individualspecific developmental risk factors for poor mental health in children. Acta Psychiatr Scand, 110: 10.

Gunther, N, Drukker, M, Feron, F, van Os, J (2006) Stressful life-events, neighbourhood environment and problem behaviour in adolescence. $13^{\text {th }}$ 
European Symposium, AEP Section Epidemiology and Social Psychiatry, Bordeaux, june 2006.

Gunther,N, Drukker, M , van Os, J (2006) Neighbourhood social environment and childhood bullying. 13th European Symposium, AEP Section Epidemiology and Social Psychiatry, Bordeaux, june 2006.

\section{Reports}

PCR Noord-Nederland, PCR Rijnmond, PCR Zuid-Limburg Publicaties van de drie Nederlandse psychiatrische casus-registers. De publicaties tussen 2000 en 2003 samengevat.

Sytema, S, Gunther, N, Reelick, F, Drukker, M, Pijl, B, van 't Land, H (2006) Verkenningen in de kinder-en jeugdpsychiatrie. Een bijdrage uit de casusregisters Rijnmond, Zuid-Limburg en Noord-Nederland, Trimbos-instituut, Utrecht, p 52. 